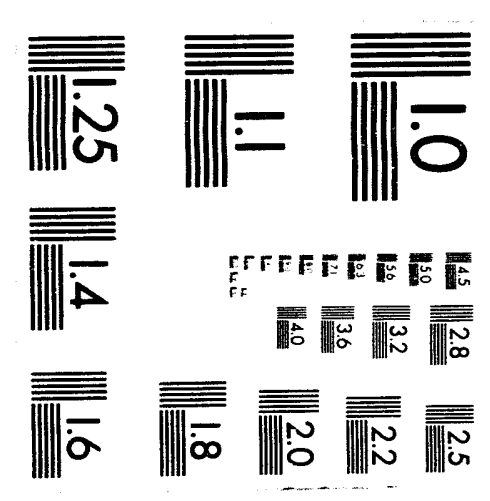



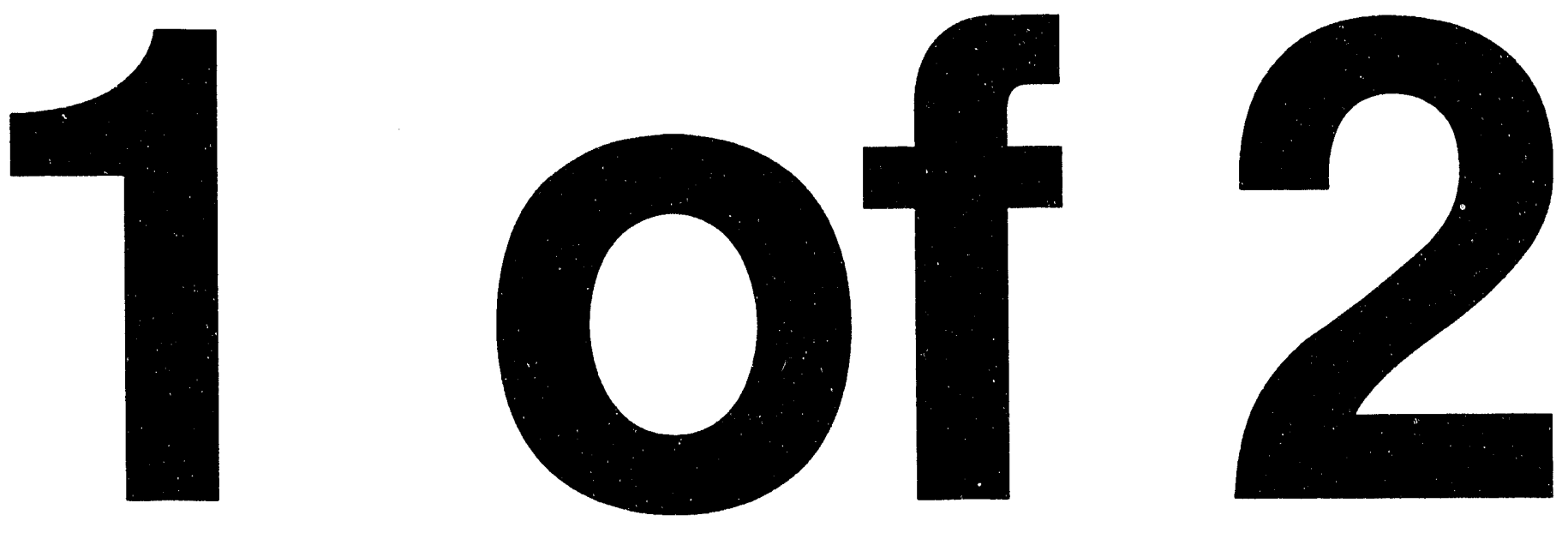


\section{Environment, Safety and Health Independent Evaluation of Fernald Environmental Restoration Management Company's (FERMCO) \\ Comprehensive Environmental Occupational Safety and Health Program (CEOSHP)}

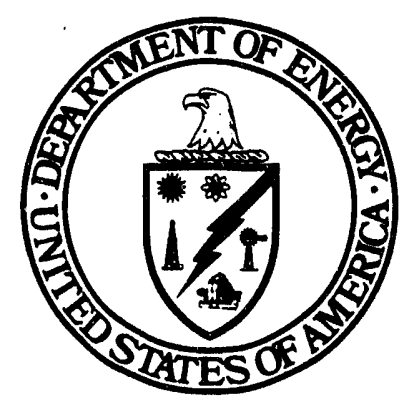

April 1994

U.S. Department of Energy Washington, DC 20585 
EXECUTIVE SUMMARY 


\section{EXECUTIVE SUMMARY}

The Office of Environmental Management (EM) requested the Office of Environment, Safety and Health (EH) to perform an independent evaluation of Fernald Environmental Restoration Malnagement Corporation's (FERMCO's) Comprehensive Environmental Occupational Safety and Health Program (CEOSHP) document. In 1992, FERMCO was awarded the Department of Energy's (DOE) first Environmental Restoration Management Contract and developed the CEOSHP to respond to contract requirements. The CEOSHP was a pioneering effort, developed in a very short period of time. Thus, although the CEOSHP needs improvement, it reflects a substantial amount of work and represents an important effort on the part of many FERMCO professionals.

EH 1 imited its review to the CEOSHP because this document constitutes FERMCO's written environment, safety and health (ES\&H) program document and thus provides the basis for FERMCO's ES\&H program. EH did not review nther FERMCO documents, such as lower-tier ES\&H program documents, bargaining agreements, or other FERMCO contract documents. In addition, no attempt was made to assess the compliance status of the Fernald Environmental Management Project (FEMP) site or to evaluate the effectiveness of FERMCO's on-site implementation of the program described in the CEOSHP.

EH's independent review identified several major areas of the CEOSHP that need to be revised if it is to function successfully as the program-level document for FERMCO's environment, safety and health program. The problems identified occur throughout the document and apply across the three CEOSHP sections evaluated by EH: the Occupational Safety and Health program, the Environmental Protection program, and the Radiological Control program.

\section{Primary Findings}

The CEOSHP:

- does not fully reflect the occupational safety and health, environmental protection, and radiological control requirements of the Department;

- does not convey a strong sense of management leadership of the program or clearly delineate employee rights, responsibilities, and roles in FERMCO's ES\&H program;

- is not a program management-leve1 document;

- does not describe a "seamless" ES\&H program;

- does not clearly convey how 'ERMCO's ES\&H program actually works.

\section{CEOSHP Modifications}

A comprehensive revision of the CEOSHP should focus on describing a comprehensive and integrated management organization and support systems that fully satisfy DOE occupational safety and health, environmental protection, and radiological control requirements. The CEOSHP should more clearly convey the framework of the program and describe how the program actually works. This would enable managers, 
supervisors, and front-line workers interested in learning about FERMCO's ES\&H program to find the guidance they need in the CEOSHP. For the CEOSHP to function as a program management-level document, many requirements and procedures that pertain to sub-programs should be moved into lower-tier documents. Involving employees in the process of revising the CEOSHP will help to ensure that the new CEOSHP is understandable and useful to the employees for whom it is intended.

\section{Principal Recommendations}

Key areas where the CEOSHP could be strengthened are:

- identifying clear and succinct roles, responsibilities, and authorities;

- conveying a strong sense of management commitment to, and leadership of, the ES\&H program;

- effectively communicating employee rights and responsibilities and active employee involvement in all phases of the ES\&H program;

- establishing policy statements that clearly establish FERMCO's high-level management commitment to a continually improving ES\&H program;

- $\quad$ identifying meaningful goals and expectations that extend beyond mere compliance;

- eliminating conflicting and redundant requirements;

- including radiological control requirements that would qual ify the radiological control section of the CEOSHP as FERMCO's Site-Specific Radiological Control Manual.

EH's detailed evaluation of FERMCO's CEOSHP, along with specific recommendations are presented in Sections 2, 3, and 4 of this report. EH believes that EM will find this review and analysis useful in its efforts to assist FERMCO in a comprehensive redrafting of the CEOSHP. 


\section{TABLE OF CONTENTS}




\section{TABLE OF CONTENTS}

Page

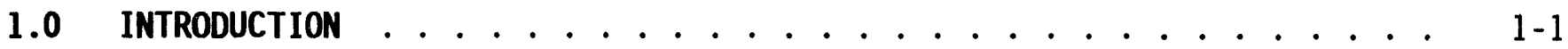

2.0 CEOSHP Occupational Safety and Health

Evaluation and Recommendations ............. 2-1

2.1 Management Commitment and Employee Involvement ....... 2-1

2.1.1 Management Commitment ............ 2-1

2.1.1.1 Written OSH Policy Statement ......... 2-1

2.1.1.2 Written Program, Policies and Procedures ..... 2-2

2.1.1.3 Active Management Involvement ......... 2-3

2.1.1.4 OSH Professional Staff Qualifications ....... 2-4

2.1.1.5 OSH Program Planning and Budgeting ....... 2-5

2.1.1.6 Contractor Compliance with DOE-Prescribed

2.1.1.7 Subcontractor Compliance with DOE-Prescribed $\cdots$

2.1.1.8 Host/Tenant OSH Responsibilities . . . . 2-10

2.1.2 Employee Involvement ........... 2-10

2.1.2.1 OSH Responsibilities and Personnel Accountability . . 2-10

2.1.2.2 Position Descriptions and Personnel Evaluation Plans 2-12

2.1.2.3 OSH Program Promotion and Employee Involvement ... 2-13

2.1.2.4 Safety and Health Committees ......... 2-15

2.1.2.5 Employee Rights ............. 2-16

2.2 Worksite Analysis ............... 2-18

2.2.1 Analysis of Planned, New, or Modified Facilities,

Processes or Equipment ....... 2-18

Hazard Analyses by Front-Line Employees and Supervisors . 2-19

2.2.3 Annual Compliance Inspections ........... 2-20

2.2.4 Routine Compliance Inspections .......... 2-22

2.2.5 Analyze $\mathrm{OSH}$ Performance ............... 2-23

2.2.6 Recording and Reporting Work-Related Incidents . . . . 2-24

2.3 Hazard Prevention and Control .............. 2-25

2.3.1 Proper Design of Facilities and Equipment ........ 2-25

2.3.2 Hazard Control Hierarchy ............ 2-26

2.3.3 Personal Protective Equipment (PPE) ......... 2-26

2.3.4 Maintain Hazard Abatement Program . . . . . . . . . 2-27

2.3.4.1 Hazard Abatement Priorities .......... 2-27

2.3.4.2 Interim Protective Measures ......... 2-28

2.3.4.3 Management of Hazard Abatement Activities . . . 2-28 
Table of Contents (continued)

2.4 Occupational Safety and Health Training ........... 2-31

2.4.1 General Employee OSH Training........... 2-31

2.4.2 Manager $\mathrm{OSH}$ Training .............. 2-32

2.4.3 Supervisor $\mathrm{OSH}$ Training .............. 2-33

2.4.4 Employee Representative $\mathrm{OSH}$ Training .......... 2-33

2.4.5 Non-Supervisory Employee OSH Training.......... 2-33

2.4.6 OSH Professional Training ................... 2-34

2.4.7 Visitor $\mathrm{OSH}$ Training .............. 2-35

2.4.8 Recordkeeping ................. 2-35

3.0 CEOSHP Environmental Protection

Evaluation and Recommendations ................. 3-1

3.1 Management Commitment and Employee Involvement . . . . . . 3-1

3.1.1 Management Commitment ............. 3-1

3.1.1.1 Environmental Policy ............ 3-1

3.1.1.2 Organizational Structure ........... 3-3

3.1.1.3 Environmental Program Planning and Budgeting . . . 3-6

3.1.1.4 Environmental Staffing ........... 3-7

3.1.1.5 Written Environmental Programs, Policies,

3.1.1.6 External Communications . . . . . . . . . $3-11$

3.1.2 Employee Involvement ............. 3-12

3.1.2.1 Environmental Responsibilities

3.1.2.2 $\quad$ and Personnel Accountability $\ldots . . . . . . . . . .53-12$

3.1.2.3 Environmental Concerns Reporting System ..... 3-14

3.2 Environmental Assessments and Controls . . . . . . . . . 3-14

3.2.1 Self Assessment and Appraisal Programs . . . . . . . 3-14

3.2.2 Risk Management ................. 3-16

3.2.3 Corrective Actions .............. 3-16

3.2.4 Environmental Documentation and Recordkeeping ..... 3-17

3.3 Environmental Training Program ................ 3-19

3.3.1 Environmental Professional Training ........... 3-19

3.3.2 Personnel Training Needs ........... 3-20 


\section{Table of Contents (continued)}

\subsection{CEOSHP Radiological Control}

Evaluation and Recommendations .................. 4-1

4.1 Management Commitment and Employee Involvement . . . . . . . . 4-1

4.1.1 Management Commitment ................. 4-1

4.1.1.1 Site-Specific Radiological Control Manual . . . . . 4-1

4.1.1.2 Subcontractor Compliance with Manual ........ 4-2

4.1.1.3 Senior Management Written Commitment . . . . . . . . 4-3

4.1.1.4 Improvement Goals and Performance Indicators . . . 4 4-4

4.1.1.5 Radiological Waste and Exposure Reduction . . . . . 4-5

$\begin{array}{ll}\text { 4.1.1.6 } & \text { Promotion of Radiological Control } \\ & \text { and Constant Improvement . . . . . . . . . . 4-5 }\end{array}$

4.1.2 Employee Involvement ................ 4-6

4.1.2.1 Radiological Awareness Committee . . . . . . . . . . 4-6

4.1.2.2 Radiological Awareness Reports System . . . . . . 4 4-7

4.1.2.3 ALARA Committee ................ 4-7

4.1.2.4 Worker Awareness of Radiological Conditions . . . . . 4-8

4.1.2.5 Supervisor and Worker Accountability . . . . . . . . 4-8

4.2 Worksite Analysis . . . . . . . . . . . . . 4-9

4.2.1 Internal Assessments ................ 4-9

4.2.2 Review of Work in Progress . . . . . . . . . . . . 4-10

4.2.3 Work Activities .................. 4-11

4.3 Hazard Prevention and Control ................ 4-11

4.3.1 Facility Administrative Control Levels . . . . . . . . 4-11

4.3.2 Radiological Control Areas ............. . 4-12

4.3.3 Planned Radiological Work .............. . 4-13

4.3.3.1 Incorporation of RAD in the Conduct of Work . . . . . . . 4-13

4.3.3.2 Trigger Levels for Formal RAD Review . . . . . . . . 4-15

4.3.3.3 Documentation of RAD in Job Plans and Procedures . . . . 4-15

4.3.3.4 ALARA Committee Reviews of Activities . . . . . . . . 4-16

4.3.4 Exposure Controls . . . . . . . . . . . . 4-16

4.3.4.1 Minimization of Internal Exposure . . . . . . . 4-16

4.3.4.2 Radiological Work Permits . . . . . . . . . . 4-17

4.3.4.3 Personal Protective Equipment .......... . 4-18

4.3.4.4 Access Control Measures.............. 4-18

4.3.4.5 Prioritization System . . . . . . . . . . . 4-19

4.3.4.6 Management Feedback .............. . 4-19

4.3.4.7 Stop Work Authority .. . . . . . . . . . . 4-20

4.3.5 Radioactive Waste Minimization . . . . . . . . . . 4-21

4.3.6 Radiological Monitoring and Surveys............. . 4-21 


\section{Table of Contents (continued)}

4.4 Training . . . . . . . . . . . . . . 4 4-22

4.4.1 Pre-Job Briefings ................ 4-22

4.4.2 Standard Training ............. 4-. 4-. .

4.4.2.1 General Employee Radiological Training . . . . . 4 4-23

4.4.2.2 Radiological Worker I and II Training....... 4-24

4.4.2.3 Radiological Control Technician Training . . . . . 4-25

4.4.3 Site-Specific Training of Employees . . . . . . . . 4-25

4.4.4 Refresher Training and Retraining........... 4-26

4.4.5 Respiratory Protection Training........... 4-26

4.4.6 Visitor Radiological Orientation ......... 4-27

4.4.7 Other Radiological Training ............. 4-27

4.4.8 Maintenance of Training Records ........... 4-28

Appendix A Evaluation Elements .................. A-1

Appendix B Acronyms and References ................. B-1 
Section 1.0

\section{INTRODUCTION}


The Department of Energy (DOE) places the highest priority on the health and safety of its workers, the public, and the environment, and is committed to ensuring that all work conducted on its behalf by DOE contractors conforms to this high standard of performance. The Fernald Environmental Restoration Management Corporation (FERMCO) operates the Fernald (Ohio) Environmental Management Project (FEMP) under contract to the Department. This contract, a DOE Environmental Restoration Management Contract (ERMC), is the first of its kind. It provides for greater incentives for the contractor to perform quality work on time and within budget, and it is designed to grant more flexibility to the contractor in the day-to-day management of the site and to assign the contractor a greater share of the risks and liabilities associated with site operations. FERMCO developed a written environment, safety and health program document entitled Comprehensive Environmental Occupational Safety and Health Program (CEOSHP) to provide the framework and requirements for all of its activities. The CEOSHP specifies the environment, safety and health policies that apply to all activities at FEMP and provides the organizational structure and related responsibilities and authorities of the FERMCO Environmental Safety and Health Division.

In developing the CEOSHP, FERMCO relied on DOE Order 5483.XX (draft dated 4-14-92), "Occupational Safety and Hea? th Program for DOE Contractor Employees" and cited the DOE N 5480.6, "Radiological Control Manual" along with a number of other environment, safety and health Orders, evaluation documents, and assessments. Since its initial development in October 1992, many sections of the CEOSHP have undergone substantial revision.

DOE's Office of Environmental Management (EM) requested that the office of Environment, Safety and Health (EH) perform an independent review of the FERMCO CEOSHP to ensure that it fully embodies sound environment, safety and health practices.

This report summarizes EH's findings. The review was conducted by a team of environment, safety and health professionals composed of representatives from the Office of Environment, the Office of Safety and Quality Assurance, and the Office of Health (EH-20, EH-30, and EH-40, respectively), who identified the evaluation elements used to perform the review and worked together to analyze and assess provisions of the CEOSHP.

The direction given to the review team was to determine how well the CEOSHP provides the framework and guiding principles for an effective, continually improving environmental, safety and health program at FEMP, and to identify aspects of the CEOSHP that could be strengthened to better achieve this goal. The review team also developed recommendations to assist EM in strengthening FERMCO's environment, safety and health program.

To ensure that the evaluation was conducted in a thorough and consistent manner, the review team identified a set of evaluation criteria based on the four principal elements of any effective occupational safety and health program: management commitment and employee involvement, worksite analysis, hazard prevention and 
control, 1 and employee training. The criteria corresponding to these elements that apply to each of the programs included in this review were derived from three sources. Occupational safety and health criteria were derived from DOE 5483.XX (11-12-93 draft); FERMCO used an earlier draft in their initial development of the CEOSHP. Criteria for the environmental protection program were derived from DOE's Performance Objectives and Criteria for Conducting DOE Environmental Audits (1994), which is an updated version of a 1992 document under the same title. Criteria for the radiological control program were derived from DOE's Radiological Control Manual. Appendix A presents these evaluation elements.

The four program elements of the review team's evaluation are widely recognized throughout the private sector as providing the essential foundation for successful environment, safety and health programs. These elements have been endorsed by the Occupational Safety and Health Administration (OSHA) in its voluntary Management Guidelines (54 FR 3904), and are required components of that Agency's Voluntary Protection Program, an initiative that provides public recognition for the bestmanaged and riost effective occupational safety and health programs in the private sector. These elements have al so been mandated by six State OSHA programs since 1991 and provide the guiding principles of DOE's foundation occupational safety and health program Order, draft DOE 5483.XX.

Using these evaluation elements, the review team systematically analyzed those portions of the CEOSHP pertaining to FERMCO's occupational safety and health, environmental protection, and radiological control programs. In each case, the team described the results of its evaluation and then made recommendations for ways in which the CEOSHP could be strengthened as it undergoes a comprehensive revision and restructuring by FERMCO. The review process also took into consideration how well the CEOSHP ties these program elements together to form an integrated, cohesive whole. Finally, the review team evaluated how effectively the CEOSHP conveys program expectations, implementation guidance, and program requirements to the ultimate users of the CEOSHP: the managers, supervisors, and workers who are expected to carry out the program on a day-to-day basis.

The evaluation performed by EH-20, EH-30, and EH-40 personnel was confined to a review of the CEOSHP, through Rev 0.3 , because this document is FERMCO's top-tier environment, safety and health program document. The team conducted a thorough but not exhaustive review of the CEOSHP, i.e., team members read and analyzed those chapters of the document addressing the three programs of concern but did not review every entry in the volume. The sections of the CEOSHP cited in the evaluation for each criterion thus represent selections from the CEOSHP rather than all relevant entries in that document.

The team focused on the identified evaluation elements; they did not evaluate the technical adequacy of lower-tiered programs, e.g., hoisting and rigging, scaffolds, and electrical safety. The review team did not obtain and analyze any other FERMCO documents for this project, nor did members of the team interview FERMCO personnel or seek to determine the compliance status of activities at the FEMP site. The team

1 For the review of FERMCO's environmental program, the worksite analysis and hazard prevention and control elements were combined into a single element designated Environmental Assessments and Controls. 
recognizes that FERMCO may have other documents pertaining to various aspects of its environment, safety and health program and believes that the CEOSHP would be strengthened by clear cross-references to any such documents. Finally, the review team is aware that, although a company's written environment, safety and health program provides the foundation for effective and successful programs, it cannot address how these programs are actually implemented on a daily basis. The evaluations and recommendations made in this report should therefore be interpreted with these consiferations in mind.

As FERMCO undertakes a comprehensive revision of the CEOSHP, it will be necessary to determine which broad program management requirements belong in the CEOSHP, and which requirements would be more appropriately contained in lower-tiered documents. 
This page intentionally left blank. 
Section 2.0

\author{
CEOSHP \\ OCCUPATIONAL SAFETY AND HEALTH \\ EVALUATION AND RECOMMENDATIONS
}




\section{SECTION 2.0 \\ CEOSHP Occupational Safety and Health \\ Evaluation and Recommendations}

\subsection{Management Commitment and Employee Involvement}

\subsubsection{Management Commitment}

\subsubsection{Written Policy Statement}

Paragraph III.2.a.(1) of DOE 5483.XX requires contractor management to develop a written occupational safety and health (OSH) policy statement that expresses management's commitment to the OSH program. This policy statement must stress the active, personal involvement of senior officials of the organization in the occupational, safety and health program and must also clearly establish that employee safety and health is a top priority within the organization.

\section{Evaluation}

The CEOSHP contains numerous policy statements expressing management's commitment to the various elements of the OSH program. For example, several sections in Chapters I and II include the following policy statements:

ESH 1-1, paragraph 1.0, "FERMCO's policy is focused on safety, health, and continuous performance improvement."

ESH 1-2, paragraph 1.0.A, "Safety is a very special commitment at FERMCO. Good safety performance is an item of added value that FERMCO takes pride in bringing to Fernald."

ESH 1-2, paragraph 1.0.B, and SPR 1-0, paragraph 1.0.C, "The heart of our safety and heaith program is the firm commitment by all members of management, supervision, and our employees to prevent accidents and the conditions that lead to injuries. Although safety flows from the top down, it depends on the awareness and cooperation of each individual employee in his or her daily work assignment to meet this challenge. Management must provide effective training, a safe environment, and must enforce the safety and health program."

ESH 1-3, paragraph 1.0, and SPR 1-0, paragraph 1.0.B: "Al1 injuries and occupational illness can be prevented. At FERMCO, we believe that this is a realistic goal and not just a theoretical objective."

ESH 1-3, paragraph 3.0.A: "Safety is a condition of employment; each employee must assume responsibility for working safely. At FERMCO, safety is as important as production, quality, and cost control."

ESH 1-3, paragraph 3.0.H, and SPR 1-0, paragraph 3.1.A: "People are the most critical element in the success of a safety and health program. Management responsibility must be complemented by employees' suggestions and their active involvement in keeping workplaces safe."

These statements, taken together, indicate that FERMCO places a high priority on employee safety and health. However, the fact that they are introduced at many places throughout the document detracts from their overall impact. 


\section{Recommendation}

The CEOSHP would be strengthened if it included one clear and concise policy statement that expresses FERMCO's commitment to the OSH program, outlines the company's expectations for management, supervisory, and employee involvement, and demonstrates to all employees the high priority management places on occupational safety and health.

\subsubsection{Written Program, Policies and Procedures}

Paragraph III.2.a.(6)(b) of DOE 5483.XX requires contractors to develop a comprehensive written $\mathrm{OSH}$ program, including policies and procedures, that provides for safe and healthful workplaces and implements DOE'S OSH program requirements. This document must describe the roles, responsibilities and authorities, functions, interrelationships, and methodologies for the performance of each element of the contractor's 0 SH program. The program must be sufficiently defined such that each group of emplnyees can carry out their responsibilities and implement the contractor's OSH program.

\section{Evaluation}

The CEOSHP is FERMCO's comprehensive written OSH program document. It contains sections addressing many of the program elements specified in DOE 5483.XX; however, similar program functions and associated roles, responsibilities and authorities are located in different sections of the CEOSHP. Arranged in such a manner, they are perceived to be independent, stand-alone components, with no indication of how these separate components integrate with each other to provide one comprehensive occupational safety and health program. For example, it is not clear how the ES\&H Training section (ESH 1-8) integrates with the Safety Orientation section (SPR 1-3); how the Walk Your Space Philosophy section (SPR 2-1) integrates with the ES\&H Performance-Based Inspections/Audits section (EAPR 3-2); how the FERMCO Accident Reporting and Investigation section (SPR 2-62) integrates with the Incident Investigation and Reporting section (EAPR 3-3); how the Pre-Job Safety Requirements section (SPR 3-4) integrates with the Pre-Job Safety and Health Survey section (SPR 3-16); or how the Mission section (ESH 1-0) integrates with the Culture section (ESH 1-1), the Safety Philosophy section, (ESH 1-2), and the Safety Principles section (ESH 1-3).

\section{Recommendation}

The CEOSHP would be enhanced by integrating all of the OSH program management components (i.e., organization, training, self-assessment, accident investigation, hazard abatement, etc.) into one comprehensive and integrated $O S H$ program section, built on the four recognized program management elements: management commitment and employee involvement, worksite analysis, hazard prevention and control, and training. This section would define FERMCO's OSH program structure and organization, assign responsibilities for implementation of each of the elements, and define how each of the elements integrates with others to provide effective and comprehensive safety and health protection for all FERMCO and subcontractor employees. The CEOSHP should also delineate how employees are involved in program and policy development. In addition, the section should define procedures and responsibility for tracking changes to $\mathrm{OSH}$ requirements and guidance (e.g., Safety Note, Health Hazard Alert, and other DOE lessons-learn publications) that may impact site operations; updating the CEOSHP and other FERMCO procedures; and for developing and implementing lower-tiered programs and procedures that support and define 
workplace $\mathrm{OSH}$ requirements (e.g., the programs and procedures provided in CEOSHP sections SPR 2-10 through SPR 2-57).

\subsubsection{Active Management Involvement}

Paragraph III.2.a.(1) of DOE 5483.XX requires contractor management to demonstrate top-level management commitment through the active, personal involvement of senior officials in meeting the requirements of the occupational safety and health program. Such top-level involvement is necessary to provide program leadership, motivation, and direction, as well as the resources needed to organize and manage an effective OSH program that will demonstrate to all employees that the organization regards occupational safety and health as a value as fundamental as other management objectives (e.g., productivity and profit).

\section{Evaluation}

The CEOSHP contains numerous statements that discuss top-level management involvement. These statements, however, are found in various sections of the CEOSHP, are often redundant and sometimes confusing. These statements would be more effective if they provided a cohesive set of measurable requirements or guidelines for ensuring vigorous management involvement in every element of the program. For example, the Safety Principles section (ESH 1-3, paragraph 2.1) and the Occupational Safety and Health Program section (SPR 1-0, paragraph 2.1.A) both designate FERMCO's President as the "Chief Safety Officer," although neither section defines this individual's responsibilities and authorities.

The CEOSHP is vague about the specific responsibilities of other FERMCO managers for the occupational safety and health program. The Safety Philosophy section (ESH 1-2, paragraph 1.0.B) and the Occupational Safety and Health Program section (SPR 1-0, paragraph 1.0.C) both assert that,

"The heart of our safety and health program is the firm commitment by members of management, supervision and employees to prevent accidents that lead to injuries."

However, neither section identifies the actions that managers are required or encouraged to take to demonstrate their "firm commitment" and to achieve the goal of accident prevention. This lack of specificity is apparent in the Walk Your Space Philosophy section (SPR 2-1, paragraph 2.1), which states that managers and supervisors should conduct themselves in a manner that:

A. "Exemplifies the walk-your-space philosophy and conveys its message to all employees and subcontractors.

B. Supports this philosophy by providing the appropriate communication channels and support for identifying and correcting hazards in an employee's work space."

However, the CEOSHP does not require managers and supervisors to perform these activities and does not provide guidance about what kinds of actions and procedures might be employed to carry out these activities. 


\section{Recommendation}

The CEOSHP should provide guidance for the development of a single, well-integrated and comprehensive program which includes specific requirements for top-level management involvement in the implementation of each element of the occupational safety and health program. These requirements must explain how management's commitment to the program can be evidenced through actions which will demonstrate to employees at all levels of the organization the high priority management places on occupational safety and health. Required management activities should be linked directly to specific elements of the program; examples of such requirements are:

The specific responsibilities and duties of the Chief Safety Officer, such as meeting with each employee who suffers a lost-workday injury and his or her supervisor to discuss the accident and its causes and to address appropriate control measures; presenting the opening portion of safety and health orientation sessions for new employees; and conducting quarterly meetings with managers and supervisors to review and discuss their safety and health performance, accident and injury trends, and upcoming safety and health projects;

- A requirement that all managers walk their spaces (or a defined portion of their spaces) at least weekly and that supervisors walk their spaces daily to anticipate and identify workplace hazards;

- A requirement that every manager accompany DOE OSH evaluators during walkthrough inspections of that manager's spaces; etc.

\subsubsection{OSH Professional Staff Qualifications}

Paragraph III.2.a.(2) of DOE 5483.XX requires that contractor OSH professionals satisfy, at a minimum, the requirements contained in the Office of Personnel Management standards for safety and occupational health managers/specialists, safety engineers, and industrial hygienists, as these apply to their responsibilities, and that these professionals have the training specified in Chapter IV of DOE 5483.XX. The Order also states that contractor OSH professionals should be encouraged and supported in their professional growth by providing them with the funding and official time needed to participate in the activities of local, national, and international professional organizations; prepare for and maintain professional certifications; and present and publish the products of their professional activities.

\section{Evaluation}

Section SPR 1-2, paragraph 3.0 of the CEOSHP provides specific qualification requirements for all levels of FERMCO OSH professionals, from OSH technicians to the manager of the Occupational Safety and Health Department. These FERMCO qualifications are consistent with and exceed the Office of Personnel Management standards for OSH professionals referenced in DOE 5483.XX. The supervisor qualification requirement in the CEOSHP, however, contains a minor error in the statement that refers to "ABIH or ASSE certification:" The ASSE does not certify OSH professionals. The correct certifying organization for safety professionals is the Board of Certified Safety Professionals (BCSP).

Section SPR 1-2, paragraph 2.2 of the CEOSHP clearly recognizes the need to support OSH professionals in advancing their professional qualifications and training; for 
example, this section states that the manager of the Occupational Safety and Health Department must ". . . ensure that a program is in place to foster career development and advancement through continuing education, training, certification processes, etc. in an effort to advance the qualification level of the overall organization."

\section{Recommendation}

The Occupational Safety and Health Personnel Qualifications section of the CEOSHP could be further improved by addressing funding and support of career development efforts that go beyond professional training and certification to include participation in the activities of local, national, and international OSH professional societies and organizations.

\subsubsection{OSH Program Planning and Budgeting}

Paragraph III.2.a.(3) of DOE 5483.XX requires contractor organizations to request funding and $\mathrm{pl}$ an for the personnel, training, and materials necessary to support $\mathrm{OSH}$ program requirements, including provision for the necessary engineering controls, monitoring equipment, and reference documents. In addition, paragraph III.2.a. (5) requires that contractors use guidance received from DOE to prepare an annual $0 \mathrm{SH}$ Program Plan. This plan must address the contractor's goals and objectives, required $O S H$ staffing levels, any variation from required 0 SH elements in the Safety and Health Five-Year Plan, specific program improvements and initiatives and a methodology to track progress throughout the year, and activities designed to correct adverse trends in $\mathrm{OSH}$ performance. The dynamic nature of environmental remediation planning and other planning processes make it necessary to build flexibility into the development of the annual OSH Program Plan, in order to incorporate changes as they occur. The annual OSH Program Plan should serve as a tactical tool for FERMCO since it documents FERMCO's planned occupational safety and health activities; it can also be used as a performance measurement tool by DOE.

\section{Evaluation}

The CEOSHP, in SPR 1-0, paragraph 3.1.C, requires that:
"Each level of management annually establish the goals and objectives of the Occupational Safety and Health program. An implementation plan is developed with milestones, budget, staffing and planned evaluations."

Although this paragraph requires the development of an implementation plan, the CEOSHP does not identify the FERMCO organization responsible for developing and coordinating an overall plan. Several statements dispersed throughout the document identify specific organizations responsible for the development of program plans (e.g., ESH 2-0, paragraph 1.0, suggests that the Environmental Safety and Health Division is responsible for the development of a program plan; ESH 2-1, paragraphs 2.0. I and 3.2.B indicate that the Occupational Safety and Health Department is responsible for the development of $\mathrm{OSH}$ program plans and a comprehensive OSHA program plan; SPR 2-59, paragraph 3.1 includes in the 1ists of manager's and supervisor's OSH program responsibilities planning, budgeting and programming, and EAPR 3-0, paragraph 2.0. E requires the ES\&H Self-Assessment Manager to develop an annual Self-Assessment Program Implementation Plan). However, these statements do not indicate whether these program plans are identical to or comprise a part of the plan identified in SPR 1-0, paragraph 3.1.C, nor do they specify the required 
elements of such program plans. The CEOSHP does not address coordination and approval of these plans with DOE.

In addition, the CEOSHP does not provide enough detaii about the contents of the implementation plan discussed in SPR 1-0, paragraph 3.1.C. For instance, the paragraph requires that the $\mathrm{plan}$ include milestones, budget, staffing, and planned evaluations; however, it does not identify what activity milestones are to be established (e.g., scheduled completion dates for OSH projects), what the budget is for (e.g., OSH equipment, 0 SH abatement activities, training, etc.), what office, organization, or project the staffing is to support (e.g., OSH staff, clean-up staff, maintenance staff), or what types of evaluations must be included in the plan (e.g., internal OSH evaluations, evaluations conducted by DOE, or evaluations conducted by external organizations).

Several sections throughout the CEOSHP address various budgeting and planning elements. For example,

- ESH 2-4, paragraph 2.0.G requires the ES\&H Assurance Department to "Develop and maintain an . . ES\&H tracking system for regulatory and technical commitments . . . which clearly identifies the following: issue, action, responsible individuals, milestone dates, completion dates, verification dates.";

EAPR 3-0, paragraph 2.0.C and 2.0.F requires the ES\&H Self-Assessment Manager to "ensure adequate personnel/resources and facilities to support self-assessment activities" and "Integrates the self-assessment program activities with other ongoing programs (e.g., strategic planning, 5 year plan)."; and,

EAPR 3-5, paragraph 3.0.D, note, requires that, "If [an] infraction cannot be corrected within the time frame established in the [safety infraction] report, the manager must... establish an appropriate plan for correcting the infraction."

However, these sections do not specify that these budget or planning elements be included in the annual OSH Program Plan or indicate how they are to be integrated into the annual OSH Program Plan.

Finally, the requirements in SPR 1-0, paragraphs 3.1.C and 3.1.D that each management level develop annual OSH program goals and objectives and ". . communicate the goals and objectives to their employees to ensure that safety is a condition of empioyment ..." suggests that numerous OSH goals and objectives are in existence throughout FERMCO, and that the =oals and objectives of different management levels and organizations may have been established independently from each other and without reference to focused or guiding criteria. Several additional statements throughout the CEOSHP do address FERMCO's overall goal of preventing all injuries and 111 nesses (e.g., ESH 1-3, paragraph 1.0; SPR 1-0, paragraph 1.0.B); however, the CEOSHP does not indicate how this overall goal relates to the establishment of annual goals and objectives.

In summary, although the CEOSHP appears to touch upon some OSH program planning and budgeting requirements, the document does not establish a structured, integrated, and cohesive system for planning and budgeting for the OSH program. In addition, there are no procedures to communicate $\mathrm{OSH}$ planning and budgeting activities with DOE. 


\section{Recommendation}

The OSH budgeting and planning elements of the CEOSHP could be strengthened by identifying the organization with the ultimate responsibility for the development of the annual OSH program plan. This designation of responsibility should indicate how the responsible organization will integrate the OSH budgeting and planning needs of each FERMCO organization into the comprehensive program plan. The CEOSHP should provide guidance and criteria on the development of OSH goals and objectives and should indicate that goals and objectives should be established at the top level of FERMCO management based on the goals and objectives established by DOE. The CEOSHP should indicate that FERMCO, for each part of its organization, will translate the goals and objectives established by DOE into meaningful and achievable goals and objectives that support top level FERMCO goals and objectives. Requirements for the OSH program $\mathrm{plan}$ should integrate each element of the OSH program into the program $\mathrm{plan}$ and should address the planning and budgeting of compliance inspections, self assessments, investigations, awards, safety and health training, safety and health support for upcoming projects, hazard abatement projects, monitoring requirements, etc. In addition, the CEOSHP should address and assign the responsibility for the integration of the annual OSH program $\mathrm{plan}$ and the required safety and health fiveyear plan.

\subsubsection{Contractor Compliance with DOE-Prescribed OSH Standards}

Paragraphs 4.a, I.2, and 10.d.(1) of DOE 5483.XX require that contractors comply with DOE-prescribed Occupational Safety and Health (OSH) standards. This requirement applies to all contractors performing work at DOE-sponsored facilities, without regard to the type or value of the contract under which the contractor is working, the number of employees employed by the contractor, or the jurisdictional status of the facility (i.e., whether it falls under OSHA or DOE jurisdiction). Contractors are required to comply with all DOE-prescribed OSH standards, which include: DOE standards; OSHA standards; Adopted Standards (including international, national non-governmental standards and federal and other U.S. agency standards); and the General Duty Standard of DOE 5483.XX. When more than one DOE-prescribed OSH standard could apply, contractors are required to follow a hierarchy established in the order.

\section{Evaluation}

The CEOSHP makes a number of general references to compliance with DOE and other regulatory requirements. For example, ESH 1-0, paragraph 2.1.A, states that it is the responsibility of the Environmental Safety and Health Division to ensure that "proper ES\&H programs, systems, and procedures are in place such that all regulatory and DOE requirements are met"; ESH 2-1, paragraph 1.0.A states that the Occupational Safety and Health Department will "focus on reducing employee injuries and exposures to hazardous materials through the creation of a safe work place. The program will be based on strict DOE, OSHA, TSCA, and NIOSH compliance." Section ESH 2-1, paragraph 3.1, titled "Governing Regulations," asserts that the occupational safety and health program will be governed by a long list of requirements, including DOE 5483.XX, 29 CFR 1910.120, 29 CFR 1910, 29 CFR 1926, and "TSCA, NFPA, NIOSH, [and] ACGIH." Similarly, paragraph 3.0.A of section SPR 1-0 states:

"The program is based on strict DOE, Occupational Safety and Health Administration (OSHA), Toxic Substance Control Act (TSCA), and National Institute for Occupational Safety of Health (NIOSH) compliance, as well as all relevant local and state regulations." 


\section{Recommendation}

The clarity and usefulness of the CEOSHP would be strengthened if it included a single, comprehensive section stating that: (1) compliance with all DOE-prescribed OSH standards is mandatory for all contractors, including all covered subcontractors; (2) in case of conflict between two standards, e.g., between two different exposure limits for the same toxic substance, the hierarchy of standards contained in draft DOE 5483.XX is to be followed; (3) under the General Duty Standard, which is similar to OSHA's General Duty Clause (section 5(a)(1) of the OSH Act), contractors have an obligation to protect their employees from recognized occupational safety and health hazards even if no regulatory requirement specifically addresses that hazard. To avoid confusion and facilitate compliance, this section of the CEOSHP should al so include a 1 ist of those standards with which FERMCO and its subcontractors will comply; this list should specifically include all standards designated as DOE-prescribed OSH standards in DOE 5483.XX. Finally, for OSH, references to occupational safety and health or other standards that are not included in DOE 5483.XX, e.g., to NIOSH, should be deleted, because compliance with these standards is not a generally accepted OSH practice and could lead to considerable confusion. In addition, the CEOSHP should indicate the location of the referenced standards, describe the procedures used to update the 1ist, and indicate the frequency with which the list is reviewed and updated. It is also suggested that the CEOSHP reference the "DOE Interpretations Guide to OSH Standards" and the "DOE OSH Standards Interpretations Response Line" (a 1-800 hotline) as resources which can be accessed to obtain official DOE interpretations of OSH standards.

\subsubsection{Subcontractor Compliance with DOE-Prescribed OSH Standards}

Paragraph 10.d.(2)(j) of DOE 5483.XX requires that contractors ensure that subcontractor services require compliance with DOE-prescribed OSH standards and specify appropriate DOE program requirements.

This means that all covered contractors performing work at DOE-sponsored facilities are responsible for ensuring that any subcontractors working under contract to them comply with all DOE-prescribed OSH standards, including DOE standards, the OSHA standards, the adopted standards 1isted in Chapter I, paragraph 2 of DOE 5483.XX, and the General Duty Standard contained in DOE 5483. XX. By holding contractors responsible for the $\mathrm{OSH}$ performance and regulatory compliance status of their subcontractors, DOE 5483.XX ensures that accountability for occupational safety and health is established at all contracting levels, from the smallest industrial hygiene contractor to the largest Management and Operating (M\&O) or Environmental Restoration and Management (ERMC) contractors, and that compliance with DOEprescribed 0 SH standards is standard practice at all sites within the complex. In addition, by mandating that all subcontracts specify which program requirements, as outlined in DOE 5483.XX, Chapters III through VI and Attachments 3 and 6, a subcontractor must comply with, it will be clear what the contractor is requiring of the subcontractor and what program requirements will remain the responsibility of the contractor. This will ensure that appropriate OSH program requirements and standards are consistently implemented across the complex.

\section{Evaluation}

The CEOSHP recognizes that contractors have $O S H$ responsibilities for their subcontractors. For example, several sections in chapters I, II, and III include statements such as the following: 
ESH 1-0, paragraph 2.1.B, "Environmental Safety and Health Division develops policies and procedures to govern all work at the FEMP site, and audits FERMCO and subcontractor activities."

SPR 2-6, paragraph 3.0.B, "FERMCO maintains these [occupational and illness] records and requires subcontractors to maintain similar records in accordance with these [OSHA and DOE recordkeeping] standards."

SPR 3-3, paragraph 1.0, "FERMCO recognizes that safety begins with management commitment. Supporting the FERMCO Safety and Health program is as important a responsibility as any of the other management concerns. FERMCO will place the same emphasis on subcontractors that work at the FEMP site."

SPR 3-4, paragraph 2.1.B, "[It is the responsibility of subcontractors to] comply with DOE, State, and Federal safety regulations."

SPR 3-4, paragraph 3.1.C, "Subcontractors who bring lower-tiered subcontractors to the work site must ensure their compliance with DOE, State, Federal, and FERMCO safety policies."

SPR 3-5, paragraphs 1.0 and 3.0 state that "FERMCO is committed to contracting only individuals or companies who are safety conscious," and require that "[e]ach subcontractor will be systematically and equally evaluated using the guidelines and instructions [contained in referenced FERMCO documents]."

As these examples demonstrate, the CEOSHP reflects FERMCO's awareness of the importance of considering the safety and health performance of contractors of all tiers in evaluating the site's overall safety and health experience. However, locating these and other similar examples was difficult, and users of the CEOSHP may have a difficult time trying to develop a clear and succinct understanding of what FERMCO's responsibility is for subcontractors, and how this responsibility is to be implemented. For example, a number of these statements were contained in the "Construction Safety and Health Program" section of the CEOSHP (i.e., SPR 3-3, 3-4, 3-5) and presumably would not apply to all FERMCO operations and subcontractors.

\section{Recommendation}

The CEOSHP would be strengthened if it included a section that clearly establishes FERMCO's responsibility for including, in any subcontract, a statement that compliance with DOE-prescribed OSH standards is mandatory and that all subcontractors must comply with the program requirements as specified by FERMCO. This section should include provisions for selecting subcontractors based on previous safety and health performance (outlined in SPR 3-5), should apply to all subcontractors (not just construction subcontractors), and should include enough information to inform subcontractor employers, supervisors, and managers which standards are included in the DOE-prescribed OSH standards category (including an explanation of an employer's inherent obligation to provide a workplace that is free of, or protected against, recognized safety and health hazards) and where copies of these documents can be obtained. In addition, many of the references in the CEOSHP omit the word "health" in descriptive phrases; it is important to refer to "safety and health" throughout the CEOSHP. 


\subsubsection{Host/Tenant OSH Responsibilities}

Paragraph III.2.a.(7) of DOE 5483.XX requires all DOE and contractor hosts and tenants to develop and include in existing and future contracts, Memorandums of Understanding, Memorandums of Agreement, or other agreements that specifically delineate the respective 0 SH roles and responsibilities of the parties to these agreements. In particular, the Order requires any statements that describe how compliance with OSH program requirements is to be achieved and how any OSH-related issues that cut across program or other lines of responsibility will be resolved to be included in contracts and agreements. Ensuring that these agreements clearly address $\mathrm{OSH}$ issues and responsibilities becomes increasingly important as the number of Federal agencies or other outside organizations at the facility increases.

\section{Evaluation}

Although the CEOSHP touches on the importance of contractor/subcontractor relationships at a number of points, it does not specifically address host/tenant relationships and the procedure for documenting who or how OSH program requirements will be accomplished among FERMCO and other organizations at the site.

\section{Recommendation}

The CEOSHP would be strengthened by including a section which addresses the requirement for host/tenant agreements where FERMCO, DOE, and other agencies and organizations reside on site at Fernald. This section should address the need to identify all other relevant agreements (e.g., tri-party agreements and memorandums of agreement) that may impact the $\mathrm{OSH}$ program and determine their compatibility and extent of interface, assign responsibility for the development and implementation of host/tenant agreements and address the basic elements required in such agreements. For example, these elements might include a description of the basic 0SH-related services that FERMCO is required to provide to the tenant (e.g., inspection services, joint accident investigations, etc.), as well as requirements that the tenant must adhere to (e.g., compliance with FERMCO's OSH requirements and procedures).

\subsubsection{Employee Involvement}

\subsubsection{OSH Responsibilities and Personnel Accountability}

Paragraph III.2.a.(8)(a) of DOE 5483.XX requires contractor line organizations to assign and communicate OSH responsibilities to employees within the organization and to ensure that employees given such responsibilities are provided with the requisite authority and resources needed to meet their assigned OSH program responsibilities. In addition, DOE 5483.XX requires that employees be held accountable for the proper performance of their 0 SH responsibilities. Making clear assignments and holding staff accountable for carrying out specific OSH responsibilities is necessary both to reflect the importance of each employee's role in the overall effective functioning of the OSH program and to ensure the active involvement of employees in the program. Employee involvement in all phases of the program has been shown to enhance awareness of the importance of safety and health throughout the organization, and to contribute to program effectiveness by encouraging employees to contribute their knowledge and insight to the program. In addition, employees who participate in decision-making and understand the rationale underlying safety and health procedures tend to respect those procedures and to feel a sense of ownership in the $\mathrm{OSH}$ program. 


\section{Evaluation}

The CEOSHP addresses the OSH responsibilities of each group of FERMCO employees; however, statements asserting these responsibilities are found in various sections of the document, are referred to within the document both as responsibilities and requirements, and many are vaguely worded. This presentation of OSH responsibilities makes it difficult for FERMCO employees to obtain a complete and integrated picture of any given individual's OSH responsibilities. The following example demonstrates these points. In several places, the CEOSHP states that FERMCO personnel are required "to perform work safely" (Safety Philosophy, section ESH 1-2, paragraph 2.0; Safety Principles, section ESH 1-3, paragraph 2.2; Occupational Safety and Health Program, section SPR 1-0, paragraph 2.3), while in others, employees are exhorted to "work as safely as possible" (Employee Safety Responsibilities, section ESH 1-6, paragraph 2.0.A), to "comply with FERMCO safety requirements" (Culture, section ESH 1-1, paragraph 2.2), to "comply with FERMCO's safety, health, and environmental regulations" (Responsibilities for Safety and Health, section ESH 1-4, paragraph 2.3), and to "obey all FERMCO safety rules, regulations, and instructions given to [the employee]" (Employee Safety

Responsibilities, section ESH 1-6, paragraph 2.0.C). Other statements of employee OSH responsibilities, which are worded as if they were requirements, include "safety shall be the responsibility of each and every employee" (Culture, section ESH 1-1, paragraph 3.2), "each employee has the responsibility to perform work safely..." (Safety Philosophy, section ESH 1-2, paragraph 3.0.A), "...each employee must assume responsibility for working safely" (Safety Principles, section ESH 1-3, paragraph 3.0.A) and "you [the employee] are responsible for providing the safest possible workplace for yourself and all personnel" (Employee Safety Responsibilities, section ESH 1-6, paragraph 3.0.C).

The repetition (with slight variations) and rephrasing of the same two ideas (i.e., that employees must work safely and comply with safety and health rules) may detract from the emphasis that would be conveyed by a single, well-expressed, and comprehensive statement of employee $\mathrm{OSH}$ responsibilities. In addition, despite attempts to convey the importance of each employee's 0 SH responsibilities, the CEOSHP does not define clear and meaningful roles for employees at various organizational levels.

Other sections of the CEOSHP are more successful in defining the OSH roles of employees. For example, the Walk Your Space Philosophy section (SPR 2-1, paragraph 2.2.A) requires employees to "implement the walk your space philosophy," while the Job Safety Analys is section (SPR 2-4, paragraph 3.0.E) suggests that supervisors ask employees performing specific tasks to participate in analyzing such tasks, and the Safety Incentive Policy section (SPR 6-0, paragraphs 2.2 and 3.0.A) indicates that FERMCO encourages employee input into the design of the Safety Incentive Program. Although these sections of the CEOSHP identify several ways in which employees can participate in the safety and health program, they do not specifically require that employees perform these tasks or describe how employees are expected to carry out their tasks.

Finally, the CEOSHP does not discuss how employees will be held accountable for their assigned responsibilities. Several sections state that safety is a condition of employment (e.g., ESH 1-2, paragraph 3.0.A, ESH 1-4, paragraph 3.0.B, ESH 1-6, paragraph 3.0.b, SPR 1-0, paragraph 2.3), that disciplinary action will result from disobeying safety and health rules (e.g., ESH 1-6, paragraph 3.0.A), and that disregard for safety and health procedures will not be tolerated (e.g., ESH 1-1, paragraph 3.2, ESH 1-6, paragraph 3.0.A). Section SPR 3-15 identifies specific 
disciplinary procedures for contractors and subcontractor employees in construction operations; however, no other section delineates how FERMCO employees will be held accountable for compliance with safety and health requirements in other FERMCO operations.

\section{Recommendation}

The CEOSHP should be a well-integrated and comprehensive OSH program document which includes a section that defines the specific 0 SH authorities and responsibilities of each group of FERMCO employees. These authorities and responsibilities should be clear and concise (i.e., it may not be necessary to have five or ten statements at various places throughout the document encouraging or requiring employees to work safely or to comply with rules); instead, the CEOSHP could clearly and succinctly describe the specific activities that each group of employees must perform to support the OSH program. For example, the CEOSHP might require employees to review their workplace at the beginning of each workday, using checklists developed by the supervisor and employee based on the job safety analysis conducted for that job. The CEOSHP could also specifically delineate the extent to which employees have the auticrity to correct workplace deficiencies. In addition, the CEOSHP should indicate how employees are involved in the development and implementation of the OSH program. Finally, because positive reinforcement, prompt feedback, and a clear understanding of roles and responsibilities have been shown to increase employees' sense of belonging and enhance compliance with standard procedures, the CEOSHP should seek to express employee accountability in positive rather than negative terms. A clear and succinct description of the various steps in the facility's disciplinary process should also be provided.

\subsubsection{Position Descriptions and Personnel Evaluation Plans}

Paragraph III.2.a.(8)(a) of DOE 5483.XX requires contractor I ine organizations to assign and communicate OSH responsibilities to supervisors and managers and to hold supervisors and managers accountable for the proper performance of their $\mathrm{OSH}$ activities through the use of position descriptions and formal personnel evaluation plans.

\section{Evaluation}

As discussed in the Evaluation section of evaluation element 2.1.2.1 above, the CEOSHP presents the OSH responsibilities of personnel at all levels of the FERMCO organization, including those of non-supervisory employees, supervisors, and managers; these responsibilities are addressed in many sections of the document. Although a number of these statements emphasize that FERMCO staff at all levels will be held accountable for their OSH performance, the document does not describe the methods FERMCO will use to ensure manager and supervisor accountability. For example, paragraph 3.0.A of section ESH 1-2 states that "each supervisor must accept responsibility and be held accountable for the safety performance of those employees under their direction;" ESH 1-3, paragraph 2.1 states that ". . . each leve] [of site management is] accountable to the one above and responsible for the level below," and ESH 1-5, paragraph 3.0.E, states that "supervisors who do not uphold [their OSH] obligations may be subject to disciplinary action, including termination of employment." Other sections include similar statements regarding accountability (e.g., ESH 1-9, paragraph 3.0.D; SPR 1-0, paragraphs 2.1 and 2.2; EAPR 1-1, paragraph $3.0 . \mathrm{F})$. However, none of these sections indicates that OSH accountability

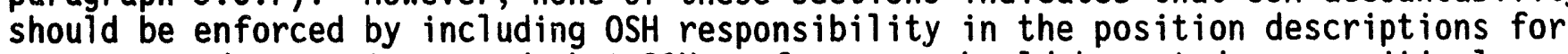
managers and supervisors and that $\mathrm{OSH}$ performance should be rated as a critical 
element in their formal performance appraisals. Furthermore, a number of the CEOSHP accountability statements are broad in nature (e.g., ESH 1-3, paragraph 2.1 ". . . each level is accountable to the one above and responsible for the level below") to hold managers or supervisors accountable for carrying out any specific elements of the $\mathrm{OSH}$ program, such as the performance of job safety analyses, ensuring that personnel receive appropriate training, reviewing the workplace, investigating accidents, etc.

\section{Recommendation}

The broad statements regarding supervisor and management accountability should be refined to focus on the specific OSH responsibilities of managers and supervisors. In addition, the CEOSHP wOuld be strengthened by including a description of the mechanism FERMCO will use to hold managers and supervisors accountable for the performance of their 0 SH duties. This mechanism should include position descriptions for manager and supervisor positions that incorporate specific $0 \mathrm{SH}$ responsibilities and manager and supervisor performance evaluation plans that rate $\mathrm{OSH}$ performance as a critical element.

\subsubsection{OSH Program Promotion and Employee Involvement}

Paragraph III.2.a.(8)(b) of DOE 5483.XX requires the contractor to develop and implement activities to encourage and promote employee involvement in and commitment to the contractor's $O S H$ program. Such activities might involve a variety of $0 \mathrm{SH}$ promotional and communication activities, such as providing positive reinforcement for safe behaviors, making awards for safe performance, publicly recognizing special work activities accomplished by groups of employees in a safe and healthful manner, publishing OSH newsletters, or any other approach that achieves the desired endpoint. The goal of such employee participation is to provide free and ready opportunities for two-way communication about $\mathrm{OSH}$ issues, to permit information about the OSH program to be disseminated to employees, and to encourage and support safe and healthful job performance. In addition, paragraph III.2.b. (2) of DOE 5483.XX requires contractors to have a system for employees to report $0 S H$ concerns.

\section{Evaluation}

Sections SPR 6-0 through 6-2 of the CEOSHP establish an employee incentive and award program for safety and health achievements in the workplace. This program recognizes FERMCO employees who have made significant contributions to the FERMCO safety and health program either by avoiding personal injury through the use of personal protective equipment, by performing a life-saving act, or by completing a specified number of work hours without a lost workday injury or illness. SPR 6-4 extends this awards system to FERMCO contractors who have contributed to the OSH program by meeting established project-specific safety and health goals. The incentive system for FERMCO employees and contractors includes elements that have been proven to promote employee OSH involvement, such as personal awards (e.g., cash bonuses, gift certificates, plaques), recognition from top management (e.g., the FERMCO president presents the awards), and public recognition (e.g., article and picture in the FERMCO newspaper and, when possible, in the local newspaper). However, by rewarding employees who perform life-saving activities, FERMCO may inadvertently be promoting unsafe behaviors in employees by encouraging them to attempt rescue efforts without regard to their qualifications or training, or to the availability of the proper protective equipment. For example, a large percentage of the nation's confined space fatalities involve individuals who attempted to rescue 
an unconscious victim without first implementing appropriate protective measures. Because rescue efforts present significant hazards to rescuers, they should not be encouraged unless personnel are adequately trained to undertake them and have been provided with, and trained in the use of, the necessary rescue equipment.

SPR 6-3 of the CEOSHP further encourages employee participation in the OSH program by establishing safety and health suggestion and complaint systems. Reference to an employee "concern" or a "report of an unsafe or unhealthful condition" as a "complaint" does not encourage employee participation, strengthen relationships between various groups of FERMCO employees or contribute to the identification and control of hazards. In addition this policy does not guarantee protection to workers who raise $\mathrm{OSH}$ concerns.

The system as presented in the CEOSHP does not specifically provide that employees whose suggestions have significantly contributed to the FERMCO safety and health program be recognized. In addition, the procedures employees are to follow to elevate their $\mathrm{OSH}$ concerns to higher levels of FERMCO management are also not clearly defined; for instance, SPR 6-3, paragraphs 3.0.F and G state that, ". . . if complaints are not addressed to the satisfaction of the employee, several standing safety committees and meetings are available to present the complaint for further discussion," and ". . . any individual may also submit a written complaint to DOE. . . ." These statements suggest that, if the employee is not satisfied with the supervisor's response, the employee should bypass other levels of FERMCO management and elevate the concern directly to DOE for final resolution. Following this process would appear to contravene established organizational management practices and may al so not be effective.

\section{Recommendation}

The safety incentives and award provisions of the CEOSHP could be enhanced by clearly indicating that employees should not attempt rescue activities unless they are provided with and trained in the use of necessary rescue equipment. The awards program should clearly indicate that employees who unnecessarily endanger their health and safety or the health and safety of others by attempting rescue activities without employing the necessary protective measures will not be eligible for an award.

The term "complaint" should be replaced with a more positive term, such as "concern or "report of unsafe or unhealthful condition." This would give the proper impression that reporting hazards is beneficial to the OSH program.

The suggestion and complaint system could be strengthened by integrating this system with the incentives and awards system. Employees should be recognized for suggestions or complaints that significantly contribute to the FERMCO hazard prevention effort by identifying workplace hazards and viable control mechanisms. The suggestion and complaint system could also provide employees a mechanism to elevate the resolution of suggestions or complaints up through the FERMCO management chain if the employee's supervisor cannot resolve the issue. This section should indicate that, where necessary, the preferred method for resolution of suggestions or concerns is elevation through FERMCO management but that employees can, at any time, resort to DOE for resolution. This policy should encourage workers to identify and report safety and health issues and concerns without fear of reprisal, and guarantee that protection. 


\subsubsection{Safety and Health Committees}

Paragraph III.2.a.(9) of DOE 5483.XX requires contractors to establish a safety and health committee, or committees, to assist in the $\mathrm{OSH}$ program and to make recommendations regarding methods of addressing OSH hazards. The committee, or committees, should consist of managers and employees working at the site who are committed to achieving optimal levels of safety and health in the workplace. Such committees are widely acknowledged throughout industry as effective forums for the exchange of $\mathrm{OSH}$ information, as a means of ensuring employee participation, and as a method of enhancing understanding of the principles of $\mathrm{OSH}$ throughout the organization.

\section{Evaluation}

The CEOSHP includes several statements throughout the document that reference various types of committees or meetings:

SPR 2-0, paragraph 3.2.B, includes as part of the supervisor's role the conduct of "regular meetings ... with personnel to ensure that they understand and follow all facets of the Occupational Safety and Health program."

SPR 2-1, paragraph 3.0.C, "Supervision will follow-up on new employee training by providing specific information as to the hazards associated with the workplace. Supervision will accomplish this through: ... monthly safety meetings."

SPR 2-62, paragraph 2.4.B, [the Manager of 0ccupational Safety and Health ii11] "Chair [a] periodic review meeting of injuries and illnesses."

SPR 6-3, paragraph 3.0.F, "If [employee] complaints are not addressed to the satisfaction of the employee, several standing safety committees and meetings are available to present the complaint for further discussion."

SPR 2-59, paragraph 3.2, which refers to the training requirements of a "safety awareness team."

However, the CEOSHP does not state whether these groups and committees are a required part of the 0 SH program. In addition, the CEOSHP does not include guidance on the required membership, charter, or interrelationships of any of these various committees, meetings, or teams, or prescribe the role and function of these groups within the OSH program. The CEOSHP does not discuss how these groups are to be used as potential sources of advice or assistance for managers, supervisors, or OSH professionals in the implementation of the $\mathrm{OSH}$ program.

\section{Recommendation}

The CEOSHP should provide for a safety and health committee and guidance on the committee's charter and its required membership. The committee charter should address the frequency of meetings as well as the responsibilities and proposed activities of the committee (i.e., review and advise on 0 SH program issues and documentation, safety and health records, and hazard abatement logs and plans, and observe workplace $\mathrm{OSH}$ activities). In addition, FERMCO should review all references to committees, meetings, or teams currently in the CEOSHP and ensure that the 
membership and charter of each of these groups is defined or that the function of the group is incorporated into or fulfilled by the safety and health committee.

\subsubsection{Employee Rights}

DOE 5483.XX requires that contractors provide their employees the right to be represented during DOE oversight assessments [IV.7], the right to participate in the establishment of hazard abatement methods [V.E.C], the right to be appraised of variance proceedings [I.8.b.(8)] and to appeal approved variances [I.8.d], the right of access to medical and monitoring data [III.2.a.(9)(b)(5)] and the authority to stop work (through their supervisor) if they believe that a serious injury could result if work continues. These rights are designed to ensure that employees can express their concerns regarding workplace hazards, provide input on the methods used for hazard control, gain a clearer understanding of the necessity of these controls, be informed of any hazardous workplace exposures and protect themselves and their fellow employees from hazards that pose the threat of serious injury. Employee input about hazards and controls is essential to an effective OSH program because employees typically possess a high level of understanding of the work process and therefore often have great insight into the hazards present and the feasibility of potential controls.

\section{Evaluation}

Employee rights to participate in the FERMCO OSH program are addressed generally throughout the document, in a number of statements that are similar to that in SPR 1-0, paragraph 3.1.A, which states that "people are the most critical element in the success of a safety and health program. Management responsibility must be complemented by employees' suggestions and employees' active involvement in keeping workplaces safe." Other paragraphs (ESH 1-8, Attachment A, item K, and SPR 1-3, paragraph 3.0.C) state that employee training must include an element addressing employee rights. The CEOSHP, however, does not identify the specific rights afforded to employees or specify which rights must be addressed in employee training.

Employee walk-around rights during DOE oversight assessments are not specifically addressed in the CEOSHP, although the CEOSHP does contain a section addressing FERMCO inspections. However, this section (EAPR 3-6, paragraph 3.1.C) states "Under the Occupational Safety and Health Act, only representatives of the Secretary of Labor .... are to conduct the investigation)" and would thus appear to apply only to OSHA inspections. This entry is confusing because DOE, not OSHA, has jurisdiction on the Fernald site. In the same section (EAPR 3-6, paragraph 2.2.F), inspectors are allowed to confer privately with the employees of their choice, but employee representatives are not given the right to accompany the inspector during the walk-around portion of the inspection. In fact, this section states that only management representatives shall participate in agency inspections.

SPR 2-58, the FERMCO hazard abatement management program, does not address employee notification of or involvement in hazard abatement activities, particularly when an Abatement Plan approved by DOE is required.

The CEOSHP does not include a process to request a variance from DOE-prescribed OSH standards. It is not clear whether this omission of a variance process in the CEOSHP indicates that FERMCO does not intend to request variances from any DOEprescribed $\mathrm{OSH}$ standards, or if the omission was an oversight. 
With respect to employee access to exposure monitoring and medical records, SPR 5-0, paragraph 3.4.A, requires that "employees... [be] notified of the results of exposure monitoring as required by OSHA regulations and DOE Orders." SPR 5-1, paragraph 3.4.J, states that employees are to be provided, within 15 days of receiving a written request, a copy of related air and/or biological monitoring results, while SPR 7-9, paragraph 3.1.D, states that "access to employee medical records shall be in accordance with ...29 CFR 1910.20 ..." These sections of the CEOSHP, however, do not present the procedures employees are to follow to request their medical or monitoring data, and do not delineate FERMCO procedures for periodically providing employees and visitors with exposure data.

SPR 2-2, paragraph 1.0 requires the designation of a "competent person to either perform or supervise work that has been mandated by a specific regulatory agency standard involving hazardous conditions that could endanger the safety and health of themselves, other FERMCO employees, subcontractors or visitors." This paragraph further requires that the "competent person" have the authority to take prompt corrective actions (including the authority to stop work) to correct or eliminate existing or predictable hazards or working conditions that are dangerous to employees. This section however, does not grant stop work authority to all empioyees and does not address the coordination of stop work orders with responsible supervisors. This section implies that a competent person may not be necessary for all operations. In addition, this section does not specifically mandate that for those operations where a competent person is considered necessary, that the competent person remain onsite during all work operations.

\section{Recommendation}

The CEOSHP could be strengthened by addressing the employee rights delineated in DOE 5483.XX. The agency inspection provisions of the CEOSHP should address the right of employees to be represented during the walk-around phase of DOE oversight assessments.

The FERMCO hazard abatement management program should require that FERMCO not ify affected employees when a proposed abatement plan is submitted to DOE for approval and should inform employees of their right to submit comments to DOE on the abatement plan within 15 days of the FERMCO submittal. In addition, the abatement program should require supervisors to notify affected employees of identified hazards and the interim protective measures that will be taken, as well as to post a copy of approved abatement plans at the affected workplace.

The CEOSHP should also indicate FERMCO's policy regarding variances from DOE-prescribed OSH standards. If FERMCO anticipates that it may need to request a variance at any time, then a variance process should be addressed in the CEOSHP. In addition, the CEOSHP should address employee rights and procedures in the appeal of approved variances.

The CEOSHP should clearly delineate procedures for employees to follow to request their medical and exposure monitoring records and summarize all employee OSH rights in a provision which contains employee safety and health rights and responsibilities.

Finally, the stop work authority provision should be modified to allow any employee in any work activity the ability to initiate stop work procedures. Provisions for stop work authority should address the requirement to coordinate all stop work orders with the supervisor responsible for the affected activity or operation. This 
would ensure that appropriate measures are taken to prevent the introduction of additional hazards related to the stopped work and to minimize adverse impacts on the operation.

\subsection{Worksite Analysis}

\subsubsection{Analysis of Planned, New, or Modified Facilities, Processes or Equipment}

Paragraphs III.2.b.(1)(a) and IV.3.a.(1) of DOE 5483.XX require contractors to conduct a number of hazard identification activities to ensure that occupational safety and health hazards are identified at their workplaces in a proactive manner, i.e., before employees are exposed to OSH hazards that may cause injuries or illnesses. In addition, these provisions require contractors to implement a systematic 0 SH assessment program to identify job-related safety and health hazards potentially arising at all stages of the facility's life cycle and in all operational phases. The Order recognizes that effective worksite analysis requires the on-going and cooperative efforts of front-line employees, supervisors, and managers, assisted as necessary by professional occupational safety and health staff.

\section{Evaluation}

Hazard identification and evaluation activities are established for different groups of FERMCO employees in various sections of the CEOSHP. For example, the CEOSHP contains the following statements, among others:

ESH 1-4, paragraph 2.1.A, "Supervisor ensures that all applicable safety, health, and environmental practices and policies have been considered when planning work."

ESH 2-1, paragraph 2.0.B, "The Occupational Safety and Health Department ensures that new or modified facilities/equipment minimize worker exposure to ALARA [As Low As Reasonably Achievable]."

ESH 2-1, paragraph 2.0.F, "The Occupational Safety and Health Department identifies all potential and existing health hazards."

SPR 1-0, paragraph 3.3.A, "Occupational safety and health hazards shall be identified, evaluated, and mitigated. Engineering controls are designed for new or modified facilities, equipment, and processes to eliminate or control potential or existing safety and health hazards."

SPR 1-0, paragraph 3.3.B, "Safety audits are conducted for safe work and to identify safety and health hazards, and recommend controls."

SPR 2-4, paragraph 1.0.B, "A11 jobs or tasks must be analyzed for hazards. A properly analyzed job will indicate what safety measures must be taken."

SPR 2-4, paragraph 3.1.B (Job Safety Analysis), "A JSA must be completed prior to the start of work for any new project, existing tasks, and routine tasks, to identify potential hazards." 
SPR 2-4, paragraph 3.1.D, "These tasks should be selected and studied on the basis of potential hazards or high incidence rates. The hazards should be identified and eliminated or reduced."

SPR 2-4, paragraph 3.1.E, "When conducting a Job Safety Analysis, the employee performing the task should always be asked to assist. They should be told about the analysis and review the completed JSA."

Thus, the CEOSHP contains many statements that refer to worksite analysis, includes hazard identification activities in the lists of responsibilities for several levels of employees (e.g., supervisors), describes the JSA process, and includes JSA forms. However, the fact that references to worksite analysis activities occur throughout the document, and that these references are listed or described rather than stated as requirements, detracts from their impact and leaves the reader confused about precisely who in the organization is charged with carrying out what hazard identification and evaluation activities. It is difficult to identify employee responsibilities and duties within the $\mathrm{OSH}$ program.

\section{Recommendation}

The importance of worksite analysis, which is the cornerstone of any proactive OSH program, would be clarified and brought home to users of the CEOSHP if this document were reorganized to include a section clearly outlining the various steps in the worksite analysis portion of the OSH program, including hazard identification at all stages of the life cycle, an $\mathrm{OSH}$ assessment program that evaluates the compliance and performance status of all operations within FERMCO's purview, analyzes jobs using JSAs or equivalent methods, and analyzes contract documents and plans for new projects to ensure that $\mathrm{OSH}$ has been adequately considered.

The CEOSHP should identify who is to perform an activity; how often the activity is to be performed; what the possible outcomes and follow-up actions should be; and whether and how the activity should be documented.

In addition, the CEOSHP could be strengthened by including OSH program responsibilities for each group of FERMCO employees, i.e., employees, supervisors, and managers, in one place.

\subsubsection{Hazard Analyses by Front-Line Employees and Supervisors}

Paragraph IV.3.a.(1)(a) of DOE 5483.XX requires that OSH hazards be identified, documented, and analyzed by supervisory and non-supervisory employees during the course of daily work activities to ensure that $\mathrm{OSH}$ hazards are anticipated, identified, prevented, and controlled. The hazard analyses envisioned by this provision of the Order are a central part of any facility's OSH program because they rely on the "eyes and ears" of front-1ine employees and their supervisors to anticipate and identify hazards before they pose a threat to the safety and well being of employees. To enable employees and their supervisors to work together effectively, they must have been trained to recognize safety and health hazards and be familiar with methods of controlling or eliminating them. In addition, the culture of the organization must encourage two-way communication, trust, and cooperation, and workers must be involved in the OSH program in meaningful ways. Once this kind of participation has been achieved, employees at all levels of the organization become proactive safety and health advocates, identifying hazards in their workplaces on a routine basis and actively protecting their own and their coworkers' safety and health. 


\section{Evaluation}

The CEOSHP has several entries that reflect FERMCO's awareness of the importance of non-supervisory and supervisory involvement in routine safety and health activities. For example:

ESH 1-4, paragraph 3.0.D, "Managers must set high expectations effectively. They must also encourage and facilitate self-auditing of safety, health and environmental practices and policies."

ESH 1-2, paragraph 1.0.B, "The heart of our safety and health program is the firm commitment by all members of management, supervision, and our employees to prevent accidents and the conditions that lead to injuries."

ESH 1-2, paragraph 3.0.A, "At FERMCO, safety is viewed as a specific quality that cannot be delegated. . . Each supervisor must accept the responsibility and be held accountable for the safety performance of those employees under their direction. Each employee also has the responsibility to perform the work safely and for reporting unsafe acts or conditions to his or her supervisor without fear of reprisal."

ESH 1-3, paragraph 3.0.H, "Management responsibility must be complemented by employees' suggestions and their active involvement in keeping workplaces safe."

As these quotations show, the CEOSHP contains many references that point to FERMCO's awareness of the importance of involving all levels of employees--from the frontline employee to management at the highest level--in OSH program implementation. However, these entries are widely dispersed and may not convey strong, purposeful program direction.

\section{Recomendation}

The CEOSHP would be strengthened if it included a single, well-integrated section on worksite analysis, its role in the function of the overail program, and the details of the involvement of each employee group in such analyses. Such a provision would permit employees to understand why such on-going OSH involvement is necessary, who is responsible for what, and how the worksite analysis process works in practice.

\subsubsection{Annual Compliance Inspections}

Paragraph IV.3.a. (2)(a) of DOE 5483.XX requires all covered contractors to conduct inspections of their workplaces to determine their compliance status with all DOEprescribed OSH standards and to identify any weaknesses in the facility's OSH program. The compliance inspections required by these provisions must be conducted by the contractor and, if special expertise is needed, can be augmented by technical experts outside the company. Examples of such special experts are industrial ventilation engineers, toxicologists, and ergonomists. DOE 5483.XX specifically notes that compliance inspections must include walkthroughs of the facility, as well as programmatic reviews of relevant $\mathrm{OSH}$ information and materials.

All workplaces, including permanently housed construction workplaces, must receive a comprehensive "wall-to-wall" inspection that is designed to serve as a baseline for future annual compliance inspections. Thus the first annual inspection must be an in-depth evaluation of all workplaces to observe and evaluate work practices, 
operations, hazard controls, and compliance status. The results of this first evaluation provide direction for subsequent annual compliance inspections and other routine compliance inspections, described further in the next subsection.

\section{Evaluation}

The CEOSHP mentions compliance-based activities, self-assessment actions, and workplace inspections at a number of places, e.g., in 1 ists of departmental or individual personnel responsibilities and in various sections of the overall document. Examples are:

ESH 1-3, paragraph 3.0.C, "Safety assessments must be conducted. Management must audit performance in the workplace to assess the effectiveness of facilities and programs, and to detect areas for improvement."

ESH 1-4, paragraph 2.2.B, "[The Occupational Safety and Health Department] audits performance."

ESH 1-5, paragraph 3.0.D, "The safety and health professionals at FERMCO are available to assist supervisors as a consultant or advisor on safety matters."

ESH 2-1, paragraph 2.0.E, "[The OS\&H Department] implements rigorous, performance-based, self-assessment program for OSHA issues."

ESH 2-4, paragraph 2.0.B, "[The ES\&H Assurance Department ] develops and implements a comprehensive, integrated, performance-based, self-assessment program which crosses all ES\&H functional 1ines."

\section{Recommendation}

It is clear from these entries that FERMCO is aware of the importance of inspections and program evaluations to the effectiveness of the facility's overall safety and health program. However, the requirements of DOE 5483.XX are more specific in the area of compliance inspections and programmatic reviews than the corresponding CEOSHP entries. Including in the CEOSHP a concise description of the company's overall compliance inspection program, including a delineation of the scope and depth of the first annual inspection (the baseline inspection) and how the results of this and subsequent inspections can be used to "scope out" and define the frequency of routine inspections (discussed further below) would ensure the establishment and implementation of a sound, performance-based inspection program.

Other information that would enhance this section includes identifying who performs what aspects of the inspection and programmatic review, what elements should be included in each part of the process, examples of factors to be considered when determining how often and with what depth various workplaces need to be inspected, etc. The extent to which compliance inspection and program review activities should be documented should also be addressed in this section of the CEOSHP. For example, it is important to document the absence of hazards, as well as their presence: documenting that a previous inspection revealed no OSH hazards in a particular area and knowing that nothing has changed since may avoid unnecessary duplication of effort on subsequent inspections. 
It is suggested that the CEOSHP identify the benefits of using OSH professionals who are cross-trained in several disciplines, e.g., occupational safety and health, safety engineering and industrial hygiene, who can conduct most compliance inspections and call in specialists or technical experts only when needed.

\subsubsection{Routine Compliance Inspections}

Paragraph IV.3.a.(2)(b) of DOE 5483.XX mandates that contractors perform routine compliance inspections to ensure that their workplace is in compliance with all DOEprescribed OSH standards and that the elements of an effective OSH program are in place and functioning effectively. Contractors must conduct enough routine compliance inspections of subcontractor workplaces to ensure that subcontractors al so meet DOE-prescribed OSH standards.

Unlike the annual compliance inspections mandated by paragraph IV.3.a.(2)(a) of DOE 5483.XX, routine compliance inspections may vary in scope and depth from cursory to comprehensive, depending on such factors as the degree of hazard in a particular process, operation, or workplace; the interval of time since the last inspection; the adequacy of the documentation for the prior inspection; whether new substances, equipment, or methods have been or will be introduced to the operation; and the training and skill levels of the personnel involved. DOE 5483.XX (at paragraph IV.3.a.(2)(b)) lists many events that might serve to trigger a routine compliance inspection, such as the filing of employee OSH concerns, the occurrence of a workrelated injury, an increase in the number of related health incidents, etc. Other program elements that may be evaluated during routine inspections include the training program and its adequacy, the reporting and recordkeeping systems in place, the contractor's method for tracking and abating hazards, etc.

\section{Evaluation}

The CEOSHP addresses the need for contractors to conduct routine evaluations of their own and their subcontractors' workplaces; these references are frequently found in the sections of the CEOSHP dealing with specific programs, e.g., Radiological Protection, Construction, Fire Protection. For example:

EAPR 3-7, paragraph 3.0.B, "[The ES\&H Compliance Group must] perform periodic field surveillances, consistent with other Quality Assurance programs, to assess compliance with requirements of the manual [i.e., the CEOSHP]."

SPR 4-0, paragraph 2.4.C., states that the Fire Protection Group "inspects various buildings, structures and/or areas on the site monthly for fire safety."

SPR 4-24, paragraph 3.7, "Construction work site safety and fire protection inspections shall be conducted weekly and documented."

SPR 5-1, paragraph 3.4.C, "Personal air sampling shall be performed as necessary to verify compliance with DOE Orders for personnel exposure limits for chemical air contaminants."

RPR 3-1, paragraph 3.0.J, "Periodic inspections and assessments of the RWP [Radiation Work Permit] job site shall be conducted to ensure conditions of the RWP are being adhered to by all personnel involved." 


\section{Recommendation}

As mentioned above, the CEOSHP would be enhanced if it included a concise section on compliance inspections, including routine compliance inspections. Such a section might provide examples of criteria that could be used to determine the scope, frequency, and intensity of routine inspections. In addition, this section could describe what elements should be evaluated in a programmatic review and how best to accomplish this type of evaluation.

\subsubsection{Analyze OSH Performance}

Paragraph III.2.b.(3) of DOE 5483.XX requires contractors to analyze their OSH performance to identify program strengths and weaknesses and their underlying causes and to provide managers with feedback that they can use to strengthen the $\mathrm{OSH}$ program's effectiveness. The kinds of performance analyses envisioned by DOE 5483.XX include determining whether management systems are functioning properly, analyses of injury and illness and workers' compensation trends and root cause analyses of accidents and near misses.

\section{Evaluation}

Various sections of the CEOSHP suggest that the responsibility to analyze OSH performance and provide feedback on the effectiveness of the OSH program rests with the ES\&H Assurance Department. For instance, EAPR 1-2, paragraphs 3.0.C and D indicate that the ES\&H Assurance Department must provide "management with objective, timely, and reliable information on ES\&H performance; including significant achievements and deficiencies . . . [and] . . . with recommendations, where appropriate, for improvement of ES\&H program performance." A1though these paragraphs do not provide guidance on how the ES\&H Assurance Department will accomplish this task (i.e., evaluation of specific OSH performance indicators), other sections in the CEOSHP identify possible approaches. For example, EAPR 3-0, paragraph 2.0.H, requires the ES\&H Self-Assessment Manager to "Conduct causal factors/root cause analyses; [evaluate] the effectiveness of corrective actions, [report] findings (lessons learned), [track] corrective actions/deficiencies, and [adjust] other ongoing planning actions as appropriate;" EAPR 3-1, paragraph 2.0.E, requires evaluators conducting performance-based audits to "investigate the background and supporting information to determine the root cause of the deficiencies;" EAPR 3-2, paragraph 3.0.C, lists among its guidelines for the ES\&H assurance self-assessment activity, "Trending--the organization will have an established and effective program to identify significant trends; " and EAPR 3-3, paragraph 3.0.B, states that the purpose of incident investigations is to pursue "factual, complete, and timely discovery of the causes of an incident. . . to identify areas where corrective action should be taken to prevent recurrence." These suggested approaches, however, are found in a number of different sections of the CEOSHP, and the responsibilities are assigned to a number of different individuals or organizations with in the ES\&H Assurance Department, with 1ittle guidance or instruction as to how these evaluation data will be coordinated, integrated, or applied. It does not appear that "lessons learned" and other results from accident investigations are shared with employees in general.

The focus of and responsibility for FERMCO's OSH performance evaluation and improvement effort are diffused by numerous blanket statements found in various parts of the CEOSHP that address the need for continual performance evaluation and improvement of the $O S H$ program. For example, ESH 1-0, paragraph 3.0.B, states that the ES\&H Division wi11 "provide feedback to the ES\&H organization through effective 
oversight utilizing a performance-based self-assessment process;" ESH 1-1, paragraph 1.0 , states that "FERMCO's culture is focused on safety, health, and cont inuous performance improvement;" ESH 2-1, paragraph 3.2.F, identifies "applying 'Tessons learned' from the success of asbestos abatement program" as a "key issue" for the OS\&H department; and SPR 1-0, paragraph 3.3.B, requires that "management audits performance in the workplace to assess the effectiveness of facilities and programs, and to detect areas for improvement." These various statements, however, do not identify the specific 0 SH performance elements to be evaluated and, in several cases, do not identify the individuals responsible for conducting the evaluation or for implementing the program improvements.

\section{Recommendation}

The CEOSHP would be strengthened by clarifying and integrating the document's $O S H$ performance analysis and feedback requirements. The CEOSHP should identify specific OSH performance indicators to be analyzed, with respective analytical techniques and required frequencies (i.e., quarterly trend analys is of injury and illness and workers' compensation data, quarterly tracking of hazard abatement efforts, identification of root causes of accidents and incidents), and snould also designate the individuals responsible for each element of the analysis. The CEOSHP should also identify how each element is to be integrated and communicated to responsible management organizations, and should identify and describe methods for implementing program improvements, including development of program improvement and accident prevention activities (see also paragraph 2.1.1.5 on OSH Program Plans). The CEOSHP should clarify how lessons learned and the results from accident investigations will be shared with employees in general.

\subsubsection{Recording and Reporting Work-Related Incidents}

Paragraph 10.d.(2)(h) of DOE 5483.XX requires contractors and subcontractors to record and report work-related accidents and incidents.

Paragraph II.3.b.(1) of DOE 5483.XX requires contractors and subcontractors to record separately on OSHA form 200, "Log and Summary of Occupational Injuries and 111 nesses," work-related fatalities, injuries, and illnesses occurring among their employees while performing work for DOE;

Paragraph II.3.b.(2) of the Order requires contractors and subcontractors to record additional information on DOE Form 5484.3, "Individual Accident/ Incident Report" for each recordable work-related fatality, injury, or illness occurring among their employees while performing work for DOE as early as practicable but no later than 6 working days after receiving information that a recordable case has occurred; and paragraph II.5 requires contractors and subcontractors to record work hours, vehicle usage, and property valuation on DOE Form 5484.4 "Tabulation of Work-Hours, Vehicle Usage, and Property Valuation."

\section{Evaluation}

The CEOSHP (SPR 7-3, paragraph 2.0) requires employees to notify their supervisor of workplace injuries and supervisors to complete the FERMCO Form "Supervisor's Report of Injury." The supervisor must provide a copy of this form to the Industrial Health and Safety Department within 24 hours. This FERMCO form is intended to provide the Industrial Health and Safety Department with the information necessary to complete required State, Federal, and DOE occupational i1lness or injury reporting forms. SPR 2-62, paragraphs 2.3.E and F, require the Industrial Safety 
and Health Department to "maintain the OSHA 200 Log... [and]...complete the DOE 'Individual Accident/Incident Report' form (DOE Form 5484.X-renamed

DOE Form 5484.3)," and EAPR 2-0, paragraph 3.0.N, requires the ES\&H Procedures and Document Control Organization to maintain the OSHA 200 forms and other injury and illness reporting forms in accordance with 29 CFR 1904 and DOE 5483.XX. The CEOSHP does not address FERMCO's completion of DOE Form 5484.4 "Tabulation of Work-Hours, Vehicle Usage, and Property Valuation."

\section{Recommendation}

The reporting and recording requirements of the CEOSHP could be enhanced by including FERMCO'S requirements for the completion of DOE Form 5484.4, "Tabulation of Work-Hours, Vehicle Usage, and Property Valuation" in accordance with DOE 5483.XX. References to DOE Form 5484.X should be modified to reference DOE Form 5484.3, "Individual Accident/Incident Report."

\subsection{Hazard Prevention and Control}

\subsubsection{Proper Design of Facilities and Equipment}

Paragraphs III.2.C and IV.3.a.(1) of DOE 5483.XX emphasizes the need to consider hazards during the design of new or modified facilities and equipment to eliminate hazards to the extent possible, and also requires the contractor to use a hazard control hierarchy to control those hazards that cannot be "designed out." The first means of control is the use of "engineering techniques where [these are] feasible and appropriate." Engineering hazards out up front, in the design phase, is the best means of preventing hazards from being present in the workplace.

\section{Evaluation}

Several entries in the CEOSHP address the issue of preventing or minimizing hazardous conditions during the design of facilities and equipment. For example, ESH 2-1, paragraph 2.0.B states that the OS\&H Department is responsible for ensuring:

"That new or modified facilities/equipment minimize worker exposure to ALARA."

SPR 1-0, paragraph 3.3.A states:

"Occupational safety and health hazards shall be identified, evaluated, and mitigated. Engineered controls are designed for new or modified facilities, equipment, and processes to eliminate or control potential or existing safety and health hazards."

Although these and other statements found in various sections of the CEOSHP reflect an understanding of the importance of "designing out" hazards during the design or modification stage, the responsibility for ensuring that this happens is not clearly assigned, and procedures for accomplishing this goal are not described in the CEOSHP.

\section{Recommendation}

The CEOSHP would be strengthened if it included provisions describing the responsibilities and procedures for ensuring that potential OSH hazards are considered at 
the design and modification stage, procedures for reviewing new work (including facilities, equipment and projects) to achieve this goal, and methods for ensuring coordination between the various departments (engineering, industrial hygiene, safety, supply, etc.) involved in the review process. The CEOSHP should specify that the hierarchy of controls discussed in the first paragraph of evaluation element 2.3.2 be applied during the development of design specifications and drawings to ensure that, for instance, engineering controls are fully considered before any other controls are "designed" into the modified facility or equipment, or new project.

\subsubsection{Hazard Control Hierarchy}

DOE 5483.XX establishes a coordinated approach to hazard prevention and control that begins with the design stage and then requires contractors to follow an established hierarchy of control measures to reduce or eliminate hazards in the workplace.

Paragraph III.2.C.(2) of DOE 5483.XX requires contractors to establish procedures to detect and correct or mitigate current and potential hazards using a prescribed hierarchy of controls. This hazard control precedence, which is part of the contractor's overall hazard abatement program, focuses initially on the use of engineering controls because this approach controls the hazard at its source and thus eliminates the hazard before employees are exposed. The next tier in the hierarchy involves the use of work practices or administrative controls, which change the manner in which the work is performed by employees, e.g., by altering their work practices or reducing the amount of time they are exposed. The last tier in the hierarchy involves the use of appropriate personal protective equipment (PPE); such equipment serves as a barrier between the hazard and the potentially exposed individual. Because this line of defense often fails and is subject to individual variation, it is the least-preferred method of control.

\section{Evaluation}

Several references in the CEOSHP implicitly recognize the hierarchy of controls; however, no section which explicitly addresses the hierarchy of controls was identified. For example, ESH 1-7, paragraph 3.0.B describes the need to address "actions to be taken to mitigate existing hazards (e.g., engineering controls, procedures, or containment of contaminated materials)." Similarly, SPR 5-0, paragraph 3.1.A [Industrial Hygiene], refers to the "effectiveness of engineering and/or administrative controls, selection, use and care of personal protective equipment." Many statements that reflect the same ordering of the tiers of the control hierarchy al so appear in different sections of the CEOSHP, e.g., chemical exposure and air monitoring; contamination control; and radiological control precedence.

\section{Recommendation}

The CEOSHP would be enhanced if it specifically addressed the hierarchy of controls and the rationale underlying this hierarchy. Examples of situations where each tier of the hierarchy might be used would also be helpful to users of the CEOSHP.

\subsubsection{Personal Protective Equipment (PPE)}

DOE 5483.XX, paragraph 10.d.(2)(f), requires the contractor to provide, maintain, and require the use of personal protective equipment, approved safety equipment, and other devices required to protect contractor employees. 


\section{Evaluation}

SPR 2-14, paragraphs 2.1.A and E, require FERMCO management to provide PPE to personnel and further require that the PPE provided be "maintained in a sanitary and reliable condition." SPR 2-0, paragraph 3.2.C specifically mandates that all personnel have and be required to use the appropriate personal protective equipment.

\section{Recommendation}

Although the CEOSHP contains requirements for the provision, maintenance, and use of appropriate personal protective equipment, the CEOSHP would be enhanced if it included additional requirements. The CEOSHP should include a section (or reference an existing procedure) on PPE selection; use; fitting procedures; use considerations; cleaning, inspection, and replacement procedures; and responsibility for these elements of the PPE program.

\subsubsection{Maintain Hazard Abatement Program}

\subsubsection{Hazard Abatement Priorities}

In DOE 5483.XX it is recognized that many hazards can be corrected immediately but that others take longer to abate; for control problems that require some time to resolve, a systematic process must be in place to ensure quick and efficient abatement. This system must enable the contractor to establish priorities among hazard abatement activities; this process is accomplished by assigning a risk assessment code (RAC) to each OSH hazard. The assignment of RAC codes allows contractors to follow the worst-first principle in most cases, although other factors, such as the costs and availability of controls, must also be considered. Paragraph V.4.b of DOE 5483.XX requires DOE contractors to establish a prioritization system for hazard abatement activities based on the risk assessment code determined for each OSH hazard (or condition of noncompliance). It should also be noted that when contractors or subcontractors involved in project-related work introduce hazards into the workplace, the hazards should be abated immediately.

\section{Evaluation}

An entire section of the CEOSHP (section SPR 2-58) is devoted to FERMCO's Hazard Abatement Management Program. This program assigns responsibilities for abatement activities, RAC assignment, maintenance of a hazard abatement $10 \mathrm{~g}$, and the development of hazard abatement plans. Several statements in this section of the CEOSHP assert the importance of "fixing hazards quickly" and of having some mechanism for "prioritizing those not fixed quickly." For example, ESH 1-3, paragraph 3.0.D states that "all deficiencies must be corrected promptly...," while SPR 2-58, paragraph 3.4. A states that "Al1 hazards shall be promptly addressed and SPR 2-58, paragraph 3.1.C, reiterates that "A11 hazards requiring abatement shall be promptly addressed."

Regarding the prioritization of hazards, SPR 2-58, paragraph 2.0.B describes the same process as that identified in DOE 5483.XX, i.e., a RAC is assigned to hazards, and the assigned RAC is then used to prioritize hazard abatement activities (SPR 2-58, paragraph 3.2.B.). The CEOSHP assigns responsibility for implementation of the RAC system to the Occupational Safety and Health Division. 


\section{Recommendation}

None.

\subsubsection{Interim Protective Measures}

In cases where the hazard has been identified but final hazard abatement is not yet complete, interim protective measures must be provided to protect contractor employees. DOE 5483.XX, paragraphs V.3.a and V.5.b.(7), require contractors to establish interim protective measures that provide employees exposed to OSH hazards with a level of protection that is equivalent to, or greater than, that required by the applicable DOE-prescribed OSH standards.

\section{Evaluation}

Section SPR 2-58, Hazard Abatement Management Program, discusses the provision of appropriate interim controls during hazard abatement activities. The Occupational Safety and Health Division is assigned the responsibility for providing the respective facility owner with information, as requested, concerning the feasibility and appropriateness of interim controls. The Facility Owner is required to determine and ensure the implementation of appropriate interim corrective measures (SPR 2-58, paragraph 2.3.A). In addition, SPR 2-58, paragraph 3.4.B states:

If abatement cannot be accomplished immediately, interim control measures shall be instituted and the abatement date established.

These statements reflect FERMCO's awareness of the importance of providing appropriate interim protective measures; however, the CEOSHP does not specifically mandate that interim protective measures should provide a level of protection equivalent to, or greater than, that required by the applicable DOE-prescribed OSH standards.

\section{Recommendation}

The CEOSHP would be strengthened if it specified that any interim protective measures provided be at least as protective as the primary hazard protection method required by the DOE-prescribed $\mathrm{OSH}$ standard.

\subsubsection{Management of Hazard Abatement Activities}

The primary purpose of any Hazard Abatement Management Program is to ensure the timely, effective abatement of hazards; secondarily, such programs are intended to ensure that abatement occurs in a systematic manner. Documentation of the hazard abatement process is necessary to permit both DOE and the contractor to track the status of the abatement activities. The primary mechanism for tracking the progress of abatement activities is the $\mathrm{OSH}$ hazard abatement log. The data elements to be included on this ? g are to be kept current and must be made available to both DOE and contractor employees or their authorized representatives. Paragraph V.5 of DOE 5483.XX requires the contractor to use an OSH Hazard Abatement Log to maintain a hazard abatement program that includes the management of hazard abatement activities through tracking, follow-up, and close-out. 


\section{Evaluation}

SPR 2-58, paragraph 2.1.A assigns responsibility to the 0ccupational Safety and Health Division to ensure that a Hazard Abatement Log (HAL) is established and maintained. This requirement is supported by another statement that appears in the CEOSHP paragraph (SPR 2-58, paragraph 3.3.A) discussing the requirements for the log itself, which states that a HAL is to be maintained to show the status of hazards requiring abatement. The log data elements appearing in the CEOSHP mirror the elements contained in DOE 5483.XX, with the exception of identifying which standard was referenced: DOE 5483.XX asks for the DOE-prescribed OSH standard for which abatement is needed, while the CEOSHP asks for the "ANSI standard" for which abatement is needed. With this exception, it appears that FERMCO management mandates that the "log" be used in the same manner as prescribed by DOE 5483.XX. The CEOSHP also requires HAL information to be made available to responsible supervision and facility owners for action and information. However, the CEOSHP does not require this information to be made available to employees or their representatives.

\section{Recommendation}

The CEOSHP would be strengthened if it specifically allowed employees and employee representatives access to the hazard abatement log.

\subsubsection{DOE Approval of Certain Abatement Activities}

Paragraph V.6 of DOE 5483.XX requires contractors to obtain DOE approval of hazard abatement logs when the hazards of concern require extended abatement periods to correct and are medium- or high-risk hazards. In some cases, the abatement of hazards may take months instead of days. For these cases, DOE 5483.XX establishes a process that ensures review and approval of the respective planned or revised abatement activities. The two thresholds established by DOE for such approval are: if the hazard is classified as high risk and the abatement activities are expected to take longer than 90 days or hazards are classified as medium risk and the abatement activities are expected to take longer than 180 days. Paragraph V.6 of DOE 5483. XX requires DOE contractors to obtain DOE approval for abatement activities that exceed either of these thresholds.

\section{Evaluation}

Section SPR 2-58 does not require DOE approval of abatement logs or plans. In addition, paragraph 3.5.A. of this section establishes thresholds (exceeding 90 days for both medium- and high-risk hazards needing abatement) that no longer coincide with DOE 5483. XX's requirements.

\section{Recommendation}

The CEOSHP would be strengthened by including a requirement for obtaining DOE approval based on the same thresholds noted above.

\subsubsection{Restart Procedures}

DOE 5483.XX, paragraph $V .3 . b$, requires contractors to establish formal written procedures and designate the personnel responsible for approving the resumption of operations which posed an imminent danger condition and were subsequently terminated by a contractor or DOE OSH professional. 


\section{Evaluation}

In the description of general criteria for the Competent Person Designation (SPR 2-2, 1.0), the CEOSHP indicates that the designated "competent person" has the authority to stop work; however, the CEOSHP does not indicate who has the authority to authorize the resumption of work.

In a discussion of the requirements for radiological safety (RPR 1-3, 3.0.C), the CEOSHP indicates that Radiological Control Technicians and their supervisors, line supervision, and any worker through their supervision have the responsibility and authority to stop radiological work if such action is justified. Resumption of work requires the approval of the responsible line manager as well as the Radiological Control Manager. Similar requirements, for restarting work that was stopped due to the existence of OSH hazards, do not exist in the CEOSHP.

\section{Recommendation}

The CEOSHP should be revised to include procedures and responsibilities for the resumption of operations following the recognition of imminent danger conditions by OSH professionals.

\subsubsection{Provision of Physician and Medical Care}

An effective occupational medical program can play a vital role in both the prevention and treatment of injuries and illnesses related to the workplace. DOE emphasizes accident and illness prevention by requiring occupational physicians and selected medical staff to make regular visits to workplaces and facilities to become familiar with employee job tasks, worksite environments, and existing or potential health hazards. Information obtained from these visits could lead to recommendations to management for corrective action or preventive measures. DOE 5483.XX, paragraph III.2.C.(2)(c), requires that contractors provide physician and medical care in accordance with DOE 5480.8A, "Contractor Occupational Medical Program," in order to minimize the effect of injuries and illnesses to contractor employees. DOE 5483.XX, paragraph II.9. requires contractors to report excess illnesses and injuries, indicating that contractors should consistently determine employee exposures in the workplace, and analyze exposure data for the prevention and early detection of work-related diseases.

\section{Evaluation}

An entire section of the CEOSHP is devoted to describing the implementation of FERMCO's medical service program. FERMCO's medical surveillance program does not cover all of the requirements of the most recent edition of DOE $5480.8 \mathrm{~A}$ or the epidemiological requirements of DOE 5483.XX.

\section{Recommendation}

The CEOSHP would be strengthened if it were updated to include exposure monitoring for the prevention and early detection of work-related diseases and to reflect the requirements in the Occupational Medicine Order, which was issued in final form since this version of the CEOSHP was developed. 


\subsubsection{Emergency Training and Drills}

DOE 5483.XX, paragraph III.2.C.(1), requires contractors to conduct training and drills to ensure that responses to emergency conditions are performed quickiy and in an organized and controlled manner.

\section{Evaluation}

The CEOSHP indicates that FERMCO provides a program of drills and exercises, integrated with the training program, [is to be implemented]...to develop, maintain and test emergency response capability; identify areas of improvement; and to serve as a planning basis by indicating areas of improvement (EAPR 4-2, paragraph 1.0.C).

\section{Recommendation}

The CEOSHP would be enhanced if it assigned responsibility for ensuring that emergency response training and drills are carried out as indicated and specified the frequencies and employees to be covered by such drills and training.

\subsection{Occupational Safety and Health Training}

Paragraph VI.2 of DOE 5483.XX requires contractors to develop and implement OSH training programs to instruct employees in safe and healthful work practices. In addition, employees are required to be educated about potential hazardous exposures and to be trained in hazard recognition and prevention skills (III.2.d.). The contractor is also required to tailor the OSH training program to the level of responsibility of their employees. Chapter VI of DOE 5483.XX includes requirements for initial entry-level OSH training for all contractor employees and specific OSH training requirements for the following groups of personnel: management, supervisors, employee representatives, non-supervisory employees, OSH professionals, and visitors to DOE-sponsored facilities. For each category, required training topics are identified. At a minimum, the training must provide contractor employees with sufficient knowledge to protect themselves against the potential OSH hazards inherent in their jobs and with an understanding of the employee's rights and responsibilities within the contractor's 0 SH program.

\subsubsection{General Employee OSH Training}

DOE 5483.XX identifies required initial entry level OSH training for all contractor employees. This training (orientation) is to address employee rights and responsibilities, mechanisms for reporting 0 SH concerns, methods for dealing with discrimination issues, information on reporting and responding to emergencies, and methods for accessing employee exposure monitoring data and medical records.

\section{Evaluation}

General employee training is discussed at several different points in the CEOSHP. For example, ESH 1-8, paragraph 3.2, "New Employee Safety Orientation," states:

"New employees reporting to work shall be informed of basic safety rules, regulations and equipment used at FERMCO through 'New Employee Safety Orientation';" and

"New Employee Safety Orientation shall include those elements specified in applicable DOE Orders and Federal Regulations." 
A review of the training required to be covered in the New Employee Safety Orientation Programs shows that the orientation program exceeds minimum requirements. For example, SPR 1-3, paragraph 3.0.A, discusses "Safety Orientation," and refers to the "New General Employee Training" (GET) Safety Program. Although the names of the two FERMCO programs are different, the required elements of the "New GET" program are identical to the required elements identified in the CEOSHP for "New Employee Safety Orientation" in Attachment A of ESH 1-8, ES\&H Training.

SPR 1-3, paragraph 2.0, also specifies that not only are FERMCO employees to attend the "New GET Program," but subcontractors and vendors must do so as well.

SPR 2-1, paragraph 3.0.A., again discusses General Employee Training (GET); this section addresses the "Waik Your Space Philosophy" and specifies that employees are to receive this training (GET) so that it will "provide...them with a basis for identifying hazards in the workplace," which is one of the most important requirements. This section of the CEOSHP also requires supervision to follow-up on new employee training by:

"providing specific information as to the hazards associated with the workplace" (SPR 2-1, paragraph 3.0.C).

"Supervisors are to accomplish this through...monthly safety meetings, safety awareness briefs, and maintaining an open-door policy," a policy established to "expedite the identification and control of hazards in the workplace" (SPR 2-1, paragraphs 3.0.C and 3.0.D).

\section{Recommendation}

None.

\subsubsection{Manager OSH Training}

Paragraph VI.3.a of DOE 5483.XX requires contractors to ensure that contractor management personnel (defined as supervisors above first-line supervisors) receive "sufficient $O S H$ training to enable them to actively and effectively support $O S H$ programs in their specific areas of responsibility." Training topics for management personnel are identified and focus on planning and budgeting, reporting requirements, compliance with standards, and hazard identification, evaluation, and control. The general emphasis of this training is to ensure implementation of an aggressive and ongoing $\mathrm{OSH}$ program.

\section{Evaluation}

The CEOSHP does not make a distinction between management personnel and supervisors with regard to 0 SH training requirements. Instead, the CEOSHP identifies managers and supervisors both as "management," and applies the same OSH training requirements to both levels of management personnel. SPR 2-59, paragraph 3.1, contains a 1ist of minimum requirements in the OS\&H Training section that exceeds the topics required by DOE 5483.XX to be covered in the training of management personnel.

\section{Recommendation}

None. 


\subsubsection{Supervisor OSH Training}

Paragraph VI.3.b of DOE 5483.XX requires that within 90 days of their initial assignment, first-line supervisory personnel receive the training necessary to manage the workplace OSH program. The Order places particular emphasis on the analysis of work conducted under the supervisor's direction, maintaining OSH hazard controls, and reinforcing employee training. Required training topics that are to be included, based on the supervisor's particular responsibilities, are listed in the Order. Refresher training for supervisors is to be provided at least biennially.

\section{Evaluation}

As discussed in the section on "Manager's OSH Training," the CEOSHP requires both managers and supervisors to receive the same training. The training requirements in the CEOSHP for supervisors exceed minimum requirements for employees at this level. The CEOSHP did not specify a time frame for supervisors to receive their training and it did not specify a refresher training requirement.

\section{Reconmendation}

A statement should be added to the CEUSHP indicating the time frame (preferably 90 days) in which supervisors are to receive their training. Also, a refresher training requirement should be added.

\subsubsection{Employee Representative OSH Training}

Paragraph VI.3.C of DOE 5483.XX requires contractors to ensure that the training of employee representatives includes introductory and specialized courses to enable them to recognize, analyze, and report unsafe and unhealthful working conditions at their workplace and to effectively participate in safety and health committee functions.

\section{Evaluation}

SPR 2-59, paragraph 3.2 of the CEOSHP, which addresses the training of employee representatives, includes employee representative training requirements. They include the need for introductory and specialized courses for these employees but do not specify the topics to be covered. Thus, the CEOSHP recognizes the need for employee representatives to be able to recognize, analyze, and report unsafe and unhealthful working conditions and acts in order to participate fully in the facility's OSH program.

\section{Recormendation}

None.

\subsubsection{Non-Supervisory Employee OSH Training}

Paragraph VI.3.d of DOE 5483.XX requires contractors to ensure that non-supervisory employees receive the training necessary to identify OSH hazards and minimize the risks associated with their jobs. The focus of this training is on employee awareness of the hazards specifically associated with their workplace, trade, and/or occupation, and such training must be provided prior to the employee's exposure to these hazards. Specific training in accordance with DOE-prescribed OSH standards is 
also required. OSH training for non-supervisory employees is to be conducted as often as necessary for these employees to be continually aware of DOE OSH requirements, but not less than annually.

\section{Evaluation}

SPR 2-59, paragraph 3.3, states that non-supervisory employees are to be trained in the hazards associated with their jobs. The CEOSHP does not specifically state that employees must be trained about DOE-prescribed OSH standards but does include, in sections addressing specific programs, e.g., confined spaces, hoisting and rigging, specific employee training requirements. For example, training is required for donning, properly wearing, and doffing of personal protective equipment (PPE); for working with electrical equipment; operating shop equipment or motorized equipment; operating cranes; entering confined spaces, etc.

\section{Recommendation}

The CEOSHP would be enhanced if it specified that non-supervisory employees should be trained in DOE-prescribed OSH standards that may apply to their workplaces.

\subsubsection{OSH Professional Training}

OSH professionals play a vital role in ensuring the effectiveness of an occupational safety and health program. The OSH professional's training needs to be continually upgraded to ensure that both technical and management knowledge and skills are optimized. DOE 5483.XX, VI.3.e, addresses this need both by identifying the training topics to be covered in OSH professional training and by requiring the establishment of individual development plans. The Order also recognizes the need for management to encourage the on-going involvement of $\mathrm{OSH}$ professionais in appropriate professional organizations and the attainment of professional certification.

\section{Evaluation}

FERMCO management recognizes the need to provide OSH professionals with the necessary on-going training to carry out their responsibilities. For example, SPR 2-59, paragraph 3.4.A., states:

"Training will be provided to ensure that technical monitoring, consulting, testing, evaluating, and other tasks required of an OSH professional can be satisfactorily performed."

Another section of the CEOSHP (SPR 2-59, paragraph 3.4.B.) assigns to OSH Management the responsibility for establishing individual development plans to ensure that all OSH professionals receive the necessary training and experience. The same paragraph identifies OSH management's intent to encourage employees to participate in professional organizations and to obtain certification in their areas of expertise.

\section{Recommendation}

None. 


\subsubsection{Visitor OSH Training}

Paragraph VI.4 of DOE 5483.XX requires that FERMCO provide training for all visitors (for occupational duties) that is tailored to the tasks or responsibilities to be carried out by the visitor. The Order identifies specific topics that must be covered, such as training in site-specific hazards and ways to minimize these hazards, including the use of personal protective equipment, if necessary; applicable emergency procedures; and specific training when required by applicable DOE-prescribed OSH standards. The Order also identifies alternative means of communicating this information to visitors and requires records of visitor orientations to be documented.

\section{Evaluation}

ESH 1-8, paragraph 3.3 and Attachment B, Training Requirements for FERMCO visitors, contains requirements for the orientation and training of FERMCO visitors. For example, in addition to receiving a Site Safety and Health Orientation, all visitors must be escorted at all times while on site.

\section{Reconmendation}

None.

\subsubsection{Recordkeeping}

Paragraph VI.5 of DOE Order 5483.XX requires contractors to maintain training records and documentation for all contractor training activities mandated by the Order; contractor personnel are to maintain such records at each DOE-sponsored facility. The Order also discusses the accessibility of these records to authorized DOE personnel and the retention of employee performance records and all lesson plans and attendance lists. The Order additionally specifies that personnel OSH training records are to be maintained for the duration of employment, while other training records, e.g., lesson plans, are to be maintained for at least five (5) years.

\section{Evaluation}

The CEOSHP addresses the documentation of OSH-related training in at least two different places (ESH 1-8, paragraph 3.4, and SPR 2-59, paragraph 3.6). For example, the discussion of requirements related to "new employee safety orientation" and "visitor training" (ESH 1-8, paragraph 3.4) states:

"A record of all formal training conducted (both for new employees and visitors) shall be generated."

The same paragraph also identifies what such documentation must consist of: name of training course or course content; date of training; name of individual conducting training and the roster of personnel attending training. In the OS\&H Training section (SPR 2-59, paragraph 3.6), the following section is included:

"Documentation of training, including attendance roster and lesson plans, must be conducted in accordance with DOE requirements and those established by the [FERMC0] Training Department." 
The CEOSHP does not appear to contain requirements for the retention of employee training performance records or lesson plans. In addition, no requirements for the duration of record retention were identified.

\section{Recommendation}

The CEOSHP should be modified to include requirements for the retention of lesson plans and employee performance records and training records retention. 
Section 3.0

\author{
CEOSHP \\ ENVIRONMENTAL PROTECTION \\ EVALUATION AND RECOMMENDATIONS
}


SECTION 3.0

CEOSHP Environmental Protection

Evaluation and Recommendations

\subsection{Management Commitment and Employee Involvement}

\subsubsection{Management Commitment}

\subsubsection{Environmental Policy}

Criterion EM.2.I.A. of the DOE document Performance Objectives and Criteria for Conducting DOE Environmental Audits (1994) states that DOE contractors' top management should c?early communicate their commitment to environmental excellence through policies that explicitly state environmental goals and expectations. Top management should issue a formal environmental policy statement that articulates the contractor's high-level, formal commitment to excellence in environmental protection activities, serves as the foundation for lower-level managers to follow in formulating their individual environmental policy statements, sets the priority fur environmental protection above production, and establishes environmental compliance as the minimum acceptable standard (EM.2.II.A and B). In addition, criterion EM.2.II.C states that contractors should establish and implement a formal approval process for issuing lower-level, issue-specific policy statements that define and supplement the top-level policy statement for major environmental issues in a way that is consistent with the scope of operations.

\section{Evaluation}

The CEOSHP contains a number of broad statements addressing the overall commitment of management to the environmental, safety and health program and many references to required compliance with regulations and other requirements. However, these statements are scattered throughout the CEOSHP and do not represent a clear and concise statement expressing top management commitment to environmental excellence. For example:

ESH 1-0, paragraph 2.1.A, states that the ES\&H Division is to "[e]nsure that proper ES\&H programs, systems and procedures are in place such that all regulatory and DOE requirements are met;"

ESH 1-4, paragraph 3.0.D states that "[m]anagers must set high expectations effectively."

EPR 1-1, paragraph 2.0.A, requires FERMCO management to maintain "the performance and commitment of an environmental protection organization."

EPR 2-0, paragraph 2.0, establishes the responsibilities of the Environmental Protection Manager to plan, direct, and ensure compliance. The responsibilities of the Effluent Monitoring and Control Manager include the establishment and implementation of systems and procedures to comply with applicable federal and state statutes and regulations; DOE Orders; the terms and conditions of FERMCO air and water permits relating to the treatment, monitoring and control of liquid and gaseous discharges from the site; compliance with the reporting requirements of SARA title III; and implementation of effective programs for surveillance, oversight, and self- 
assessment to assure continuing compliance with regulatory requirements and FERMCO procedures.

Chapter I, "ES\&H Execution," contains sections on "Safety Principles" (ESH 1-3), "Responsibilities for Safety and Health" (ESH 1-4), Supervisor Safety Responsibilities" (ESH 1-5), and "Employee Safety Responsibilities" (ESH 1-6). There is no section similarly addressing environment. Only one of these sections refers to environmental responsibilities, practices, or policies. A section entitled "Environmental Protection Policy" appears only later, in volume II.

Section ESH 1-1 "Culture," identifies no environmental responsibilities for the ES\&H Division or for FERMCO personnel, only safety responsibilities. It identifies mitigation of environmental insult and elimination of increased risk to the public as requirements for the ES\&H Division; but there is no reference to compliance with environmental laws and regulations. There is no suggestion that these are requirements for FERMCO personnel beyond the organizational boundaries of the ES\&H Division.

The CEOSHP does contain a section entitled "Environmental Protection Policy" (EPR 1-0); however, this section focuses mainly on compliance with environmental regulations. For example:

Paragraph 1.0 states that "[t]his policy is designed to...manage those programs and supporting activities needed to satisfy... Federal, state, and DOE requirements;"

Paragraph 2.2 requires that the FERMCO Vice Presidents "[d]elegate responsibility for...ensuring environmental compliance with various Federal, State and DOE regulations;"

Paragraph 2.4 requires that FERMCO managers "[a]ssure compliance with all permits, licenses, consent orders and applicable regulations...;" and

Paragraph 3.0 B requires that "[a]11 FERMCO operations shall comply with the applicable environmental Federal, State and DOE requirements."

This Environmental Policy section of the CEOSHP thus does not clearly and unequivocally state top management's commitment to environmental excellence or explicitly state FERMCO environmental goals and expectations. In addition, the CEOSHP does not convey that the priority for environmental protection is above that of production or other corporate goals (e.g., profitmaking), and does not provide for the establishment of lower-level issue-specific environmental policy statements. Other statements throughout the CEOSHP do address the need for lower-level policies (e.g., ESH 1-1, paragraph 2.1.A and ESH 2-0, paragraph 3.0.A, require the ES\&H division to develop and implement effective ES\&H policies, and ESH 2-3, paragraphs 2.0.A and 0, require the Environmental Protection Department to develop and implement environmental policies). However, these statements do not identify or reference the guiding, top-level FERMCO policy statement on which the lower-level policies should be based.

\section{Recomendation}

The CEOSHP would be strengthened if it included a section which contained a statement of environmental policy that clearly establishes FERMCO's high-level 
management commitment to an excellent, continually improving environmental program, and to identified, meaningful environmental management goals and expectations that extend beyond mere compliance with applicable regulations. This policy statement should establish that environmental protection is a top priority at FEMP. The CEOSHP should establish a formal approval process for issuing lower-level, issuespecific policy statements that define and supplement top-level policy statements for major environmental issues in a manner that is consistent with the scope of FEMP operations.

\subsubsection{Organizational Structure}

Criteria EM 1.I.A, 1.I.C, and 1.I.E of the DOE document, Performance Objectives and Criteria for Conducting DOE Environmental Audits (1994) establish performance objectives for environmental programs in the area of organizational structure. EM.1.I.A of that document states that the organizational structure of the environmental management function should be characterized by clear lines of authority and responsibility for the program. EM.1.I.C states that reporting relationships within the environmental management function should be well defined, clearly communicated, and effectively integrated into the contractor's overall organizational structure to ensure that accountability can be established and exercised. The last criterion that relates specifically to environmental program management structure is EM.1.I.E, which states that periodic review of the integrity and effectiveness of the organizational structure should be accomplished to ensure that revisions are made if and when warranted.

\section{Evaluation}

The CEOSHP addresses the responsibilities of each of the organizations in the Environmental Protection Department and traces its authority to the ES\&H Division and to FERMCO's President. For example:

EPR 1-1, paragraph 2.0, entitled "Responsibilities," addresses the responsibilities of the management of the Environmental Protection Department. The responsibilities consist of maintaining the performance and commitment of the environmental protection organization and allocating sufficient resources to adequately staff and operate the organization to achieve and maintain compliance with all applicable regulations.

EPR 1-1, paragraph 3.0.A, states that the organizational structure of the Environmental Protection Department must be such as to provide clear leadership with accountable responsibilities.

EPR 2-0, paragraph 2.0, establishes the responsibilities of the Environmental Protection Manager to plan, direct, and ensure compliance. The responsibilities of the Effluent Monitoring and Control Manager include 1) the establishment and implementation of systems and procedures to comply with applicable Federal and State statutes and regulations; DOE Orders; the terms and conditions of FERMCO air and water permits relating to the treatment, monitoring and control of liquid and gaseous discharges from the site; 2) the evaluation of all spills or releases of hazardous materials relative to listed reporting requirements; 3 ) compliance with the reporting requirements of SARA Title III; 4) compliance with federal and state requirements concerned with the management and abatement of asbestos-containing materials; 5) the selection, installation, operation, maintenance and use of state-of-the-art 
monitoring equipment to measure and document emissions; 6) the development and conduct of training programs necessary to assure employee and contractor understanding of equipment, procedures and reporting requirements; 7) the implementation of effective programs for surveillance, oversight, and selfassessment to assure continuing compliance with regulatory requirements and FERMCO procedures; 8) direction of the preparation of reports required by applicable DOE Orders, Federal and State regulations, or permit terms and conditions; and 9) maintenance of good communications with personnel in the regulatory agencies.

EPR 1-1, paragraph 3.0.E: "The Effluent Monitoring and Control Section shall monitor for compliance with all applicable Clean Air, Clean Water, and Safe Drinking Water regulations, and assure that FERMCO operations remain within applicable permit limitations. Superfund Amendments and Reauthorization Act (SARA) Title III compliance and required reports shall be developed and submitted within the regulatory requirements submittal dates by the Effluent Monitoring and Control Section."

EPR 1-1, paragraph 3.0.H: "The Groundwater Monitoring Section maintains compliance with all applicable Clean Air and Clean Water regulations while ensuring operations within applicable permit limitations. SARA Title III compliance and required reports are developed and submitted with the regulatory requirement submittal dates by the Groundwater Monitoring Section."

EPR 4-2, paragraph 2.1: "The Environmental Monitoring and Surveillance Manager develops and administers the Site Media Sampling Program."

EPR 4-2, paragraph 2.2: The Site Media Sampling Manager "maintains a comprehensive Site Media Sampling Program."

EPR 6-0, paragraph 2.1: The Environmental Protection Manager "develops and administers the Facilities Characterization Section."

EPR 6-0, paragraph 2.2: The Facilities Characterization Manager "maintains a comprehensive Facilities Characterization Program."

EPR 7-0, paragraph 2.1: The Environmental Protection Manager "develops and administers the Groundwater Monitoring Program."

EPR 7-0, paragraph 2.2: The Groundwater Monitoring Manager is responsible for maintaining a "comprehensive integrated Groundwater Monitoring Program that is capable of determining groundwater quality, direction of flow, and extent of contamination."

These sections illustrate that many responsibilities and authorities are defined for a large number of components within the Environmental Protection Department. However, the CEOSHP does not provide the user with a clear picture of how these responsibilities and authorities fit together and are coordinated for the efficient and environmentally sound operation of environmental protection activities at FEMP.

In addition, the FERMCO environmental program in the broadest sense, includes and affects many activities and several specific offices outside the Environmental Protection Division (e.g., the Regulatory Technology Programs Division, the Quality Assurance Division, and public involvement activities.) The responsibilities of 
these offices and their interactions with the Environmental Protection Department are not clearly defined.

Reporting relationships for the ES\&H Division are addressed in two sections of the CEOSHP: in Environmental Safety and Health Execution and in Environmental Protection Execution. The first section addresses the reporting relationships within the entire ES\&H Organization of which environmental protection is a part; the second addresses reporting relationships within the Environmental Protection Organization. The primary statements about those reporting relationships are:

ESH 2-0, paragraphs 2.0.B and C: The ES\&H Division "reports directly to the President of FERMCO... [and] has the following four departments reporting to the Vice President, ES\&H: Occupational Safety and Health, Radiological Control, Environmental Protection, and ES\&H Assurance." Attachments A and B illustrate the corporate reporting structure and the reporting structure within ES\&H, managers' names are given in these attachments.

ESH 2-3, paragraph 1.0.B, "The organization [of the Environmental Protection Department] will be under the leadership of the Environmental Protection Manager."

EPR 1-0, paragraph 2.3, the Environmental Protection Manager "provides management, planning, and compliance for all environmental protection programs."

EPR 1-1, paragraph 1.0, "The Environmental Protection Department is divided into six sections to provide enhanced focus for ensuring regulatory compliance." Attachment A illustrates the reporting structure of those six sections within the Environmental Protection Department and within ES\&H. Managers' names are given.

The head of the Environmental Protection Program, like the head of the Occupational Safety and Health Program and the Radiological Control Program, reports to the Vice President in charge of the ES\&H Division, and this individual, in turn, reports directly to the President of FERMCO. These programs are thus clearly recognized as having a high priority within the organization.

This review of the CEOSHP identified no provisions specifically requiring that FERMCO's environmental protection program's overall organizational structure be reviewed at regular intervals to ensure its integrity and on-going effectiveness.

In opening the CEOSHP document, FERMCO employees will not find a concise statement of their environmental responsibilities, or the environmental requirements applicable to all FERMCO activities.

\section{Recomendation}

The CEOSHP should be revised to provide an integrated description of all the activities that are a part of or affected by the environmental program. This description should identify all the responsible organizations, including those outside the ES\&H Division; it should describe the interfaces of these elements; and it should reference the documents describing the organization and responsibilities of these other elements. Care should be taken throughout the document to 
distinguish between the "ES\&H Program" which presumably involves all employees, and the "ES\&H Division" which is an administrative entity.

The CEOSHP would be strengthened if it included a section presenting the environmental responsibilities and requirements for all FERMCO employees.

The CEOSHP would be enhanced if it included requirements for the periodic review (and revision if necessary) of the organizational structure of the environmental program. Such requirements might address the frequency of reviews, identify performance measures, and establish responsibilities for correcting any problems with organizational structure identified by such reviews.

\subsubsection{Environmental Program Planning and Budgeting}

Criteria EM.8.I.B and EM.8.I.F of the Performance Objectives and Criteria for Conducting DOE Environmental Audits (1994) state that contractors should ensure that environmental protection considerations are adequately addressed in the planning and budgeting of other organizational functions. The organization should plan for environmental management activities to support all work conducted at the site so that environmental resource needs are adequately addressed and budgeted for. Such planning helps to ensure that the organization's environmental goals will be met.

\section{Evaluation}

Several broad statements in the CEOSHP address FERMCO's intent to consider environmental protection in all work conducted at the FEMP site and to require the allocation of appropriate resources to support the site's environmental protection activities. For example:

ESH 1-0, paragraph 2.1.B: The Environmental Safety and Health Division "[d]evelops policies and procedures to govern all work at the FEMP site..."

ESH 1-0, paragraph 3.0.B: The Environmental Safety and Health division must "[e]nsure adequate and appropriate resources."

ESH 1-4, paragraph 2.1.A: FERMCO supervisors "[e]nsure that all applicable safety, health, and environmental practices and policies have been considered when planning work."

ESH 2-3, paragraphs 2.0.A and B: The Environmental Protection Department "[d]evelops and implements policies, plans, and procedures to minimize environmental insult during restoration and waste management activities [, and] ensures design of new and modifications to current facilities and equipment will minimize environmental releases."

EPR 1-1, paragraph 2.0.B: FERMCO management "[a]llocates sufficient resources to adequately staff and operate the [Environmental Protection] Organization to achieve and maintain compliance with all applicable regulations."

Although each of these statements indicate that all activities be conducted in an environmentally sound manner and that the environmental protection program be adequately funded, the environmental section of the CEOSHP does not provide a structured, formal approach to achieve this goal. Other sections of the CEOSHP 
contain more formal requirements for the incorporation of safety and health considerations in other FERMCO work activities (e.g., site-specific safety and health plans (ESH 1-7) and job safety analyses (SPR 2-4)); however, these requirements do not extend to environmental considerations and environmental protection activities are not clearly integrated into the FERMCO budgeting process.

\section{Recommendation}

FERMCO could enhance the environmental planning aspects of the environmental protection program by establishing requirements in the CEOSHP that ensure that environmental protection is integrated into the planning of all FERMCO work activities.

\subsubsection{Environmental Staffing}

Criterion EM.6.I.A of the Performance Objectives and Criteria for Conducting DOE Environmental Audits (1994) states that contractors should have a system in place to ensure that environmental staffing levels are adequate to achieve environmental performance goals. This includes dedicated environmental support staff and others with collateral environmental duties (e.g., line managers with other support functions) and, as identified in criterion EM.6.I.D, short-term, temporary environmental staff as well. This system should have provisions for identifying environmental staffing needs and reevaluating those needs on a regular basis.

\section{Evaluation}

The Environmental Protection section (Section IV) of the CEOSHP establishes the responsibility for FERMCO management to ensure adequate staffing of the Environmental Protection Department. For example:

EPR 1-1, paragraph 2.0.B: FERMCO management is responsible for allocating "sufficient resources to adequately staff and operate the organization to achieve and maintain compliance with all applicable regulations."

EPR 1-2, paragraph 1.0: "It is FERMCO policy to provide an experienced and well qualified environmental protection organization with sufficient staffing to administer the environmental protection program during both routine and emergency situations." Staffing shall include managers, environmental scientists, engineers, specialists, hydrogeologists, hazardous waste compliance specialists, supervisors, technicians, data entry personnel and secretaries.

EPR 1-1, paragraph 1.0, "FERMCO policy is to provide a qualified and experienced environmental protection staff organized to efficiently execute environmental protection at the FEMP site."

EPR 1-2, paragraph 2.0: FERMCO management "[p]rovides the necessary resources to maintain an adequate staffing level in the Environmental Protection Department... [and to]...attract and maintain qualified and experienced individuals through offering competitive market place salaries while requiring continuing education and/or specialized training to ensure a state-of-the-art environmental protection program." 
EPR 1-2, paragraph 3.0.B: "Staffing levels for the Environmental Protection Department shall be sufficient to achieve and maintain compliance with all environmental and hazardous waste regulations and DOE Orders during all operations at the FEMP site."

These sections of the CEOSHP clearly indicate FERMCO's intent to adequately staff the Environmental Protection Organization; however, these provisions do not define the system for identifying environmental staffing needs, or periodic re-evaluation of staffing levels to ensure adequacy, which would include performance goals or criteria to be applied in measuring the adequacy of staffing, and provisions for short-term or temporary environmental staff.

\section{Recommendation}

The environmental staffing provisions in the CEOSHP could be strengthened by establishing a more formal program for ensuring adequate staffing levels. This program should address both short-term and long-term (permanent) environmental staffing needs, outline provisions or criteria for identifying approved staffing levels, and clearly establish requirements and responsibility for periodically reevaluating the adequacy of staffing levels.

\subsubsection{Written Environmental Programs, Policies, Procedures, and Standards}

Criteria EM.4.II.B, EM.4.II.C, EM.4.1.A, and EM.4.I.B of the DOE document, Performance Objectives and Criteria for Conducting DOE Environmental Audits (1994), all relate to the need for organizations engaged in environmental protection work to have a formal system in place to promulgate environmental standards, policies, and procedures for specific environmental programs. This system should be designed to track Federal, state, and local regulatory developments and DOE Orders potentially affecting environmental policies and to incorporate such policies and procedures into site-specific organizational procedures. Criterion EM.4.II.B states that DOE contractors should ensure that all environmental procedures and standards are issued by management at an organizational level that has sufficient authority to ensure that such standards and procedures are binding on the organization. Environmental procedures and standards are addressed at the level of specific environmental programs in criterion EM.4.II.C, which states that DOE contractors should conduct environmental protection operations in accordance with a consistent and auditable set of requirements, standards, and responsibilities.

Criterion EM.4.I.A states that contractors should have a formal system in place to capture applicable regulatory and policy requirements from all sources and then compare these requirements against those already in place at the site. Ensuring that new regulatory and policy requirements are incorporated into organization- or site-specific standard operating procedures is addressed in criterion EM.4.I.B. This provision is nccessary to ensure the timely implementation of new requirements and policies of direct relevance to environmental protection activities. A closely related criterion (EM.5.I.E) states that contractors should establish a formal policy for the communication of environmental protection directives that ensures that such directives are distributed to all personnel with environmental management responsibilities in a timely manner. This policy should specifically assign responsibility for the implementation of this system of communication. 


\section{Evaluation}

Top-level management involvement in policy and procedures development, which ensures that such requirements will be binding on the organization, is reflected in the ES\&H Execution section of the CEOSHP. This section establishes that the head of the ES\&H Division reports directly to the President of FERMCO (ESH 2-0, paragraph 2.0.B); this Division is specially charged with responsibility for developing and implementing ES\&H policies, plans, and procedures (ESH 2-0, paragraph 3.0.A). For example:

ESH 1-0, paragraph 1.0.B states that the structure of the ES\&H organization is specifically designed to "enhance oversight of all FERMCO activities" and enhance "authority to act by [having the head of the ES\&H organization report] directly to the FERMCO President."

The CEOSHP contains a number of statements relating to the development and implementation of environmental policies, plans, and procedures, including those governing FERMCO's environmental protection activities. Examples of such provisions are:

ESH 1-0, paragraph 2.1.A, which requires the Environmental Safety and Health Division to ensure "that proper ES\&H programs, systems, and procedures are in place such that all regulatory and DOE requirements are met...."

ESH 1-1, paragraph 2.1.A, which assigns to the ES\&H Division the responsibility for developing and implementing ES\&H policies, p1 ans, and procedures that will ensure "safe and cost-effective completion of all environmental restoration and waste management activities."

The CEOSHP specifically recognizes the importance of maintaining up-to-date environmental policies, procedures, and requirements, and assigns this responsibility to the ES\&H Procedures and Document Control Manager, who:

"Establishes the programmatic aspects of procedures, document control, and records management...." (EAPR 2-0, paragraph 2.0.B) and "Maintain[s] all current applicable ES\&H regulatory documents" (EAPR 2-0, paragraph 3.0.C).

An important element in any formal procedures and standards development system is document control, which is necessary to ensure that only current copies of policies, standards, and procedures are in place and being used within the organization. The CEOSHP deals with this aspect of the program as follows:

EAPR 2-0, paragraph 1.0, states that "ES\&H procedures and documentation records will be managed in accordance with applicable DOE Orders and regulations, and other applicable Federal and State regulations.

Individual ES\&H Departments will produce and maintain their appropriate documents and records in accordance with the procedures, document control, and records management program requirements established by the ES\&H Assurance Manager."

The CEOSHP thus includes requirements designed to ensure that policies, plans, and procedures affecting the environmental protection program at FEMP are issued by top- 
level management and will therefore be binding throughout the program. However, the CEOSHP does not specifically refer to environmental standards in these provisions. The CEOSHP also establishes a document control system to ensure the maintenance and timely dissemination of current policy and procedures documents.

Several entries in the CEOSHP reflect FERMCO's understanding of the need to track relevant regulatory agency and DOE requirements and compare them with existing procedures. For example:

EAPR 1-2, paragraph 3.0.E, requires the ES\&H Assurance organization to determine "the adequacy of DOE requirements for achieving DOE policy and Federal, State, and Local statutory ES\&H requirements."

EAPR 2-0, paragraph 3.0.B, requires the ES\&H Procedures and Documents Control Organization to establish "a centralized and consistent program for the development, revision, control, and issuance of ES\&H policies, plans, reports, and procedures," and EAPR 2-0, paragraph 3.0.F, requires the same organization to "ensure that all ES\&H policies, plans, and procedures are reviewed and updated based on an established periodic review and approval schedule."

The CEOSHP identifies several FERMCO organizations that are explicitly assigned responsibility for translating or incorporating Federal and state regulations and DOE orders into FERMCO's system of procedures and processes and into the procedures of organization- and site-specific standard operating procedures. For example:

ESH 1-0, paragraph 2.1.A, states that the ES\&H Division is to "[e]nsure that proper ES\&H programs, systems, and procedures are in place such that all regulatory and DOE requirements are met."

EPR 5-0, paragraph 1.0, establishes that the Waste Characterization organization is "to develop, interpret, and implement all RCRA hazardous waste characterizations in accordance with...all applicable regulatory requirements."

The CEOSHP does not address the communication of environmental directives to all personnel with environmental management responsibilities in a timely manner. Without a formal management system for disseminating such directives, FERMCO cannot ensure that all personnel are aware of the environmental policies and requirements that directly affect their duties, which could open the way for inadvertent noncompliance with environmental requirements.

\section{Recomendation}

The examples demonstrate that most of the points addressed in the criteria are covered somewhere in FERMCO's CEOSHP. However, the value of the CEOSHP to its users would be enhanced if it included a consolidated section on FERMCO's formal system for developing new or revising old policies, procedures, and standards and tracking and interpreting new or revised Federal, state, and local regulations and DOE Orders and policies that are applicable to FERMCO's environmental operations at FEMP. The system should clearly assign responsibilities for identifying and tracking pertinent requirements and regulations, and should establish procedures for interpreting the impact of new or revised requirements on the program, informing potentially affected organizations at FEMP of the new or revised requirements, tracking new or revised 
requirements against any mandatory implementation schedules, and providing regular reports to management on the status of the revisions.

In addition, mechanisms should be detailed in this section for ensuring that newly developed or revised standards, policies, and procedures, and newly issued or revised regulatory requirements are incorporated into FERMCO's organization- and site-specific procedures in a timely manner.

Finally, the CEOSHP would benefit from the establishment of a systematic administrative system to ensure that all environmental protection directives are communicated to all affected parties throughout the organization and are incorporated into administrative ald operating procedures on a timely basis. Responsibility for ensuring that such communication is effectively implemented should also be assigned by this system.

\subsubsection{Exterinal Comunications}

Criteria EM.5.II.B, EM.5.II.C, and EM.5.II.D of the Performance Objectives and Criteria for Conducting DOE Environmental Audits (1994) all relate to communications between the contractor's environment il protection program and external parties, e.g., regulatory agencies, state and local governments, environmental groups, and members of the pubiic. For example, EM.5.II.B states that the contractor's environmental protection organization should have identified those individuals within the organization who will serve as internal points of contact, as well as the points of contact within the external organizations. These designated individuals within the contractor's organization should be authorized to sign correspondence with external organizations dealing with the organization's environmental performance.

Criterion EM.5.II.C states that contractors should establish a formal program for communicating with external groups. This program should provide for a flow of information from the organization to these external parties and should also provide these groups with the opportunity to be involved in key decisions concerning environmental protection.

Criterion EM.5.II.D states that contractors should establish a formal system to document the environmental concerns expressed by external parties as well as the responses made to those concerns by the contractor's environmental organization. This system should also track progress in resolving or responding to these concerns.

\section{Evaluation}

The CEOSHP assigns responsibility for communicating with a limited set of external parties, i.e., those in the regulatory agencies, to the Effluent Monitoring and Control Manager. The Clean Air Program Manager and the Clean Water Program Manager are also assigned responsibility for maintaining good communication with these personnel. However, the CEOSHP does not describe these responsibilities in any detail, does not address points of contact with other external parties, does not identify points of contact within these external organizations, and does not assign signature authority. Examples of FERMCO's requirements in this area are:

EPR 2-0, paragraph 2.2.I: The responsibilities of the Effluent Monitoring and Control Manager include maintenance of good communications with personnel in the regulatory agencies. 
EPR 2-1, paragraph 3.0.N: The Clean Water Program maintains good communication with personnel in the regulatory agencies, while assuring that such communications are coordinated by appropriate personnel.

EPR 2-2, paragraph 3.0.I: The Clean Air Program maintains good communication with personnel in the regulatory agencies, while assuring that such communications are coordinated by appropriate personnel.

As noted above, the CEOSHP contains only a few requirements establishing responsibility for communications specifically with regulatory agencies and no requirements to establish contacts with other external organizations. The CEOSHP also has no requirements for outreach programs or public involvement in environmental decision-making, although ESH 2-4, paragraph 2.0.Y states, without further elaboration, that the ES\&H Assurance Department "[p]articipates in public awareness programs."

\section{Recomendation}

The CEOSHP should be revised to identify the primary points of contact (specific individuals) for each external party, e.g., state and local government agencies, the press, Congress and the public. Signature authorities should also be identified, as should the corresponding points of contact with each external organization. The CEOSHP would also be enhanced if it included a section describing FERMCO's system for soliciting and dealing with the environmental concerns of all outside parties. FERMCO should document a systematic program for communicating with various kinds of external agencies, including the media, the public, and environmental groups, and involving them in key decisions.

\subsubsection{Employee Involvement}

\subsubsection{Environmental Responsibilities and Personnel Accountability}

Criteria EM.1.II.A and EM.1.II.B of the Performance Objectives and Criteria for Conducting DOE Environmental Audits (1994) state that DOE contractors should clearly define and communicate environmental roles, responsibilities, and authorities to all personnel whose activities may impact environmental performance. Contractors should also ensure that all personnel understand their roles, responsibilities, and authorities. In addition, contractors should develop the management systems and documentation necessary to support personnel accountability, such as job descriptions, performance standards, and performance appraisals.

\section{Evaluation}

Numerous entries in the CEOSHP discuss environmental protection roles, responsibilities, and authorities. However, these statements tend to 1ack sufficient detail to clearly convey information on the specific roles, responsibilities, and authorities of the various personnel involved in FEMP's environmental protection program. In addition, the statements do not establish (or reference) the management systems (job descriptions, performance standards and performance appraisals) necessary to support personnel accountability. Several examples from the CEOSHP demonstrate these findings:

ESH 1-3, paragraph 2.1, states that each level of management is accountable to the one above and responsible for the level below. 
EPR 1-0, paragraph 2.0, sets forth the responsibilities of FERMCO personne1 with respect to the environmental protection program. The President "provides management support for the Environmental Protection Program." The Vice Presidents "delegate responsibility for protection of the environment and for ensuring environmental compliance with the various Federal, State and DOE regulations." The manager of the Environmental Protection Department "provides management, planning and compliance for all environmental protection programs." Other FERMCO managers "assure compliance with all permits, ifcenses, consent orders and applicable regulations governing their individual areas of responsibility." All FERMCO employees have the responsibility to "ensure their assigned work activities are conducted in such a manner as to prevent or 1 imit to As Low As Reasonably Achievable (ALARA) any radiological or chemical constituent releases to the environment."

EPR 1-1, paragraph 3.0.A, requires that the organizational structure of the Environmental Protection Department be such that it provides clear leadership with accountable responsibilities but does not delineate those responsibilities or establish the structures necessary to accomplish this objective.

\section{Recommendation}

The CEOSHP would be strengthened if it addressed, with greater clarity and specificity, the roles, responsibilities and authorities of all FEMP managers and employees. This should include the environmental responsibilities of all FERMCO employees, as well as the specific responsibilities of employees within the ES\&H program, both within the ES\&H Division and in other offices.

\subsubsection{Top Managenent Encouragement}

Criterion EM.2.II.C of the DOE document, Performance Objectives and Criteria for Conducting DOE Environmental Audits (1994) states that DOE contractors should estab1ish a formal environmental policy that encourages top management openness and receptiveness to input on environmental issues from all employees, as well as from the public at large.

\section{Evaluation}

The CEOSHP does not have a formal policy statement requiring environmental program management at FEMP to be receptive and open to input on environmental issues from al1 employees and members of the public, although other statements in the CEOSHP reflect FERMCO's awareness of the importance of management responsiveness to employee suggestions. In contrast, SPR 1-0, paragraph 3.1.A, which applies to FERMCO's Occupational Safety and Health Program, states that:

"People are the most critical element in the success of a safety and health program. Management responsibility must be complemented by employees' suggestions and the employees' active involvement in keeping workplaces safe. Management provides the means for reporting potential or existing safety and health hazards or concerns without fear of harassment, reprisal or retaliation." 


\section{Recommendation}

The CEOSHP would be strengthened if it included a requirement formally establishing a management policy stating that environmental program managers at all levels of the organization should be open and receptive to input on environmental issues from all employees and members of the public.

\subsubsection{Environmental Concerns Reporting System}

Criterion EM.5.I.B of Performance Objectives and Criteria for Conducting DOE Environmental Audits (1994) states that DOE contractors should establish a formal system to allow personnel to anonymously, and without retribution, communicate environmental concerns to upper levels of management for resolution.

\section{Evaluation}

Although the CEOSHP contains requirements for the reporting of FERMCO employees' occupational safety and health concerns, no parallel system for addressing these concerns in the environmental context were identified. For example:

SPR 6-3, paragraph 1.0, which is a part of the OS\&H Execution section of the CEOSHP, describes the FEMP Safety and Health Suggestion/Complaint System, which establishes procedures for employees to raise such suggestions/concerns to management, for management to investigate such suggestions/concerns, and for such suggestions and concerns to be resolved satisfactorily.

\section{Recomendation}

The CEOSHP should be revised to include a comprehensive employee concerns program that accommodates employee environmental protection concerns. The CEOSHP should address the establishment of a system for reporting environmental concerns or issues, tracking those issues to resolution, advising the originator of the action taken, protecting the confidentiality of the employee, and ensuring that no reprisal or recrimination occurs to the employee registering the concern.

\subsection{Environmental Assessnents and Controls}

\subsubsection{Self Assessment and Appraisal Programs}

Criteria EM.7.I.A and B of the DOE Performance Objectives and Criteria for Conducting DOE Environmental Audits (1994) state that contractors should have ongoing formal self-assessment and oversight appraisal programs in place with specific responsibilities and authorities to effectively evaluate environmental protection activities, anticipate and report environmental concerns, and implement corrective actions. The self-assessment program should be based on the guidelines provided in the December $1992 \mathrm{ES} \& H$ Self-Assessment guidance document and should establish accountability and excellence at the "grassroots" level, thus involving people who are the most familiar with the operations and their management. The program should indicate that self-assessment is a continual line management activity that acquires, assimilates, documents, and reports through all levels of an organization on the effectiveness, adequacy, efficiency, and economy of all contractor activities. 
DOE 5482.1B, "Environment, Safety and Health Appraisal Program" establishes requirements for appraisal programs at all levels of the organization including independent oversight appraisals.

\section{Evaluation}

The CEOSHP contains many provisions relating to FERMCO's Environmental Safety and Health (ES\&H) Self-Assessment Program and independent oversight appraisal activities. For example:

EAPR 1-1, paragraph 1.0, states that "Assurance principles are provided, in part, by the Environmental Safety and Health (ES\&H) Self-Assessment program consisting of internal inspections, audits, and appraisals by each ES\&H operating leve1. Additional assurances are provided through functional and management appraisals conducted by ES\&H Assurance and Quality Assurance and through independent reviews and appraisals by DOE and other outside agencies and contractor personnel."

Accountability for ES\&H self-assessment activities is reflected in EAPR 1-2, paragraph 1.0, which states that "The FERMCO ES\&H Assurance Department is under the leadership of the ES\&H Assurance Manager who reports directly to the Vice President, ES\&H Division."

In addition, EAPR 1-2, paragraph 3.0, 1ists as requirements of the ES\&H Assurance Program the following:

Paragraph 3.0.B, "Evaluating the effectiveness of ES\&H policies, requirements, and standards and their implementation."

Paragraph 3.0.C, "Providing management with objective, timely, and reliable information on ES\&H performance; including, significant achievements and deficiencies."

Daragraph 3.0.D, "Providing management with recommendations, where appropriate, for improvement of ES\&H program performance."

FERMCO's ES\&H Self-Assessment Program is outlined in section EAPR 3-0 of the CEOSHP. This section of the document relates specifically to FERMCO's environmental restoration and waste management activities. It assigns responsibility for the program to the ES\&H Self-Assessment Manager, who is charged with responsibility for developing a self-assessment charter and a Program Implementation P1 an (EAPR 3-0, paragraph 2.0.A). The Program Plan specifically includes program goals, objectives, priorities, and general program requirements.

\section{Recomnendation}

FERMCO has an ES\&H Self-Assessment program in place, and this program is designed to evaluate FERMCO's environmental restoration and waste management (ER/WM) programs and establish accountability. However, in addition to ER/WM activities, all of FERMCO's environmental protection activities should be evaluated in this program. FERMCO's oversight program could be strengthened if it included a section describing the roles, responsibilities, and authorities for the oversight program, describing how the independence of this program will be ensured, and discussing the scope, frequency, or conduct of such oversight activities. 


\subsubsection{Risk Management}

Criterion EM.8.II.A of the Performance Objectives and Criteria for Conducting DOE Environmental Audits indicates that contractors should establish a formal environmental risk management program that ranks the risk associated with an action or activity in order to establish the priority of each action or activity. The program should define a pricritization system that categorizes activities or actions based on the severity of potential consequences and the expected frequency of occurrence. In addition, the program should integrate with risk management programs developed to address occupational safety and radiological protection risks so that a consistent prioritization program is established organization-wide.

\section{Evaluation}

The Environmental Protection section of the CEOSHP contains several elements that identify the need to assess the risks associated with environmental protection activities. For example:

EPR 1-0, paragraph 3.0.E, establishes that "[t]he Environmental Protection Department shall develop a risk-based standards program for routine environmental monitoring activities, enabling decisions to be made through 'risk-cost-benefit analysis' activities."

EPR 6-0, paragraph 3.0. M, requires the development of a "Risk Assessment and Risk Management Plan for media sampled [and] for sampling tools used."

These statements, however, do not establish a formal environmental risk management program and do not indicate that activities should be prioritized based on risk. In fact, the focus of EPR 1-0, paragraph 3.0. E appears to be risk acceptance rather than prioritized risk elimination or control. SPR 2-58 of the CEOSHP does provide risk management and prioritization guidelines for occupational safety and health hazard abatement activities; however, this section provides no indication that these guidelines apply to or integrate with environmental risk management activities.

\section{Recomendation}

FERMCO's environmental protection program would be strengthened by including an environmental risk management program that integrates with or is an extension of the Hazard Abatement Program currently outlined in the CEOSHP. The program should also be expanded to address radiological protection issues and should focus on prioritized risk elimination or control rather than risk acceptance.

\subsubsection{Corrective Actions}

Criterion EM 4.IV.E of the Performance Objectives and Criteria for Conducting DOE Environmental Audits (1994) indicates that contractors should establish formal mechanisms to investigate, report, correct, track, and monitor trends in environmental problems and "incidents" that include provisions for correcting conditions or damage resulting from problems and incidents. In addition, the program should address the determination of root and contributory causes, the development and implementation of effective corrective actions that address the identified causes, the implementation of immediate interim measures where necessary to prevent further damages or releases, the periodic evaluation of corrective 
actions to ensure effectiveness, and a trending provision to evaluate both the causes of problems and incidents and the effectiveness of corrective actions.

\section{Evaluation}

Section $V$ of the CEOSHP, ES\&H Assurance Execution, mentions many of the required elements of a corrective action program. For instance:

EAPR 3-0, paragraph 2.0.H requires that the ES\&H Self-Assessment Manager "[c]onduct cause factors/root cause analyses; evaluating effectiveness of corrective actions, reporting findings (lessons learned), [and] tracking actions/deficiencies..."

EAPR 3-1, paragraph 2.0.E requires that self-assessment evaluators

"[i]nvestigate the background and supporting information to determine the root cause of deficiencies;"

EAPR 3-2, paragraph 2.0.B requires an evaluation of FERMCO's implementation of corrective action;

EAPR 3-2, paragraph 3.0.C indicates that the organization's self assessment activity must include "an established and effective program designed to identify significant trends;" and

EAPR 3-3, paragraphs 2.2.A and $B$ require that an inciderit investigation committee "[p] erform an investigation of incidents... [and

make]... recommendations to site management to prevent recurrence."

Although these statements generally address the elements of a comprehensive corrective action program, they lack the specific detail required for consistent and effective program implementation. For example, the statements do not establish or identify methods for conducting root cause analyses, do not establish specific responsibilities for documenting and tracking corrective actions, do not address the implementation of interim protective measures, and do not define how the corrective action efforts of the ES\&H Assurance Department integrate with the efforts of the Environmental Protection Department. This lack of detail coupled with the fragmented presentation of these statements (i.e., they are scattered throughout four subsections of the ES\&H Assurance section of the CEOSHP) results in an incomplete definition of FERMCO's comprehensive corrective action program.

\section{Recommendation}

The CEOSHP would be strengthened if all of the elements of the corrective action program were integrated and expanded to provide a formal, FERMCO-wide corrective action program that includes mechanisms to investigate, report, track, correct, and monitor trends for all kinds of environmental problems and incidents, while defining al1 of the interrelationships between the ES\&H Assurance Department and the Environmental Protection Department, or any other FERMCO organization with responsibilities for corrective actions.

\subsubsection{Environmental Documentation and Recordkeeping}

Environmental documentation and recordkeeping requirements for DOE contractors are outlined in criteria EM.4.IV.A through C of the Performance Objectives and Criteria 
for Conducting DOE Environmental Audits (1994). Criterion EM.4.IV.A indicates that contractors should have a formal system that identifies and maintains copies of all important environmental documents, including regulations, standards, and orders issued by regulatory bodies, as well as records of environmental conditions, activities and performance at the site. Criterion EM.4.IV.B states that this system should include control mechanisms to catalog, issue and revise documents as necessary, and should identify document retention requirements and archival locations. Criterion EM.4.IV.C states that DOE contractors should implement a system that ensures that required environmental reports are prepared and submitted on a timely basis. This system should identify each report required and establish responsibilities for data gathering and report preparation and review, as well as signature authorities.

\section{Evaluation}

Section EAPR 2-0 of the CEOSHP outlines FERMCO procedures and document control requirements. However, it does not clearly indicate how these procedures and requirements integrate with the reporting requirements or the centralized environmental management database system discussed in the Environmental Protection section of the CEOSHP.

In addition, although this section (paragraph 2.0.B) does assign responsibility for the establishment of the "programmatic aspects of procedures, document control and records management" in accordance with general requirements (paragraph 3.0) that address many of the required elements of an effective environmental documentation and recordkeeping system, the section does not identify (or reference other documents that identify) specific methods or procedures for implementing elements of the system. For example:

Paragraph 3.0.B requires the establishment of "a centralized and consistent program for the development, revision, control, and issuance of ES\&H policies, plants, reports and procedures," but does not identify methods or procedures to be employed in the program or who in the FERMCO organization must implement the program; and

Paragraph 3.0.A requires the establishment of "a program for the revisions, control, and issuance of [the CEOSHP]," but does not indicate the required frequency of revision, or the responsibility for the necessary coordination with other departments within the ES\&H Division.

Paragraph 3.0.E requires development of "ES\&H Division-1evel documents" but does not specify what "Division-level documents" are required, what these documents must contain, or what purposes these documents are to fulfill.

The CEOSHP contains a number of requirements addressing the reporting of environmental information to a variety of agencies and organizations. For example:

EPR 1-0, paragraph 3.0.G, establishes that the Environmental Protection Department shall report the progress of environmental management activities to DOE, EPA, Ohio EPA, and Regional and Local Authorities;

EPR 1-1, paragraph 3.0.E, states that the "Effluent Monitoring and Control Section shall monitor for compliance with all applicable Clean Air, Clean Water, and Safe Drinking Water regulations, and assure that FERMCO operations 
remain within applicable permit limitations. Superfund Amendments and Reauthorization Act (SARA) Title III compliance and required reports shall be developed and submitted within the regulatory requirements submittal dates by the Effluent Monitoring and Control Section;"

EPR 1-1, paragraph 3.0.H establishes that the "Groundwater Monitoring Section maintains compliance with all applicable Clean Air and Clean Water regulations while ensuring operations within applicable permit limitations. Title III compliance and required reports are developed and submitted with the regulatory requirement submittal dates by the Groundwater Monitoring Section;"

EPR 2-1, paragraph 2.2 establishes the responsibilities of the Clean Water Manager for ensuring proper notification and reporting of releases to the environment.

EPR 2-1, paragraph 3.0.C states that the Clean Water Program is to ensure that programs are in place so that reporting is completed within the appropriate regulatory time frames; and

These statements appear in many sections throughout the Environmental Protection section of the CEOSHP and address reporting requirements in general terms without specifically identifying required reports, and signature authorization for each report.

\section{Recommendation}

The CEOSHP would be strengthened by expanding and integrating its existing requirements for environmental documentation and recordkeeping into a FERMCO-wide system for generating and submitting reports required by Federal, state, and local regulations and DOE orders and policies and for identifying and maintaining all important environmental documents, including regulations, standards and Orders, as well as records of site environmental conditions, activities, and performance. This system should specifically identify the documents, records, and reports covered under the program and should establish detailed mechanisms to catalog, issue, and revise documents and to ensure the quality, preparation, and timely submittal and review and approval of required environmental reports. Although some of the details would be appropriately addressed in lower-tiered documents, the CEOSHP should identify responsibilities for implementing each element of the program.

\subsection{Environmental Training Program}

\subsubsection{Environmental Professional Training}

Criterion EM.6.III.A of the Performance Objectives and Criteria for Conducting DOE Environmental Audits establishes that contractors should have a formal written policy requiring that environmental training programs be defined in controlled documents such as a training program manual. This formal training policy should address environmental training requirements and standards and should require the formal identification and documentation of each environmental staff member's training requirements. In addition, the policy should provide controls to ensure that required training is completed proficiently and should address the retraining of personnel to ensure that skills, knowledge, and abilities are maintained current. Finally, the policy should contain provisions for the regular review of required training for each position and for making adjustments as appropriate. 


\section{Evaluation}

The CEOSHP contains several statements that address the need for the continuing education of the Environmental Protection Organization staff. For example:

EPR 1-2, paragraph 2.0.B. establishes that FERMC0 management must require "...continuing education and/or specialized training [of the environmental protection staff] to ensure a state-of-the-art environmental protection program..."

EPR 1-2, paragraph 3.0.E. requires that "[t]raining onsite for the technician level of the Environmental Protection Department shall be ongoing to maintain an adequate qualified staff capable of achieving all FEMP Sitewide CERCLA Quality Assurance Project P1an and other applicable Quality Assurance/Quality Control requirements as applicable to their job function."

EPR 1-3, paragraphs 2.2 and 2.3 expand on these broad statements regarding continuing education of the environmental staff by requiring that the Environmental Protection Department section managers identify and ensure that all environmental staff members possess qualification requirements for specific job tasks within the organization and by requiring that the Environmental Protection Manager "ensure that a program is in place for career development and advancement, through continuing education, professional certification programs, etc., to advance the qualification level of the overall organization."

Although these sections demonstrate FERMCO's awareness of the importance of the continuing education and professional development of the environmental staff and allude to a career development and advancement program, the statements do not comprise (nor do they reference) a formal training program for the FERMCO environmental staff.

\section{Recomendation}

The Environmental Protection section of the CEOSHP could be strengthened by expanding the environmental professional training elements into a structured continuing education and professional development program. The program should address regular reviews of training requirements for specific job tasks within the environmental organization, and should require formal identification, documentation, and tracking of each environmental staff member's training requirements.

\subsubsection{Personnel Training Needs}

Criterion EM.6.III.B of the Performance Objectives and Criteria for Conducting DOE Environmental Audits states that contractors should have a formal written process in place to identify and evaluate environmental training needs for all personnel and to incorporate these needs into individual professional development plans. The process should include specific assignments of responsibility for the identification and evaluation of training requirements and should outline the required integration with, and describe the support expected from, the training department. Criterion EM.6.III.D further states that contractors should have a formal process in place that ensures that the necessary training is developed at an appropriate depth to provide adequate coverage of applicable regulations, policies, and procedures. This 
process should specify the methods to be used for defining the performance-based training objectives required to meet personnel training needs.

\section{Evaluation}

Several statements within the environmental protection section of the CEOSHP address environmental training needs for FERMCO personnel for various subdisciplines of the FERMCO program. For example:

EPR 2-0, paragraph 2.2.F requires that the Effluent Monitoring and Control Manager "[d] irect development and conduct of training programs necessary to assure employee and contractor understanding of equipment, procedures and reporting requirements...,"

EPR 2-1, paragraph 3.0.K establishes the requirement within the Clean Water Program to "[d] irect development and conduct of training programs necessary to assure employee and contractor understanding of equipment, procedures and reporting requirements...," and

EPR 2-2, paragraph 3.0.F establishes the requirement within the Clean Air Program to "[d] irect development and conduct of training programs necessary to assure employee and contractor understanding of equipment, procedures and reporting requirements...."

These statements, however, do not reflect a formal training program that clearly outlines responsibilities for identifying, evaluating, and documenting personnel training needs, for developing, conducting, and monitoring the effectiveness of training courses, or for ensuring the successful completion of required training courses. In addition, these statements do not provide a format for ensuring that training courses provide an adequate coverage of applicable regulations, policies, or procedures, nor do they address the development or application of performancebased training objectives. ESH 1-8 of the CEOSHP incorporates many of these program elements into the ES\&H Training section; however, the applicability of this section is limited to the development and implementation of the FERMCO ES\&H orientation training for new employees and visitors and does not address job-specific environmental training requirements for FERMCO employees.

\section{Recommendation}

The Environmental Protection section of the CEOSHP would be strengthened if it included a formal training program that clearly outlined responsibilities for identifying, evaluating and documenting personnel training needs, for developing and conducting training courses, for monitoring the effectiveness of training courses, and for ensuring the successful completion of required training courses for workers at FEMP. The program should also establish responsibilities and guidelines (including performance-based training objectives) for developing, conducting, and evaluating required environmental training and for ensuring (and documenting) that personnel complete required environmental training. This program should outi ine responsibilities for identifying, evaluating and documenting job-specific environmental training requirements in the individual development plans of FERMCO personnel. 
This page intentionally left blank. 
Section 4.0

\author{
CEOSHP \\ RADIOLOGICAL CONTROL \\ EVALUATION AND RECOMMENDATIONS
}




\section{SECTION 4.0 \\ CEOSHP Radiological Control \\ Evaluation and Recommendations}

\subsection{Management Commitment and Employee Involvement}

\subsubsection{Management Commitment}

\subsubsection{Site-Specific Radiological Control Manual}

Article 114 of the DOE Radiological Control Manual (the RadCon Manual) requires contractors to issue a Site-Specific Radiological Control Manual that invokes the requirements of the DOE RadCon Manual. The Site-Specific Manual must clearly and unambiguously state the contractor's management policies, requirements, expectations, and objectives for the site's Radiological Control Program, and must be issued and endorsed by the contractor's senior site executive.

\section{Evaluation}

Although it is not specifically identified as such in the CEOSHP, Section III of that document (Radiological Protection Execution) constitutes FERMCO's Site-Specific Radiological Control Manual. The CEOSHP is formally endorsed and approved by FERMCO's Presicient (see page ii of the CEOSHP); however, it does not in every case clearly and unequivocally state FERMCO's management policies, requirements, expectations, and objectives for the required elements of the radiological control program. For example:

The emergency response requirements listed in EAPR 4-0 through EAPR 4-3 address the need to develop emergency planning documents but do not clearly describe the specific procedures required to respond to various types of abnormal radiological events, as required by Article 346 of the RadCon Manual;

RPR 2-4 paragraphs 3.0.F and $G$ address 1 abeling requirements for radioactive sources and their containers; however, the labeling requirements for other radioactive materials (equipment, components, or other items) specified in Article 412 of the RadCon Manual are not addressed in the FERMCO Site-Specific Manual;

ESH 2-2 specifies that nuclear criticality practice be followed and invokes DOE criticality safety orders; however, the radiological protection section does not address the nuclear accident dosimetry program required by Article 515 of the RadCon Manual when the potential for a criticality exists; and

The external exposure section of the CEOSHP (RPR 2-1) does not address all of the required elements of the RadCon Manual (i.e., non-uniform exposures to the skin, Appendix 2C), and planned special exposures (Article 213.3).

A more detailed evaluation of the extent to which the CEOSHP effectively fulfills the requirements of a Site-Specific Radiological Control Manual (i.e., the extent to which Section III clearly and unambiguously states the contractor's management policies, requirements, expectations, and objectives for the site's radiological control program and provides site-specific additions, supplements, and clarifications) is discussed in the following sections. 


\section{Recommendation}

The CEOSHP should clearly indicate that Section III (Radiological Protection Execution) of that document constitutes FERMCO's Site-Specific Radiological Control Manual, and should address all required elements of an effective radiological control program as specified in the DOE RadCon Manual.

\subsubsection{Subcontractor Compliance With Manual}

Article 114.5 of the DOE RadCon Manual mandates that all subcontractors working on a DOE site comply with the requirements of the Site-Specific Radiological Control Manual.

\section{Evaluation}

The CEOSHP contains several entries referring to subcontractor compliance obligations in general. For example:

ESH 1-0, paragraph 2.1.B requires that the Environmental Safety and Health Division "audit...subcontractor activities to ensure compliance."

ESH 1-4, paragraph 3.0.B states, "All employees, including subcontractors, must comply with FERMCO's safety, health, and environmental regulations."

ESH 1-7, paragraph 3.0.D states that "[a]11 contractors and subcontractors will be given a copy of the [site-specific Safety and Health Plan] and a task-specific hazard analysis (associated with their scope of work). They will be required to comply with all PPE, training, and medical obligations of the...[P]an], as well as FERMCO Safety Procedures, Rules, and Policies."

RPR 2-0, paragraph 2.1, and RPR 2-1, paragraph 2.2 state that subcontractors who enter controlled areas or who have the potential for internal or external exposure are included in the FERMCO bioassay program and/or must wear dosimetry devices.

EAPR 1-2, paragraph 3.0.A requires the ES\&H Assurance Department to ensure "that ES\&H policies, procedures, and requirements are appropriately interpreted and implemented by... FERMCO contractor programs and organizations."

Although each of these statements clearly indicates FERMCO's intent to mandate subcontractor compliance with the CEOSHP, the statements do not identify the specific enforcement mechanisms and responsibilities in place to implement this requirement. For example, EAPR 1-2, paragraph 3.0.A requires the ES\&H Assurance Department to ensure contractor compliance with FERMCO policies, procedures and requirements but does not indicate how FERMCO will do this (i.e., through periodic inspections of contractor work activities, analysis of contractor survey documentation, investigation of contractor accidents and incidents, notification of violations, tracking of corrective actions, etc.), or what enforcement mechanisms and authority (i.e., contract mechanisms) FERMCO will use to ensure compliance. In 
addition, although these statements mandate contractor and subcontractor compliance with the CEOSHP, it is not clear which elements of the CEOSHP apply or how the contractor is expected to implement them. For instance, a number of sections in the CEOSHP describe the FERMCO ES\&H organization or assign specific responsibilities to Departments within the organization. The CEOSHP does not, however, describe how these sections apply to contractors and subcontractors (i.e., the CEOSHP does not indicate if contractors must establish parallel organizational structures or establish parallel programs such as self-assessment programs, dosimetry programs, bioassay programs, etc.).

\section{Recommendation}

The CEOSHP would be strengthened if it outlined specific mechanisms, responsibilities, and authorities for ensuring and enforcing contractor and subcontractor compliance with the CEOSHP. These mechanisms could include periodic inspections of contractor and subcontractor work activities, audits of required contractor and subcontractor documentation and written programs, investigation of contractor and subcontractor accidents, and tracking of contractor and subcontractor corrective action efforts. In addition, the CEOSHP should clearly identify FERMCO's expectations for contractor and subcontractor implementation of the specific elements of the CEOSHP.

\subsubsection{Senior Management Written Commitment}

Article 121.2 of the DOE RadCon Manual recommends that the contractor's senior managers demonstrate thcir commitment to a Radiological Control Program "of the highest quality" and that they do so in writing. This Article also states that management must demonstrate this commitment and support by providing adequate resources to the program and ensuring that all workers involved in the program are trained and qualified to carry out their assigned duties.

\section{Evaluation}

The CEOSHP contains many statements attesting to the commitment of FERMCO's management to an excellent Radiological Control Program. For example:

RPR 1-0, paragraph 1.0 states that "It is FERMCO policy to provide a radiologically-safe work environment for all

personnel onsite; including, FERMCO employees, DOE employees, contractors, and visitors; and those individuals who may reside in close proximity to the Facility site."

RPR 1-0, paragraph 2.0, "FERMCO management ensures adequate provision is made to carry out the spirit, as well as the letter of the Radiological Control policy statement."

RPR 1-2, paragraph 2.0.B., FERMCO Management "[c]ommits to the Radiological Control Program. This includes allocation of sufficient resources to staff and operate the organization, to train workers, and to reinforce rules and guidelines by personnel actions when necessary."

In the area of employee training, the CEOSHP also contains numerous statements underscoring the importance FERMCO attaches to this activity. For example, RPR 1-1, paragraph 3.0.F. states, "continuous training of an experienced work force shall be 
conducted," and RPR 5-2, paragraph 1.0 reiterates, "It is FERMCO policy that all persons entering the controlled area be trained in the aspects of radiation protection to a level commensurate with their potential for exposure to radiation and radioactive materials."

\section{Recommendation}

As it is now written and organized, users of the CEOSHP would be aware that FERMCO management is theoretically committed to excellence in the Radiological Control Program and fully intends to provide both the resources the program needs to function effectively and the training FERMCO workers need to work in a radiologically safe manner. However, the CEOSHP would be strengthened by including a single, well-integrated, and comprehensive section on excellence in radiological control that contains the key principles essential to a successful, well-managed Radiological Control Program. Such a section would spell out the performance expectations for senior managers as well as workers at other organizational levels. The CEOSHP could achieve this by incorporating sections from DOE's RadCon Manual and tailoring these as needed to reflect site-specific conditions at Fernald.

\subsubsection{Improvement Goals and Performance Indicators}

Article 121.8 of the DOE RadCon Manual requires that the contractor's senior managers require and approve measurable, realistic, auditable, and challenging radiological improvement goals. In addition, senior managers are required to review progress toward these goals at least quarterly.

Article 121.9 of the DOE RadCon Manual recommends the establishment of a performance indicator program for measuring and trending the effectiveness of the Radiological Control Program against these goals.

\section{Evaluation}

RPR 5-0, paragraph 2.4 of the CEOSHP requires that the President of FERMCO "[e]nsures that a radiological performance goals program is established, approved, and maintained," and states that Articles 121, 131, and 132 of the DOE RadCon Manual shall be adhered to. This section of the CEOSHP (RPR 5-0, Radiological Assessments and Inspections) does not, however, indicate the purpose of the "radiological performance goals program," does not assign specific responsibilities for the establishment, approval, or maintenance of the program, and does not provide criteria or guidance for the establishment of such goals.

RPR 5-3, paragraphs 3.0.E through $H$ do provide more specific details on the establishment and application of ALARA goals; however, the CEOSHP does not establish a relationship between the ALARA goals described in Section RPR 5-3 and the radiological performance goals program presented in Section RPR 5-0.

\section{Recoumendation}

The radiological protection section of the CEOSHP would be enhanced if it contained a more detailed description of the radiological performance goals program. Specifically, the CEOSHP should assign specific responsibilities for the establishment, approval, and maintenance of the program. In addition, the CEOSHP should define the relationship between the radiological performance goals program and other requiremenis within the CEOSHP related to radiological protection goals (e.g., ALARA goals). 


\subsubsection{Radiological Waste and Exposure Reduction}

Article 121.11 of the DOE RadCon Manual states that the contractor's senior managers "should be alert to opportunities for minimizing the generation of radiological waste and discharges to the environment, controliing contamination at its source and reducing radiation exposure to workers and the public."

\section{Evaluation}

There are numerous statements throughout the CEOSHP asserting FERMCO's requirements for controlling radiological contamination at its source and protecting all personnel, visitors, and the public from exposure to radiation to the extent possible. For example, RPR 1-0, paragraph 3.0 states, "FERMCO shall conduct radioactive material and radiation producing activities to maintain radiation exposure to employees, contractors, and the general public as low as reasonably achievable." RPR 1-1, paragraph 3.0.A. reiterates this principle by stating, "Equipment at the FEMP site shall be engineered to eliminate or minimize leakage of radiation or the spread of contamination," and RPR 5-3, paragraph 3.0.K. states that "The FEMP facility shall be operated and maintained in a manner which minimizes radiation and radioactive material exposure, the spread of contamination, and the release of radioactivity to uncontrolled areas." However, no requirements specifically addressing the need to minimize the volume of radioactive waste generated or recommending that FEMP managers actively seek to identify opportunities for waste reduction, minimization of discharges to the environment, controlling contamination at its source, and reducing personnel and public exposures to ALARA were identified in the CEOSHP.

\section{Recommendation}

FERMCO's Site-Specific Radiological Control Manual (Section III of the CEOSHP) would be enhanced by the addition of requirements for FERMCO's senior managers to stay alert to opportunities for minimizing the volume of radiological waste and reducing environmental discharges, controlling contamination, and reducing radiation exposures to workers and the public. This section could also provide examples of successful minimization efforts.

\subsubsection{Promotion of Radiological Control and Constant Improvement}

Article 121.6 of the DOE RadCon Manual recommends that the contractor's senior managers "adopt and promote a positive attitude toward radiological control that encourages initiatives to identify concerns at an early stage, to prevent problems from deteriorating and to promote doing the right job correctly the first time." Article 122.3 presents a complementary recommendation that states, "The attitude that constant improvement is required in radiological work needs to be developed at all levels of management and in the workforce."

Evaluation

Several entries in the CEOSHP reflect FERMCO's understanding of the continuous improvement principle. For example:

ESH 1-2, paragraph 3.0.A. states, "We recognize that cont inued good saiety performance requires constant upgrading and maintenance. At FERMCO, working safely is a condition of employment for all employees." 
RPR 1-2, paragraph 3.0.F. states that "The organization shall permit feedback from workers and line management for program improvements."

EAPR 1-1, paragraph 3.0 says that it is a principle of the ES\&H Assurance Program to "Assure that continued performance improvement is pursued throughout the entire ES\&H Division."

However, the CEOSHP does not contain specific recommendations addressing the appropriate management and worker attitudes toward radiological control and continual improvement in this area. In addition, the passive tone of many of these entries, e.g., management "shall permit" feedback, is not conducive to active employee involvement in the program.

\section{Recommendation}

The CEOSHP should include provisions specifically encouraging positive atiitudes toward radiological control and constant improvement throughout the FERMCO workforce would enhance this document. One such provision could be the establishment of a radiological protection incentives program similar to the Safety Incentives, Awards and Suggestions Program established in Section SPR 6-0 through 6-4 of the CEOSHP.

\subsubsection{Employee Involvement}

\subsubsection{Radiological Awareness Committee}

Articles 132.3 and 132.4 of the DOE RadCon Manual, which are part of a section of the Manual entitled "Management of Radiological Performance Goals, " encourage contractors to form a Radiological Awareness Committee that elicits the active participation of the workforce and further recommends that those individuals engaged in performing radiological work develop radiological performance goals for the Radiological Program. Under normal circumstances, these goals are reviewed annually and are generally made more stringent over time to reflect continued improvement in the program.

\section{Evaluation}

A review of the CEOSHP did not identify any entries recommending the establishment of a Radiological Awareness Committee. The CEOSHP does encourage employee involvement in the Radiological Protection Program, as evidenced by such statements as the following:

RPR 1-2, paragraph 3.0.F., "The [Radiological Control] organization shal1 permit feedback from workers and 1ine management for program improvements," and

EAPR 1-0, paragraph 3.1, "Employee participation in ensuring ES\&H excellence in every aspect of day-to-day operations shall be through innovative safety awareness and safety incentive programs with emphasis on 'finding a better way.'"

In addition, RPR 5-0, paragraph 2.4 addresses a radiological performance goals program; however, this paragraph does not emphasize the need for active employee involvement in the establishment, review, and update of these goals. 
Recommendation

The FERMCO Site-Specific Radiological Control Manual (Section III of the CEOSHP) would be strengthened if it included a section establishing a Radiological Awareness Committee that actively encourages employee involvement in program activities, such as the development of radiological program performance goals.

\subsubsection{Radiological Awareness Reports System}

Article 135.2 of the DOE RadCon Manual recommends the establishment of a Radiological Awareness Reports system that is supported by contractor management. The purpose of this system is to increase the radiological awareness of the workforce through continuous evaluation and improvement, tracking concerns and their resolution, providing feedback, and posting results and trends.

\section{Evaluation}

Our review of the CEOSHP did not identify any recommendations that paralleled those for a Radiological Awareness Reports system in the DOE RadCon Manual.

\section{Recommendation}

FERMCO's Site-Specific Radiological Control Manual would be enhanced by the addition of a section that specifically addresses the establishment of a Radiological Awareness Reports system and recommends management support for such a system.

\subsubsection{ALARA Committee}

Article 138 of the DOE RadCon Manual recommends that contractors establish an ALARA (As Low as Reasonably Achievable) Committee at their facilities. Committee membership should include managers and front-line workers as well as personnel from the technical support and Radiological Control organizations. The ALARA Committee may be part of another committee, e.g., a general safety committee or the facility's Radiological Awareness Committee. The ALARA Committee's responsibilities include making recommendations to management on methods of lowering radiation exposure levels and reducing the number of radiological releases.

\section{Evaluation}

The CEOSHP contains many entries requiring the establishment of an ALARA program at FEMP. For example, ESH 2-4, paragraph 2.0.F. states, "[The ES\&H Assurance Department] [d]evelops and maintains an effective ALARA program that crosses all ES\&H functions," and RPR 5-3, paragraph 2.1 assigns Site Management the responsibility for implementing "an aggressive ALARA program with established goals for various facility groups...." In addition, the CEOSHP specifically mandates the establishment of an "ALARA Committee, made up of senior representatives for all major facility disciplines, i.e., Environmental Safety and Health; Technology; Human Resources Administration; Site Services; and Construction and Engineering..." (RPR 5-3, paragraph 3.0.D). However, the CEOSHP sections on the ALARA Committee do not include all of the detail on this topic contained in the DOE RadCon Manual.

\section{Recommendation}

FERMCO's Site-Specific Radiological Control Manual (Section III of the CEOSHP) would be enhanced if the CEOSHP sections were revised to address all of the topics 
included in Article 138 of the DOE RadCon Manual (e.g., the functions of the committee, which include "review [of] the overall conduct of the Radiological Control Program").

\subsubsection{Worker Awareness of Radiological Conditions}

Article 126 of the RadCon Manual recommends that workers assigned duties in radiological areas be trained and qualified sufficiently to permit them to perform supplemental radiological surveys in the course of work. Examples of such surveys are self-monitoring of dose rates during High Radiation Area entries and the monitoring of tools and equipment during work in Contamination Areas. Article 127 of the DOE Manual recommends that a process be established "to obtain pertinent facts following an unusual radiological situation or at the satisfactory conclusion of a new or unusual operation involving radiological controls" and that worker participation in this process be encouraged.

\section{Evaluation}

This review of the CEOSHP identified no entries specifically corresponding to Articles 126 and 127 of the DOE RadCon Manual.

\section{Recommendation}

The value of FERMCO's Site-Specific Radiological Control Manual (Section III of the CEOSHP) would be increased by the addition of a section describing how employees assigned duties in radiological areas can actively participate in the Radiological Control Program by performing supplemental radiological surveys in the course of their work. Examples of such surveys are self-monitoring of dose rate during High Radiation Area entry and monitoring of tools and equipment used in Contamination Areas. In addition, FERMCO's manual should describe the process used to gather the relevant facts after the occurrence of an unusual radiological situation or at the completion of a new or unusual radiological operation. This section should also stress the importance of worker involvement in this process.

\subsubsection{Supervisor and Worker Accountability}

Article 121.4 of the DOE RadCon Manual recommends that managers hold workers and supervisors accountable for their radiological control performance and stipulates that such performance be assessed as part of each person's performance evaluation.

\section{Evaluation}

Although many statements throughout the CEOSHP convey FERMCO's policy of holding each worker responsible for his/her own safety (e.g., ESH 1-3, paragraph 3.0.A.) and each supervisor responsible for the safety and health of the employees working within the supervisor's purview (e.g., ESH 1-5, paragraph 3.0), and others (e.g., RPR 1-3, paragraph 1.0; RPR 5-3, paragraph 2.4) restate this policy in the context of FERMCO's Radiological Protection Program, this review of the CEOSHP identified no entries incorporating Article 121.4's recommendation that accountability for radiological control performance be made a part of each employee's performance evaluation. 


\section{Recommendation}

The Radiological Protection section of the CEOSHP would be enhanced by expanding on FERMCO's policy of holding each worker and supervisor responsible for safety and health performance to provide a personnel accountability system that includes mechanisms and criteria to evaluate an individual's radiological control performance. This system could include the development of specific job descriptions and performance standards defining radiological control expectations for FERMCO personnel as well as periodic (annual) performance evaluations of an individual's success in meeting his $\backslash$ her respective performance standard.

\subsection{Worksite Analysis}

The focus of worksite analysis is on the identification, evaluation, and control of workplace hazards at the earliest point in time. Worksite analysis is thus designed to eliminate hazards wherever possible and to control those that cannot be eliminated. Article 373 of DOE's Radiological Control Manual stresses the need for contractors to actively implement measures to ensure protection from radiological hazards; this article states, "Radiological controls should be implemented in a balanced way to ensure that protection from all workplace hazards can be implemented."

\section{Evaluation}

The CEOSHP contains several entries asserting FERMCO's intent to emphasize hazard evaluation, characterization, and safety analys is and to address perceived weaknesses in the Radiation Control Program (RPR 1-2, paragraph 1.0). The Radiological Engineering Section is assigned responsibility for leading in this. effort, and additionally for providing nuclear/radiological safety analyses (RPR 1-2, paragraph 3.0.L).

Worksite analysis is most effective when it is initiated as early as possible. This approach is reflected in FERMCO's requirement (RPR 1-2, paragraph 3.0.G) that:

The organization shall allow radiological safety involvement at the initial stages of projects onsite to ensure program requirements are taken into consideration at the design stage.

\section{Recommendation}

The CEOSHP would be strengthened by the addition of a worksite analysis section identifying the elements of FERMCO's hazard identification program in the radiological context. This section should incorporate radiological control considerations into all phases of radiological work, from the planning and design phase through task completion, and should include review of maintenance and modification plans and procedures, routine tasks, first-time activities, and non-routine or complex work activities to ensure maximum reduction of radiation exposure.

\subsubsection{Internal Assessments}

Article 134.1 of the DOE RadCon Manual requires DOE contractors to conduct assessments to periodically assess and review tine adequacy and effectiveness of their Radiological Control Program. The assessment process, which may consist of 
inspections, audits, reviews, investigations, and self-assessments, is intended to provide the necessary independent feedback to senior line managers. Article 134.1 requires that internal audits be conducted in such number and with such frequency that, over a 3-year period, all functional elements of the Radiological Control Program are assessed for program performance, applicability, content, and implementation. Internal audits of the Radiological Control Program should be performed by the Radiological Control Organization, the Quality Assurance Organization and other organizations (Article 134.1).

\section{Evaluation}

The CEOSHP contains requirements for assessments of the Radiological Control Program that closely parallel those required by DOE's RadCon Manual. For example, RPR 5-0, paragraph 3.0. A requires the performance of internal assessments of the FERMCO Radiological Protection program such that "over a 3-year period, all functional elements (of the program) are assessed for program performance, applicability, content, and implementation." In addition, RPR 5-0, paragraph 3.0.E requires monthly assessments/inspections of specific aspects of the radiological control program. These assessments/inspections are to be conducted by a member of the Radiological Department possessing at least the qualifications of a junior member of the Radiological Engineering group or of a supervisor in the Radiological Assessment group. FERMCO's Radiological Control Department is assigned the responsibility for administering the self-assessment program (RPR 5-0, paragraph 2.2.A), and the respective Department or Area Manager is responsible for ensuring that

assessment/inspection findings are "immediately addressed with short-term corrective action, where possible, and... in writing with long-term corrective actions to prevent recurrence (RPR 5-0, paragraph 2.3)."

The CEOSHP contains numerous other references to assessments of FERMCO's Radiological Protection Program. For example, ESH 2-2, paragraph 3.4.I indicates that one of the key issues to be addressed by the Radiological Protection Program at FERMCO is "ensuring that required tri-annual reviews and functional appraisals are conducted and findings expeditiously resolved," and one of the responsibilities of the ES\&H Self-Assessment Manager (EAPR 3-0, paragraph 2.0.G) is to conduct "selfassessment activities; including surveillances, walkthroughs, and audits throughout the year (all portions of the program at least once every 3 years) to identify strengths and weaknesses."

\section{Recommendation}

The CEOSHP contains requirements that parallel those in DOE's Radiological Control Manual and thus appears to meet this evaluation criteria.

\subsubsection{Review of Work in Progress}

Article 344.3 of the DOE RadCon Manual recommends that the Radiological Control Organization, in cooperation with line management, periodically review ongoing jobs to ensure that proper radiological controls are in place. For jobs for which a prejob dose estimate was made, the Manual recommends periodic monitoring of collective dose accumulation and a comparison of the results of this monitoring with estimates of dose made before the job began. If differences are identified between the prejob dose estimate and the actual collective dose accumulation, the causes of the difference should be identified and the need for corrective action to eliminate this difference should be assessed. 


\section{Evaluation}

No corresponding requirement was identified in Section III of the CEOSHP.

\section{Recommendation}

The CEOSHP would be strengthened if it included requirements for the periodic monitoring of collective dose accumulation, followed by a comparison of the results of this effort with the results of pre-job estimates of dose. This section should also describe procedures to be followed if the compared results disagree significantly.

\subsubsection{Work Activities}

Article 343.4 of the DOE RadCon Manual recommends that workers keep Radiological Control personnel informed of the status of work activities that have the potential to affect radiological conditions. Like many other articles in the DOE Manual, this article recognizes the importance of encouraging active worker participation in the facility's radiological control program.

\section{Evaluation}

Section RPR 1-2 of the CEOSHP, paragraph 3.0.F, contains a requirement mandating that the Radiological Control organization be organized in a manner that encourages "feedback from workers and line management for program improvements." This requirement thus captures some but not all of the intent of Article 343.4 of the DOE Manua 1.

\section{Recommendation}

The Radiological Protection Program section of the CEOSHP would be enhanced throughout by the addition of systems that actively encourage worker involvement in all phases of the program. It is not enough merely to state that the program encourages employee feedback; instead, systematic, formal mechanisms that will ensure that workers are a part of program activities, participate in decisionmaking, and are full partners are needed to achieve the goal of active worker participation.

\subsection{Hazard Prevention and Control}

\subsubsection{Facility Administrative Control Levels}

Article 211.1 of the RadCon Manual establishes a 2,000 mrem per year per person Administrative Control Level for all DOE activities. Contractors must obtain approval prior to allowing any person to exceed this 2,000 mrem exposure level. Article 211.2 of the Manual requires DOE contractors to go beyond the DOE Administrative Control Level by establishing a more restrictive facility Administrative Control Leve1. This Level must be set by the contractor's senior site executive based on an evaluation of historical and projected radiation exposure, workload, and mission, and must be re-evaluated annually to ensure that the control level is both challenging and achievable. No person at the facility is permitted to exceed the facility Administrative Control Level without prior approval from the contractor senior site executive. 


\section{Evaluation}

RPR 2-1, paragraph 3.0.0. of the CEOSHP establishes the FERMCO Administrative Control Level at 1,000 mrem per person per year. Although the CEOSHP (and therefore the FERMCO Administrative Control Level) is officially endorsed and approved by the contractor senior site executive (the FERMCO president), the CEOSHP does not require that the Control Level be reviewed annually to ensure that it is both challenging and achievable. Furthermore, the CEOSHP does not outline the consequences of exceeding the Control Level or integrate the Control Level into the other elements of the FERMCO Radiation Control Program. For example, the CEOSHP does not require that personnel obtain approval from the FERMCO president prior to exceeding the FERMCO Administrative Control Leve1, does not require FERMCO to obtain approval from the Assistant Secretary for Environmental Management (or designee) prior to exceeding the DOE Administrative Control Level, does not outline the relationship between the FERMCO Control Level and the Annual Limits discussed in RPR 2-1, paragraph 3.0.M, does not discuss the relationship between the FERMCO Control Level and the establishment, monitoring, and annual review of the FERMCO ALARA goals discussed in RPR 5-3, paragraphs 3.0.E through $G$, and does not mention the performance of surveys, audits, or investigations in response to personnel exposures in excess of the FERMCO Administration Control Level.

\section{Recommendation}

The CEOSHP should be made consistent with the DOE RadCon Manual by requiring an annual evaluation of the FERMCO Administrative Control Level. The CEOSHP should clearly designate the responsible individual or department for the evaluation and should indicate that the evaluation must include a review of historical and projected radiation exposure, and workloads and mission projections. The CEOSHP must also require and outline responsibilities and procedures for obtaining approval from the FERMCO president and the Assistant Secretary for Environmental Management for an individual to exceed the FERMCO and DOE Administrative Control Levels, respectively. The CEOSHP could be further enhanced by integrating the FERMCO Administrative Control Level into other elements of the radiological control program. For instance, the CEOSHP could describe how the Administrative Control Level relates to the trigger levels for investigation, corrective action, and work intervention established in RPR 2-1, paragraphs 3.0.M and $N$, and to the ALARA goal requirements established in RPR 5-3, paragraphs 3.0.E. through G.

\subsubsection{Radiological Control Areas}

Article 221 of the DOE RadCon Manual requires that personnel exiting radiological control areas (i.e., contamination areas, high contamination areas, airborne radioactivity areas, or radiological buffer areas) frisk for contamination as required by Article 338 of the RadCon Manual using equipment capable of detecting total contamination of at least the values specified in Table 2-2 of the RadCon Manual. Article 221 further requires that personnel found with detectable contamination on their skin or clothing be promptly decontaminated as described in Article 541 of the DOE RadCon Manual.

Article 541 of the DOE RadCon Manual includes among its decontamination requirements the need for contractors to establish decontamination methods for site-specific radionuclides, to establish skin contamination levels (not to exceed 100 mrem) that trigger the need for dose assessments for site-specific radionuclides, and to notify contaminated personnel of the extent of estimated dose resulting from the contamination. 


\section{Evaluation}

RPR 3-0, paragraphs 3.2.A and $C$ of the CEOSHP establish the requirement for FERMCO personnel exiting radiological control areas to frisk for contamination as required by Article 338 of the DOE Radcon Manual using equipment capable of detecting the contamination levels specified in Attachment A to RPR 3-2 of the CEOSHP (equivalent to the removable contamination detection limits established in Table 2-2 of the DOE RadCon Manual). RPR 3-0, paragraph 3.2.D of the CEOSHP requires that personnel with detectable levels of contamination be decontaminated in accordance with RPR 3-4 of the CEOSHP and Article 541 of the DOE RadCon Manual and that a record of the contamination incident be recorded and retained by the Radiological Dosimetry Manager in a centralized contamination incident file. The responsibility for FERMCO personnel to monitor themselves upon exiting radiological control areas and to report incidents of contamination to the FERMCO Radiological Control Department is established in RPR 3-2, paragraph 2.3 of the CEOSHP.

RPR 3-4 of the CEOSHP establishes FERMCO-specific personnel decontamination requirements that must be implemented in addition to those in Article 541 of the DOE RadCon Manual. Paragraphs 2.2.A and B of this section of the CEOSHP again establish the responsibility of FERMCO personnel to frisk themselves upon exiting radiological control areas and to notify the Radiological Control Department personnel upon the detection of personal contamination. In addition, paragraph 2.3 lists the related responsibilities of the Radiological Control Department personnel as "[p]rovides radiological support in the event of a personnel contamination," "[a]ssists in decontamination of personnel, if required," and "[d]ocuments personnel contamination events."

Decontamination methods for site-specific radionuclides have not, however, been established or referenced in this section nor have trigger levels for skin contamination for site-specific radionuclides been identified. Finally, this section of the CEOSHP does not address the requirement to or responsibility for notifying contaminated personnel of the estimated dose received.

\section{Recommendation}

Personnel frisking and decontamination requirements contained within the CEOSHP could be strengthened by consolidating the various paragraphs that address this topic into one clear, concise section discussing the responsibilities, requirements, and procedures for personnel frisking and decontamination. In addition, the section could be enhanced by establishing appropriate decontamination methods and skin contamination trigger levels for site-specific radionuclides.

\subsubsection{Planned Radiological Work}

\subsubsection{Incorporation of Radiological Protection in the Conduct of Work}

Article 311 of the DOE RadCon Manual requires contracters to incorporate radiological criteria into their technical requirements for the conduct of work (including construction, modifications, operations, maintenance, and decommissioning) to ensure safety and to maintain radiation exposures to ALARA. This effort is to commence in the design and planning processes of all activities. Article 312.1 assigns the contractor's line management the responsibility to ensure that maintenance and modification plans and procedures are reviewed to identify and incorporate radiological requirements. This Article further requires that the 
contractor's Radiological Control Organization provide line management with the necessary support for and concurrence of this review process.

\section{Evaluation}

The Radiological Control Principles section (RPR 1-1) of the CEOSHP addresses the need to incorporate radiological considerations into FERMCO work activities. RPR 1-1, paragraph 3.0 states that the "recommendations [provided in paragraph 3.0.A through 3.0.P] from the Radiological Safety Organization shall be incorporated in the initial stages of projects." Although this section clearly establishes the FERMCO requirement to include radiological considerations in design and planning activities, the section does not establish responsibilities or procedures for accomplishing this task nor does it clearly define the applicability of this requirement (i.e., applies to all work activities, including construction, modifications, operations, maintenance and decommissioning).

Sections RPR 1-2 and RPR 1-3 of the CEOSHP provide additional statements that address the requirement to incorporate radiological considerations into FERMCO operations. For example:

RPR 1-2, paragraph 3.0.G requires that the Radiological Control Organization "allow radiological safety involvement at the initial stages of projects onsite to ensure program requirements are taken into consideration at the design stage,"

RPR 1-2, paragraph 3.0.K states that the Radiological Engineering section is to ensure the proper "interface with construction/engineering groups onsite to incorporate radiological controls into projects, design changes, facility construction, etc." and

RPR 1-3, paragraph 3.0.E requires that the Radiological Control Manager implement the "review of operational procedures, workplans, change orders, etc., as they relate to radiological safety," and the conduct of "radiation safety analysis and/or evaluations of proposed changes in facility, process, or equipment changes."

Although these statements provide some clarification of the applicability of the requirement (i.e., RPR 1-2, paragraph 3.0.K states that the requirement applies to "projects, design changes, facility cunstruction, etc."), they confuse the issue of responsibility by assigning the responsibility to numerous groups (i.e., the Radiological Control Organization, the Radiological Engineering Section, onsite construction/engineering groups, and the Radiological Control Manager). In addition, these statements do not identify detailed methods or procedures for accomplishing the requirement to incorporate radiological concerns into all FERMCO activities.

\section{Recommendation}

The FERMCO CEOSHP would be enhanced by expanding on the existing requirement to incorporate radiological concerns into the planning and design of all FERMCO work activities. This expansion should clearly indicate that the requirement applies to construction, modifications, operations, maintenance, and decommissioning 
activities, and should address the methods and procedures to accomplish this task. In addition, the CEOSHP should clearly assign responsibilities for implementing the requirement and address required coordination and integration where multiple organizations share responsibilities.

\subsubsection{Trigger Levels for Formal Radiological Review}

Article 312.3 of the RadCon Manual requires DOE contractors to establish trigger levels (for estimated individual or collective dose, predicted airborne radioactivity concentration, areas where dose rates exceed 1 rem/hour and potential radioactive releases) requiring formal raciological review of non-routine or complex work activities. If tasks are identified that have the potential to exceed the established trigger levels, contractors shall conduct a formal, documented radiological or ALARA review of the task in accordance with Article 312.4 .

\section{Evaluation}

Section RPR 5-3, paragraph 3.0.N of the CEOSHP establishes FERMCO trigger levels as required by Article 312.3 of the RadCon Manual and requires the performance of a "formal ALARA review" of activities when these levels are or have the potential to be exceeded. This section, however, does not assign the responsibilities for or define the content of "formal ALARA reviews." Appendix D of RPR 5-3 provides a "Procedure Review ALARA Consideration List" that includes some of the required review elements of Article 312.4 of the DOE RadCon Manual; however, this 1ist is not referenced in the Responsibilities or Requirements elements of Section RPR 5-3 and its purpose and relationship with the "formal ALARA review" are not identified.

\section{Recommendation}

The usefulness of the trigger levels established in RPR 5-3, paragraph 3.0.N of the CEOSHP would be strengthened by clearly defining the content of and responsibility for the performance of the formal ALARA review in accordance with Article 312.4 of the DOE RadCon Manual. In addition, the CEOSHP should clarify the requirements and function of the "Procedure Review ALARA Consideration List."

\subsubsection{Documentation of Radiological Protection in Job Plans and Procedures}

Article 312.5 of the DOE RadCon Manual requires that contractors document in job plans, procedures, or work packages, any radiological requirements that evolve from a radiological review of tasks that have the potential to exceed established "trigger levels."

\section{Evaluation}

As discussed above in item 4.3.3.2, FERMCO's trigger levels and its requirements for related ALARA reviews are established in RPR 5-3, paragraph 3.0.N of the CEOSHP. This section of the CEOSHP, however, does not discuss the need to document the findings or resultant radiological requirements of the ALARA review in job plans, procedures, or work packages. RPR 3-1, paragraph 3.0.A of the CEOSHP does require that "radiological requirements" be documented in a "Radiation Work Permit procedure," but the application of this requirement is limited to activities $s_{\text {i... }}$ entry into high or very high radiation areas, entry into high contamination areas, entry into airborne radioactivity areas, etc., and does not establish a relationship between the Radiation Work Permit procedure and the trigger levels or ALARA reviews. 


\section{Recommendation}

The radiological protection section of the CEOSHP would be strengthened by the addition of a clear statement that radiological requirements identified in formal ALARA reviews in respective job plans, procedures, or work packages must be documented. This statement could be an extension of the CEOSHP's existing requirement for Radiation Work Permit procedures.

\subsubsection{ALARA Committee Reviews of Activities}

Article 313.3 of the DOE RadCon M.nis? recommends that the contractor's ALARA Committee review and approve pla ining for radiological activities that are infrequently conducted c: represent first-time operations.

\section{Evaluation}

The CEOSHP does not contain entries requiring the ALARA Committee to review the planning for infrequent or first-time activities.

\section{Recommendation}

FERMCO's Site-Specific Radiological Control Manual (Section III of the CEOSHP) would be enhanced by the addition of requirements stating that the planning process for infrequent and first-time activities include the review and approval of the ALARA Committee.

\subsubsection{Exposure Controls}

\subsubsection{Minimization of Internal Exposure}

Article 316 of the DOE RadCon Manual establishes a "hierarchy of controls" that contractors should use in the minimization and control of internal exposures to radiation. The use of engineering controls is the primary method recommended for minimizing airborne radioactivity and internal exposures of workers. The second tier of control measures in the hierarchy is "administrative controls, "which include access restrictions and the use of specific work practices designed to minimize airborne contamination. If the potential for airborne radioactivity still exists after engineering and administrative controls have been applied, then respiratory protection should be used to limit the internal exposures of workers.

\section{Evaluation}

Section RPR 4-4, paragraph 1.0, of the CEOSHP states that:

"It is FERMCO policy that... engineering and administrative controls to reduce the potential for internal exposure are evaluated before allowing personnel, with or without respiratory protection, to enter areas with occupationallyderived airborne radioactivity. Engineering controls will be used to the extent practical to minimize airborne radioactivity to a target level of 0.1 Derived Air Concentration (DAC). Respiratory protection will je used for radiological purposes if engineering and administrative controls are unable to reduce airborne activity levels below 1 DAC." 
Although this statement follows the "hierarchy of controls" concept reflected in Article 316 of the DOE RadCon Manual, other portions of Section III of the CEOSHP do not clearly reflect this hierarchy. For example:

RPR 1-1, paragraph 1.0 states that "It is FERMCO policy to practice engineered and administrative controls where possible to assure that radiation levels are controlled and radioactive material is contained for personnel protection."

RPR 1-1, paragraph 3.0 1ists among recommended radiological controls a variety of engineering and administrative controls, as well as respiratory protective equipment, without establishing a preferred hierarchy of application for these controls.

RPR 2-4, paragraph 1.0 states that "It is FERMCO policy to implement a system of engineered and administrative controls to... [maintain] radiation exposure to personnel As Low As Reasonably Achievable (ALARA)."

These statements do not clearly reflect the preference for engineering controls, followed by administrative controls, with the use of respiratory protective equipment only as a last resort. Because the hierarchy and its application are often misinterpreted, references to the use of controls from various tiers of the hierarchy should clearly state the order in which they should be applied.

\section{Recommendation}

Section III of the CEOSHP would be strengthened if it included clear statements of the hierarchy whenever controls drawn from several tiers of the hierarchy are being discussed.

\subsubsection{Radiological Work Permits}

Articles 322 and 323 of the DOE RadCon Manual require that contractors establish a radiation work permit (RWP) system to ensure adequate planning and control of specified work activities such as entry into High and Very High Radiation Areas, entry into High Contamination Areas, and entry into Airborne Radioactivity Areas. Article 321 describes the required elements of the contractor's RWP program and Article 322, paragraphs 3 and 4 establish time limits for RWPs: job-specific RWPs shall remain in effect only for the duration of the job, and general RWPs shall not be approved for periods longer than 1 year.

\section{Evaluation}

RPR 3-1 of the CEOSHP addresses FERMCO's responsibilities and requirements related to the use of RWPs. Attachment $A$ to this section $i$ 'antifies the items to be included in the RWP, as described in Article 321 of the DOE RadCon Manual, and RPR 3-1, paragraph 3.0 establishes the RWP preparation requirements and criteria in accordance with Article 323 of that Manual. RPR 3-1, paragraph 3.0.K establishes that RWPs shall be terminated "at the completion of the...work covered, or the expiration date, whichever comes first," but this section does not address the provisions or time limits for general RWPS. 


\section{Recommendation}

The CEOSHP would be enhanced by establishing that general RWPs shall not be approved for periods longer than 1 year.

\subsubsection{Personal Protective Equipment}

Article 325 and Appendix $3 C$ of the DOE RadCon Manual establish personal protective equipment (PPE) and clothing criteria for DOE contractors. These criteria include requirements for determining when protective clothing should be worn, selecting personal protective equipment and clothing, establishing clothing dress-out areas, and posting instructions for donning and removing protective clothing.

\section{Evaluation}

Section RPR 3-3 of the CEOSHP establishes FERMCO's personal protective equipment and clothing requirements consistent with the criteria of Article 325 and Appendix $3 C$ of the DOE RadCon Manual. In some cases, this section of the CEOSHP incorporates the required elements of the DOE RadCon Manual by reference. For example, RPR 3-3, paragraph 3.0.B of the CEOSHP requires that the FERMCO "Radiological Control Department... use Appendix $3 C$ of the RadCon Mancial as a guide for protective clothing selection."

\section{Recommendation}

By using a combination of cross-references and a list of specific requirements that parallel those of the RadCon Manual, the CEOSHP appears to fulfill the Personal Protective Equipment and Clothing requirements of Article 325 and Appendix $3 C$ of that Manual.

\subsubsection{Access Control Measures}

Chapter 3, Part 3 of the DOE RadCon Manual establishes contractor access control requirements for radiological areas such as controlled areas (Article 331); radiological buffer areas (Article 332); radioactive material areas (Article 333); radiation, high radiation and very high radiation areas (Article 334); and contamination, high contamination and airborne radioactivity areas (Article 335 ). In addition, Article 336 of the DOE RadCon Manual requires that contractors develop site procedures that identify area entry requirements and access restrictions for site visitors.

\section{Evaluation}

RPR 5-3 (ALARA Program), Attachment C, paragraph 2 establishes FERMCO Radiation Area Access controls as follows:

"Personnel access to controlled areas should normally be through points, which serve as a buffer between uncontrolled areas and the source of the potential exposure. Transition areas can provide space for used protection equipment, personnel survey equipment, and personnel exit surveys. Room must also be provided for stepoff pads and for perconnel entering or exiting from the controlled area." 
RPR 5-2 (Radiological Training for General Employees, Radiological Workers, Visitors and Instructors) provides additional access control considerations in paragraph 3.1.D. For example:

\begin{abstract}
"Radiological Worker I training is required for radiological workers whose job assignments require access to Controlied Areas, Radiological Buffer Areas, and Radiation Areas;"

"Radiological Worker I qualified personnel may access Contamination Areas only with a Radiological Worker II qualified escort;" and,

"Radiological Worker II training is required for the radiological workers whose job assignments involve unescorted entry to High and Very High Radiation Areas, Contamination Areas, High Contamination Areas and Airborne Radioactivity Areas."
\end{abstract}

The statements in RPR 5-2 and 5-3 do not, however, address each of the requirements of Chapter 3, Part 3 of the RadCon Manual and therefore do not constitute an integrated and comprehensive program for radiological access controls.

\title{
Recommendation
}

The radiological control portion of the CEOSHP would be enhanced by the addition of a section establishing FERMCO's access control requirements. This section needs to address the requirements of and parallel Chapter 3, Part 3 of the DOE RadCon Manual as well as the entry control requirements of DOE 5480.11(9)(1).

\subsubsection{Prioritization System}

Article 134.3 of the DOE RadCon Manual states that managers should encourage employees to view even minor deficiencies as opportunities for further improvement of the radiological control program. This Article also recommends that contractors establish a prioritization system for resolving deficiencies.

\section{Evaluation}

RPR 5-0, paragraph 2.3 of Section III of the CEOSHP requires FERMCO site management to ensure that "assessment/inspection findings are immediately addressed with shortterm corrective action, where possible," and that "findings . . . with long-term corrective actions to prevent recurrence" are also addressed. In addition, management nust require "a realistic and achievable, but timely corrective action schedule." No other entries in Section III of the CEOSHP address prioritization systems for resolving deficiencies in the radiological control program.

\section{Recommendation}

The Site-Specific Radiological Control Manual wnuld be strengthened by including specific requirements for a corrective action/deficiencies prioritization system for the radiological control program.

\subsubsection{Mariagement Feedback}

Article 134.5 of the DOE RadCon Manual recommends that management be provided, at frequent intervals, with feedback from assessments, root cause analyses, and 
corrective action status reports that pertain to the contractor's radiological control program.

\section{Evaluation}

Section III of the CEOSHP, which is FERMCO's Site-Specific Radiological Control Manual, requires that "internal self-assessments, . . . inspections, and appraisals of radiological activities [be conducted] on a periodic basis" (RPR 5-0, paragraph 1.0). In addition, the CEOSHP requires that such assessment activities be conducted "in accordance with established DOE requirements" (RPR 5-0, paragraph 1.0). Other entries describe management review of the results of assessments as follows:

RPR 5-0, paragraph 2.0.B states that site management "reviews, approves, and supports self assessment plans, reports, findings, and corrective actions as necessary."

RPR 5-0, paragraph 2.2. B requires that the Radiological Control Department "perform . . trend analysis of root causes to determine system failures."

However, although FERMCO's Site-Specific Radiological Control Manual contains several entries that reflect an awareness of the importance of root cause analysis, assessments of the radiological program, and management review of reports, it does not include a recommendation for frequent management review of feedback from all relevant sources of program information.

\section{Recomendation}

FERMCO's Site-Specific Radiological Control Manual would be strengthened if it included a statement that parallels Article 134.5 of the DOE RadCon Manual.

\subsubsection{Stop Work Authority}

Article 345 of the RadCon Manual identifies criteria for "Stop Radiological Work Authority." This authority and responsibility is given to Radiological Control Technicians and their supervisors, line supervision, and any worker through their supervisor. These criteria estabiish the conditions under which a "stop work" order is justifiable and under what conditions radiological work can be resumed after such an order is issued.

\section{Evaluation}

RPR 1-3, paragraph 3.0.C of the CEOSHP addresses "Stop Radiological Work Authority" by restating the requirements of Article 345 of the RadCon Manua1. RPR 1-3, paragraphs 2.4, 2.5, and 2.6 ident ify the "Responsibilities" of the Radiological Control Manager, onsite supervisor, and FERMCO personnel, respectively, but do not address their responsibility to stop unsafe radiological work or to approve the resumption of operations after the implementation of radiological control measures.

\section{Recomnendption}

The user-friendliness of the CEOSHP would be enhanced by including appropriate manager, supervisor and employee stop work responsibilities in the respective Responsibilities paragraphs. 


$$
\begin{aligned}
& \text { 震 }
\end{aligned}
$$

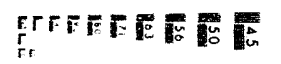

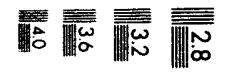

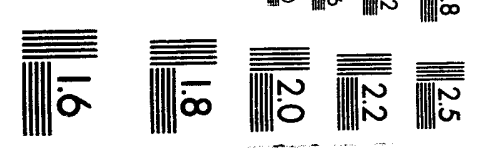



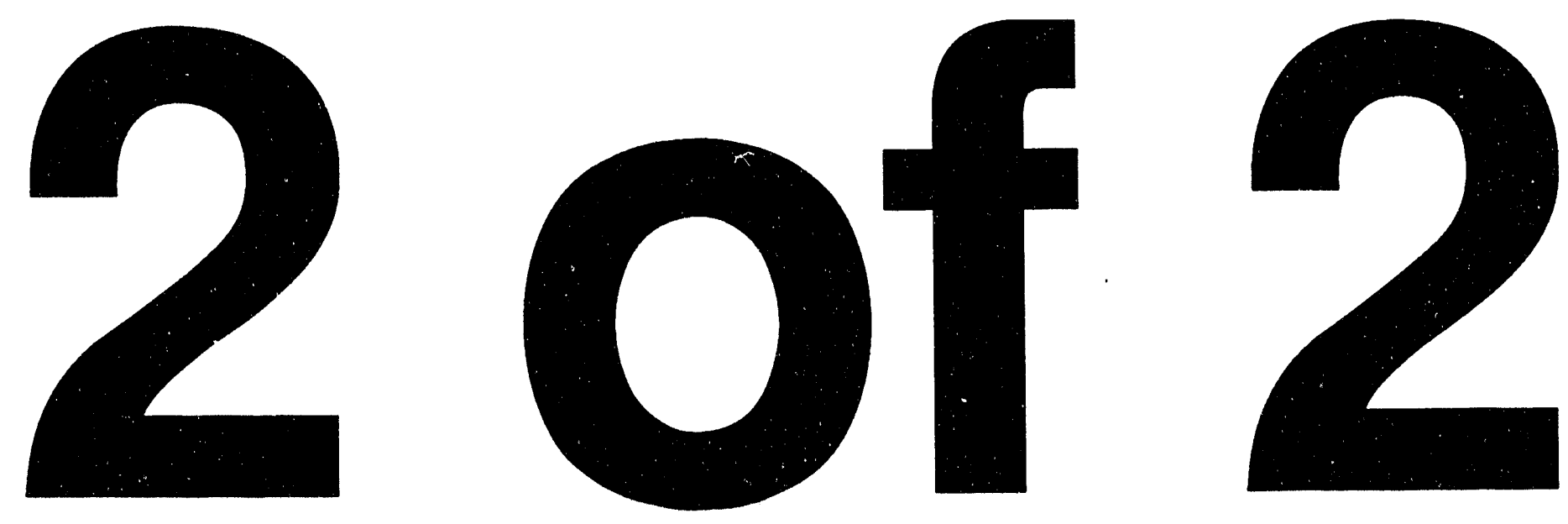


\subsubsection{Radioactive Waste Minimization}

Article 442 of the DOE RadCon Manual requires contractors to develop and implement a radioactive waste minimization program. The purpose of this program is to reduce the amount of radioactive waste generated and to reduce the spread of contamination from Contamination, High Contamination, and Airborne Radioactivity Areas. Article 442 also recommends, among other things, that a number of practices be instituted to support waste minimization, including restrictions on the amounts of radioactive and otherwise hazardous materials entering Radiological Buffer Areas, substitution of recyclable or burnable items for disposable ones, segregation of known uncontaminated from potentially contaminated waste, and training of personnel in the importance of waste minimization.

\section{Evaluation}

The CEOSHP contains a number of entries reflecting FERMCO's awareness of the importance of reducing the spread of radiological contamination. For example, RPR 1-1, paragraph 3.0.A., states that "Equipment at the FEMP site shall be engineered to eliminate or minimize leakage of radiation or the spread of contamination," and RPR 3-.2, paragraph 3.1.B., states that "Engineering controls which minimize the spread of contamination and the generation of airborne radioactivity must be used to the fullest practical extent when work is performed in High Contamination and Airborne Radioactivity Areas...." However, FERMCO's SiteSpecific Radiological Control Manual (Section III of the CEOSHP) does not contain requirements mandating the development and implementation of a Waste Minimization program. In addition, Section III does not contain cross-references incorporating Article 442 of the DOE Manual.

\section{Recommendation}

FERMCO's Site-Specific Radiological Control Manual would be strengthened if it included and supplemented the waste minimization requirements and recommendations of Article 442 of the DOE RadCon Manual.

\subsubsection{Radiological Monitoring and Surveys}

Chapter 5, Parts 5 and 6 of the DOE RadCon Manual establish the requirements for radiological monitoring and surveys and for radiological instrumentation and calibration. Part 5 specifically addresses radiation exposure surveys, area radiation monitors, contamination surveys, and airborne radioactivity monitoring, while Part 6 covers inspection, calibration, performance testing, and maintenance of radiological instruments and the activities of calibration facilities.

\section{Evaluation}

Section III of the CEOSHP (FERMCO's Site-Specific Radiological Control Manual) contains detailed requirements for radiological monitoring and surveys and specifically mandates that such activities be performed in accordance with the requirements of the DOE RadCon Manual. For example, RPR 3-0, paragraph 3.4.A., states that, "Routine radiological surveys include radiation surveys, contamination surveys, and airborne radioactivity monitoring. All routine radiological surveys will be performed in accordance with Article 551 [of the DOE RadCon Manual] requirements." 
Section III of the CEOSHP also contains detailed sections on Instrument Requirements (RPR 4-2, paragraph 3.1), Instrument Calibration (RPR 4-2, paragraph 3.2), and Instrumentation Maintenance and Operational Testing (RPR 4-2, paragraph 3.3), and these sections contain requirements that are consistent with, and in some cases more detailed than, those included in Part 6 of the DOE RadCon Manual.

\section{Recommendation}

FERMCO's Site-Specific Radiological Control Manual appears to be consistent with the DOE RadCon Manual in the area of radiological monitoring and surveys.

\subsection{Training}

\subsubsection{Pre-Job Briefings}

Article 324.1 of the DOE RadCon Manuai recommends that contractors hold pre-job briefings with employees before work begins on a project that is anticipated to exceed established "trigger levels" requiring formal radiological review of non-routine or complex work activities. These established trigger levels are to appear in the mandated Site-Specific Radiological Control Manual (Article 312.3).

Articles 324.2 and 5 of the DOE RadCon Manual provide additional recommended criteria for the pre-job briefing, such as the content of the briefing, who should conduct the briefing, who should attend the briefing, and what aspects of the briefing should be documented.

\section{Evaluation}

The CEOSHP addresses pre-job briefings in connection with the Radiation Work Permit (RWP) program (RPR 3-1, paragraph 3.E.). This paragraph states that pre-job briefings shall be conducted "in accordance with Article 324 of the RadCon Manual." Section III of the CEOSHP, which is FERMCO's Site-Specific Radiological Control Manual, thus incorporates by reference the relevant Article of the DOE RadCon Manual, an approach that is specifically endorsed by Article 114 of that Manual.

However, the pre-job briefing statement appearing in the CEOSHP indicates that only the "individuals who will perform work" covered under the RWP are to be given the pre-job briefing, while the RadCon Manual (Article 324.4) recommends that other personnel who may not be participating directly in the job, such as Radiological Control personnel and representatives from involved support organizations, also attend the briefing. In addition, the CEOSHP does not specify who is responsible for conducting the pre-job briefing.

\section{Recommendation}

The Radiological Control Program section of the CEOSHP would be strengthened by adding specific cross-references that incorporate all of the sections of the DOE RadCon Manual that pertain to pre-job briefings. Alternatively, such a section could be developed by FERMCO and be included in Section III of the CEOSHP. Such a section could be expanded upon as necessary to include site-specific requirements.

\subsubsection{Standard Training}

Chapter 6 of the DOE RadCon Manual is devoted to the training and qualifications of personnel entering or working on DOE sites. Its purpose is to ensure that such 
personnel have the training to work safely in and around radiological areas and to maintain their individual radiation exposure and the radiation exposures of others to levels as low as reasonably achievable. To achieve this goal, DOE requires the use of standardized core course training materials for General Employee Radiological Training, Radiological Worker I and II training, and Radiological Control Technician training. Successful completion of these standardized courses at any one site is to be recognized by other DOE sites. Training for each level of employee is discussed below.

\subsubsection{General Employee Radiological Training}

Article 621 of the DOE RadCon Manual requires General Employee Radiological training for personnel who may routinely enter the Controlled Area and encounter radiological barriers, postings or radioactive materials. This training is to be successfuliy completed before personnel are potentially exposed to radiation on the job. Successful completion of this training is to be demonstrated through written examinations. DOE recommends General Employee Radiological Training for all employees, but DOE 5480.11(9)(0)(1) requires that "al1 occupational workers who may enter a controlled area... shall receive an orientation in radiation safety...prior to potential exposure to radiation at that facility."

General Employee Radiological Training is to include the standardized core course training material, supplemented by site-specific information, such as site-specific radiation types, alarm responses, and policies (Article 621.2).

Article 613.3 of the DOE RadCon Manual requires General Employee Radiological Training to be completed every 2 years and recognizes that retraining may be necessary before the expiration of the 2-year period, particularly if changes have occurred to the program that need to be addressed in the training.

\section{Evaluation}

The CEOSHP contains many provisions reflecting FERMCO's recognition of the importance of training for employees potentially exposed to radiation. For example, RPR 5-2, paragraph 1.0 states that "all persons entering the controlled area [are to] be trained in the aspects of radiation protection to a level commensurate with the potential for exposure to radiation and radioactive materials." In addition, RPR 5-2, paragraph 2.2 specifies that FERMCO management is responsible for ensuring that the level of radiological training required is in fact provided.

More specifically, RPR 5-2, paragraph 3.1, states that general employee training must meet the requirements for General Employee Radiological Training appearing in the RadCon Manual (Articles 612, 613, and 621 in particular). RPR 5-2, paragraph 3.1.B, states that General Employee Radiological training is to include both standardized core course training and site-specific training, and is to be conducted in accordance with the requirements of Article 612 of the DOE Manual. RPR 5-2, paragraph 3.1.D establishes that "General Employee Radioloyical training is required for all site personnel who enter the FEMP and may encounter radiological barriers, postings, or radioactive materials."

Other sections of the RadCon Manual are also specifically cross-referenced in the CEOSHP. For example, RPR 5-2, paragraph 3.1.C states that "A11 personne1, other than designated visitors, who enter the security area, shall receive General Employee Radiological Training in accordance with Article 621 [of the DOE RadCon 
Manual]," and this paragraph also contains requirements for retraining and successful completion of courses that parallel those in the RadCon Manual.

\section{Recommendation}

Because Section III of the CEOSHP, which is FERMCO's Site-Specific Radiological Control Manual, specifically incorporates by reference all relevant articles of the DOE RadCon Manual, it appears to fulfill a17 of the General Employee Radiological training requirements required by the DOE Manual and DOE 5480.11(9)(0)(1).

\subsubsection{Radiological Worker I and II Training}

Articles 631, 632, and 633 of the DOE RadCon Manual and paragraph (9)(0)(1) of DOE 5480.11 identify training requirements for radiological workers. Workers in the Radiological Worker I category must receive the training needed to allow them to enter Radiological Buffer Areas and Radiation Areas without a qualified escort. Workers in the Radiological Worker II category must be trained to enable these workers to safely carry out their job assignments, which involve entry into High and Very High Radiation Areas, Contamination Areas, High Contamination Areas, and Airborne Radioactive Areas.

The training for both Radiological Workers I and II must use DOE standardized core course training materials and, in addition, must emphasize site-specific information. Workers are permitted to challenge Radiological Worker I or II standardized core knowledge requirements by passing a comprehensive examination. If a worker is unsuccessful in his/her attempt to "challenge out" of the examination, he or she must successfully take and complete the entire standardized core Radiological Worker I or II training.

The DOE RadCon Manual mandates (Article 613.4) Radiological Worker I and II retraining every 2 years. Refresher training is required in the alternate year when retraining is not performed.

\section{Evaluation}

The CEOSHP imposes the same policy and management responsibilities for Radiological Worker I and II training as for General Employee Radiological Training (see RPR 5-2). In addition, RPR 5-2, paragraph 3.1 states that training for radiological workers must meet the applicable requirements of the DOE RadCon Manual and specifically incorporates Articles 612, 613,631, 632, and 633 of that Manual by reference. By incorporating Article 613 of the RadCon Manual, the CEOSHP addresses the necessary retraining/refresher requirements for radiological workers. Paragraph 3.1 , however, does not specifically incorporate the requirements of DOE $5480.11(9)(0)(1)$.

\section{Recommendation}

The CEOSHP appears to fulfill the requirements of the DOE RadCon Manual as these pertain to Radiological Worker I and II training; however, it would be enhanced by requiring that radiological training also meet the requirements of paragraph (9) (0)(1) of DOE 5480.11 . 


\subsubsection{Radiological Control Technician Training}

Radiological Control Technicians perform the functions of assisting and guiding workers in the radiological aspects of the job. Their training and qualifications are directed toward routine operations and focus on the recognition and handling of situations under both normal and changing radiological conditions.

The DOE RadCon Manual establishes entry-level prerequisites for these technicians to ensure that they meet standards for physical condition and education (see Articles $612,613,614$, and 615). Radiological Control Technician training must use the standardized core course training materials and, in addition, should emphasize sitespecific information. Written examinations are to be used to demonstrate satisfactory completion of theoretical and classroom material. An Oral Examination Board is to determine the qualification of candidates for Radiological Control Technician positions (Articles 641, 642, and 643).

Qualification Standards are also identified for Radiological Control Technicians. These standards define the requirements for demonstrating the completion of training and are derived from the standardized core course, site-specific qualification elements, and on-the-job training. Radiological Control Technician qualification consists of the standardized core course training material, on-the-job training, and passing both a final comprehensive, written examination and final Oral Examination Board (Article 642).

Following Oral Examination Board qualification, these technicians begin a 2-year cycle of continuing training, which is required for re-qualification. Completion of practical training, a comprehensive written examination, and a final oral Examination Board is required by the DOE for every re-qualification (Article 643).

\section{Evaluation}

The CEOSHP contains extensive requirements for the training of Radiological Control Technicians, and RPR 5-1, paragraph 3.0.A specifically states that FERMCO will meet all applicable requirements for Radiological Control Technician training in Articles 611 through 615 and 641 through 645 of the DOE RadCon Manual.

In addition, the CEOSHP contains requirements that address subcontracted Radiological Control Technicians (RPR 5-1, paragraph 3.0.H) and Radiological Control Technician Supervisors (RPR 5-1, paragraph 3.0.I) that also parallel and specifically incorporate by reference Articles 644 and 645 of the RadCon Manual, respectively.

\section{Recommendation}

The CEOSHP appears to fulfill the requirements of the DOE RadCon Manual as these pertain to Radiological Control Technician training.

\subsubsection{Site-Specific Training of Employees}

Article 612.3 of the DOE RadCon Manual requires General Employee Radiological Training, Radiological Worker I and II Training, and Radiological Control Technician Training to include site-specific as well as standardized core course training. Site-specific training is to address those topics that may be somewhat unique to a particular site, such as site-specific radiation types, alarm responses, and policies. The requirements for site-specific information is addressed for General 
Employee Radiological training in Article 621.2, for Radiological Worker I and II training in Articles 632.2 and 633.2, respectively, and for Radiological Control Technician training in Article 642.2. In addition, for both Radiological Worker I and II training, Articles 632.3 and 633.2 of the RadCon Manual identify the minimum site-specific practical factors that the respective training should encompass.

\section{Evaluation}

RPR 5-2, paragraph 3.1 of the CEOSHP addresses the issue of site-specific training by mandating that radiological training for General Employees, Radiological Workers (I and II), and Radiological Control personnel meet the requirements of the respective Articles in the DOE RadCon Manual. The CEOSHP specifically crossreferences the pertinent RadCon Manual Articles.

\section{Recommendation}

Section III of the CEOSHP specifically incorporates by reference all relevant articles of the DOE RadCon Manual that apply to site-specific training. However, this section does not describe what additions, lessons learned, or changes in requirements FERMCO has added to its training to make it site-specific. FERMCO's Site-Specific Radiological Control Program would be substantially enhanced by the addition of such material.

\subsubsection{Refresher Training and Retraining}

Articles 613.3 and 613.4 of the DOE RadCon Manual address the requirements for retraining and refresher training applicable to General Employees and Radiological Workers (both I and II). Article 613.3 of the RadCon Manual specifies that General Employee Radiological Training is to be completed every 2 years. In the alternate year when full retraining is not administered, the DOE Manual recommends that the latest General Employee Radiological Training handbook be distributed for selfstudy. For Radiological Workers I and II, retraining is to be completed every 2 years. In the alternate year when retraining is not performed, refresher training is to be completed (Article 613.4).

\section{Evaluation}

RPR 5-2, paragraph 3.0.B. of the CEOSHP addresses the issue of retraining and refresher training by mandating that the "Requirements of Article 613

including...retraining frequency...will be adhered to."

\section{Recommendation}

This section of the CEOSHP appears to meet the requirements of the DOE RadCon Manual.

\subsubsection{Respiratory Protection Training}

Article 531 of the DOE RadCon Manual identifies the requirements of the facility's respiratory protection program. These requirements must be addressed as part of the training for radiological workers (Article 613.7). 


\section{Evaluation}

Section III of the CEOSHP, which is FERMCO's Site-Specific Radiological Control Manual, incorporates Article 613 of the DOE RadCon Manual into the CEOSHP by reference. This Article (613.7) specifically requires such training.

\section{Recommendation}

This section of the CEOSHP appears to fulfill the requirements of Article 613 in this regard.

\subsubsection{Visitor Radiological Orientation}

Article 622 of the DOE RadCon Manual identifies the topics that should be included in a radiological safety orientation for visitors who enter a Controlled Area. Criteria are also included detailing how this orientation information can be communicated (Article 622.2), what orientation records are to be maintained (Article $622.3)$, and the orientation required for continuously escorted individuals or groups (Article 622.4).

\section{Evaluation}

RPR 5-2, paragraph 3.4.D of the CEOSHP states that all visitors must receive Visitor Orientation that accords with Article 622 of the DOE RadCon Manual.

\section{Recommendation}

This portion of the CEOSHP appears to fulfill the requirements of the DOE RadCon Manual with respect to visitor orientation.

\subsubsection{Other Radiological Training}

Part 5 of Chapter 6 of the DOE RadCon Manual identifies radiological training requirements for other categories of personnel, such as Line Managers (DOE and contractors)(Article 651); technical support personnel (engineers, schedulers, procedure writers) (Article 652); planners (Article 653); Radiological Control technical staff and management (Article 654); radiographers and radiation-generating device operators (Article 655); emergency response personnel (Article 656); and tour groups, visiting dignitaries, scientists, and specialists (Article 657).

In addition, the RadCon Manual recommends that additional training be provided for different types of facilities, i.e., plutonium facilities (Article 661), uranium facilities (Article 662), tritium facilities (Article 663), and accelerator facilities (Article 664). This facility-specific training is supplemental to the standardized core training requirements.

\section{Evaluation}

RPR 5-2, paragraph 3.1.E. of the CEOSHP addresses the recommended radiological training for each of these categories of personnel as follows:

Training for special groups such as managers, engineers, planners, offsite emergency response personnel, and tour groups shall be given in accordance with the requirements of the DOE RadCon Manual. 
RPR 5-2, paragraph 3.1.B requires compliance with Article 662 of the DOE RadCon Manual and indicates that Articles 661, 663, and 664 (training requirements for plutoniuin, tritium, and accelerator facilities, respectively) do not apply to the FEMP site.

\section{Recommendation}

This section of the CEOSHP appears to fulfill the training requirements of Articles 651 through 657 and 661 of the DOE RadCon Manual.

\subsubsection{Maintenance of Training Records}

Article 725 of the DOE RadCon Manual contains requirements for the maintenance and retention of training and qualification records in radiological control. These records are to be readily available to first-line supervision and management of involved personnel. In addition to demonstrating that a person has received the information necessary to perform a respective work assignment in a safe manner, these records aid management in making work assignments.

Article 725.4 lists the types of training for which records are to be maintained. These are:
a. General employee radiological training
b. Radiological worker training (both I and II)
c. Periodic retraining
d. Respiratory protection training
e. Training of radiological control personnel
f. Instructor training
g. Qualifications for special tests or operations
h. Orientation and training of visitors
i. Training of emergency response personnel.

Article 725.3 of the RadCon Manual identifies the minimum criteria that personnel training records must include. The RadCon Manual also requires certain instructional materials to be maintained; these are identified in Article 725.5.

Article 613.6 of the RadCon Manual addresses verification of the effectiveness of radiological control training.

\section{Evaluation}

The CEOSHP incorporates Article 725 of the RadCon Manual by reference, using a twostep process, i.e., by incorporating Article 613 of that Manual, which mandates adherence to Article 725.

\section{Recommendation}

The CEOSHP appears to fulfill all training recordkeeping and maintenance requirements of the DOE RadCon Manual. 
Appendix A

EVALUATION ELEMENTS 


\section{APPENDIX A \\ EVALUATION ELEMENTS \\ FOR \\ OCCUPATIONAL SAFETY AND HEALTH, \\ ENVIRONMENTAL PROTECTION, AND \\ RADIOLOGICAL PROTECTION}

2.0 OCCUPATIONAL SAFETY AND HEALTH [reference: DOE 5483.XX, "OCCUPATIOMAL

SAFETY AND HEALTH PROGRAM FOR DOE CONTRACTOR EMPLOYEES, " dated 11-12-93]

\subsection{Management Commitment and Employee Involvement}

\subsubsection{Management Commitment}

2.1.1.1 Written OSH Policy Statement

III.2.a.(1)

2.1.1.2 Written Program, Policies and

III.2.a.(6)(b)

Procedures

2.1.1.3 Active Management Involvement

III.2.a.(1)

2.1.1.4 OSH Professional Staff Qualifications

III.2.a.(2)

2.1.1.5 OSH Program Planning and Budgeting

III.2.a.(3), III.2.a.(5)

2.1.1.6 Contractor Compliance with DOEPrescribed OSH Standards

4.a, I.2, 10.d.(1)

2.1.1.7 Subcontractor Compliance with DOEPrescribed OSH Standards

10.d.(2)(j), I.2

2.1.1.8 Host/Tenant OSH Responsibilities

III.2.a.(7)

\subsubsection{Employee Involvement}

2.1.2.1 OSH Responsibilities and Personnel Accountability

III.2.a.(8)(a)

2.1.2.2 Position Descriptions and Personnel Evaluation Plans

III.2.a.(8)(a)

2.1.2.3 OSH Program Promotion and Employee Involvement

III.2.a.(8)(b)

2.1.2.4 Safety and Health Committees

III.2.a.(9)

2.1.2.5 Employee Rights

IV.7, V.6.c, I.8.b. (8)

I.8.d, III.2.a.(9) (b) (5)

\subsection{Norksite Analysis}

2.2.1 Analysis of Planned, New, or Modified III.2.b.(1)(a), IV.3.a.(1) Facilities, Processes or Equipment 


\section{Appendix A Evaluation Elements (continued)}

2.2.2 Hazard Analyses by Front-Line Employees IV.3.a.(1)(a) and Supervisors

2.2.3 Annual Compliance Inspections

IV.3.a.(2)(a)

2.2.4 Routine Compliance Inspections

IV.3.a.(2)(b)

2.2.5 Analyze OSH Performance

III.2.b. (3)

2.2.6 Recording and Reporting Work-Related Incidents

10.d.(2)(h), II.3.b.(1), II.3.b.(2), II.5

\subsection{Hazard Prevention and Control}

2.3.1 Proper Design of Facilities and Equipment

III.2.c, IV.3.a.(1)

2.3.2 Hazard Control Hierarchy

III.2.c. (2)

2.3.3 Personal Protective Equipment (PPE)

10.d.(2)(f)

2.3.4 Maintain Hazard Abatement Program

2.3.4.1 Hazard Abatement Priorities

V.4.b

2.3.4.2 Interim Protective Measures

V.3.a, V.5.b.(7)

2.3.4.3 Management of Hazard Abatement

V.5 Activities

2.3.4.4 DOE Approval of Certain Abatement Activities

V.6

2.3.5 Restart Procedures

V.3.b

2.3.6 Provision of Physician and Medical Care

III.2.c. (2)(c), II.9

2.3.7 Emergency Training and Drills

III.2.c. (1)

2.4 Occupational Safety and Health Training

VI.2, III.2.d., VI

2.4.1 General Employee OSH Training

VI.2

2.4.2 Manager OSH Training

VI.3.a

2.4.3 Supervisor OSH Training

VI.3.b

2.4.4 Employee Representative OSH Training

VI.3.C

2.4.5 Non-Supervisory Employee OSH Training

VI.3.d

2.4.6 OSH Professional Training

VI.3.e 
Appendix A Evaluation Elements (continued)

2.4.7 Visitor OSH Training VI.4

$\begin{array}{lll}2.4 .8 & \text { Recordkeeping VI.5 }\end{array}$

3.0 ENVIROMANTAL PROTECTION [reference "Performance Objectives \& Criteria for DOE Environmental Audits" of January 1994]

3.1 Management Commitment and Employee Involvement

3.1.1 Management Commitment

3.1.1.1 Environmental Policy

EM.2.I.A, EM.2.II.A,

3.1.1.2 Organizational Structure

EM.1.I.A, EM.1.I.B,

EM.1.I.C, EM.1.I.E

3.1.1.3 Environmental Program Planning and Budgeting

EM.8.I.B, EM.8.I.F

3.1.1.4 Environmental Staffing

EM.6.I.A, EM.6.I.D

3.1.1.5 Written Environmental Programs,

Policies, Procedures, and Standards

EM.4.II.B, EM.4.II.C, EM.4.I.A, EM.4.I.B, EM.5.I.E

3.1.1.6 External Communications

EM.5.II.C, EM.5.II.D, EM.5.II.B

\subsubsection{Employee Involvement}

3.1.2.1 Environmental Responsibilities and Personnel Accountability

EM.1.II.A, EM.1.II.B

3.1.2.2 Top Management Encouragement

EM.2.II.C

3.1.2.3 Environmental Concerns Reporting System EM.5.I.B

\subsection{Environmental Assessments and Controls}

3.2.1 Self Assessment and Appraisal Programs

EM.7.I.A, EM.7.I.B

3.2.2 Risk Management

EM.8.II.A

3.2.3 Corrective Actions

EM.4.IV.E

3.2.4 Environmental Documentation and Recordkeeping

EM.4.IV.A, EM.4.IV.B, EM.4.IV.C

\subsection{Environmental Training Program}
3.3 .1
Environmental Professional Training
EM.6.III.A 


\section{Appendix A Evaluation Elements (continued)}
3.3.2 Personnel Training Needs
EM.6.III.B, EM.6.III.D

4.0 RADIOLOGICAL PROTECTION [reference: DOE N 5480.6 U.S. Department of Energy Radiological Control Manual of June 1992]

\subsection{Management Compitment and Employee Involvement}

\subsubsection{Management Commitment}

4.1.1.1 Site-Specific Radiological Control Manual

4.1.1.2 Subcontractor Compliance with Manual

4.1.1.3 Senior Management Written Commitment

4.1.1.4 Improvement Goals and Performance Indicators

4.1.1.5 RAD Waste and Exposure Reduction

\subsubsection{Promotion of RAD Control and Constant} Improvement

\subsubsection{Employee Involvement}

\subsubsection{Radiological Awareness Committee}

4.1.2.2 Radiological Awareness Reports System

4.1.2.3 ALARA Committee

4.1.2.4 Worker Awareness of Radiological Conditions

4.1.2.5 Supervisor and Worker Accountability

\subsection{Morksite Analysis}

4.2.1 Internal Assessments

4.2.2 Review of Work in Progress

4.2.3 Work Activities

\subsection{Hazard Prevention and Control}

4.3.1 Facility Administrative Control Levels 4.3.2 Radiological Control Areas
Ch 1, Part 1, Art 114, Art 114.1, 114.5

Ch 1, Part 1, Art 114.5

Ch 1, Part 2, Art 121.2

CH 1, Part 2, Art 121.8, 121.9; Part 3, Art 133

Ch 1, Part 2, Art 121.11

Ch 1, Part 2, Art 121.6, 122.3

Ch 1, Part 3, Art 132.4

Ch 1, Part 3, Art 135.2

Ch 1, Part 3, Art 138

Ch 1, Part 2, Art 126, 127

Ch 1, Part 2, Art 121.4

Ch 1, Part 3, Art 134.1

Ch 3, Part 4, Art 344.3

Ch 3, Part 4, Art 343.4 


\section{Appendix A Evaluation Elements (continued)}

4.3.3 Planned Radiological Work

4.3.3.1 Incorporation of RAD in the Conduct of Work

4.3.3.2 Trigger Levels for Formal RAD Review
4.3.3.3 Documentation of RAD in Job Plans and Procedures

4.3.3.4 ALARA Committee Reviews of Activities

\subsubsection{Exposure Controls}

\subsubsection{Minimization of Internal Exposure}

4.3.4.2 Radiological Work Permits

\subsubsection{Personal Protective Equipment}

4.3.4.4 Access Control Measures

4.3.4.5 Prioritization System

4.3.4.6 Management Feedback

4.3.4.7 Stop Work Authority

4.3.5 Radioactive Waste Minimization

4.3.6 Radiological Monitoring and Surveys

\subsection{Training}

4.4.1 Pre-Job Briefings

4.4.2 Standard Training

4.4.2.1 General Employee Radiological Training

4.4.2.2 Radiological Worker I and II Training

4.4.2.3 Radiological Control Technician Training

4.4.3 Site-Specific Training of Employees

4.4.4 Refresher Training and Retraining
Ch 3, Part 1, Art 311 and 312.1

Ch 3, Part 1, Art 312.4

Ch 3, Part 1, Art 312.5

Ch 3, Part 1, Art 312.7, 313

Ch 3, Part 1, Art 316

Ch 3, Part 2

Ch 3, Part 2, Art 325;

Appendix 3C and Table 3-1

Ch 3, Part 3

Ch 1, Part 3, Art 134.3

Ch 1, Part 3, Art 134.4

Ch 3, Part 4, Art 344.3

Ch 4, Part 4, Art 442

Ch 5, Part 5, Part 6
Ch 2, Part 2, Art 324

Ch 6, Part 1, Art 612

Ch 6, Part 2, Art 621;

Part 1, Art 613.3

Ch 6, Part 3, Art 631, 632, 633

Ch 6, Part 4, Art 641, 642, 643

Ch 6, Part 1, Art 612.3

Ch 6, Part 1, Art 613.3, 613.4 


\section{Appendix A Evaluation Elements (continued)}

4.4.5 Respiratory Protection Training

4.4.6 Visitor Radiological Orientation

4.4.7 Other Radiological Training

4.4.8 Maintenance of Training Records
Ch 6, Part 1, Art 613.7;

Ch 5, Part 3, Art 531

Ch 6, Part 2, Art 622

Ch 6, Part 5, Part 6

Ch 6, Part 1, Art 612.2, 613.6, 613.11; Part 2, Art 622.3; Part 5, Art 656.6, 657.5; Ch 7, Part 2, Art 725 
Appendix B

ACRONYMS AND REFERENCES 


\section{APPENDIX B \\ ACRONYMS AND REFERENCES}

\section{Acronyms}

ABIH--American Board of Industrial Hygiene

ACGIH--American Conference of Governmental Industrial Hygienists

ALARA--As Low As Reasonably Achievable

ANSI--American National Standards Institute

ASSE--American Society of Safety Engineers

BCSP--Board of Certified Safety Professionals

CEOSHP--Comprehensive Environmental Occupational Safety \& Health Program

CERCLA--Comprehensive Environmental Response, Compensation, and Liability Act

CFR--Code of Federal Regulations

DOE--U.S. Department of Energy

EPA--U.S. Environmental Protection Agency

ERMC--Environmental Restoration and Management Contract

ES\&H--Environment, Safety and Health

FEMP--Fernald Environmental Management Project

FERMCO--Fernald Environmental Restoration Management Company

GET--General Employee Training

HAL--Hazard Abatement Log

JSA--Job Safety Analysis

M\&O--Management and Operating

NEPA--National Environmental Policy Act

NIOSH--National Institute for Occupational Safety and Health

OSH--Occupational Safety and Health

OSHA--Occupational Safety and Health Administration

OS\&H--Occupational Safety and Health (Department)

RAC--Risk Assessment Code

RCRA--Resource Conservation and Recovery Act

SARA--Superfund Amendments and Reauthorization Act

TSCA--Toxic Substances Control Act

\section{References *}

DOE Draft Order 5483.XX, 11-12-93, Occupational Safety and Health Program for DOE Contractor Employees

DOE Form 5484.4, Tabulation of Work-Hours, Vehicle Usage, and Property Valuation

DOE Form 5484.3, Individual Accident/Incident Report, formerly 5484.X

Occupational Safety and Health Act (of 1970), Public Law 91-596, establishes Federal requirements for ensuring occupational safety and health protection for all privatesector employees.

*For DOE Orders, date refers to date of latest change.

DOE Interpretations Guide to OSH Standards, 6-1-93, provides a baseline for consistent interpretations of DOE-prescribed OSH standards. 
DOE 5480.8A, 10-19-92, Contractor 0ccupational Medical Program, contains requirements for the Department's Occupational Medicine Program.

DOE Radiological Control Manual, or RadCon Manual, DOE N 5480.6, 6-92, establishes practices for the conduct of radiological control activities.

SARA Title III, Superfund Amendments and Reauthorization Act of 1986. Title III is the Emergency Planning and Community Right-to-Know Act, details reporting requirements for facilities or operations where hazardous substances are used.

DOE 5480.19, 5-18-92, Conduct of Operations Requirements for DOE Facilities, provides requirements and guidelines for the development of directives, plans and procedures relating to the conduct of operations.

DOE 5700.6C, 8-21-91, Quality Assurance, establishes quality assurance requirements for the Department of Energy.

29 CFR 1910, Title 29 of the Code of Federal Regulations, Part 1910, Occupational Safety and Health Standards for General Industry.

29 CFR 1910.120, OSHA's Standard for Hazardous Waste Operations and Emergency Response.

29 CFR 1926, Title 29 of the Code of Federal Regulations, Part 1926, Occupational Safety and Health Standards for Construction. 

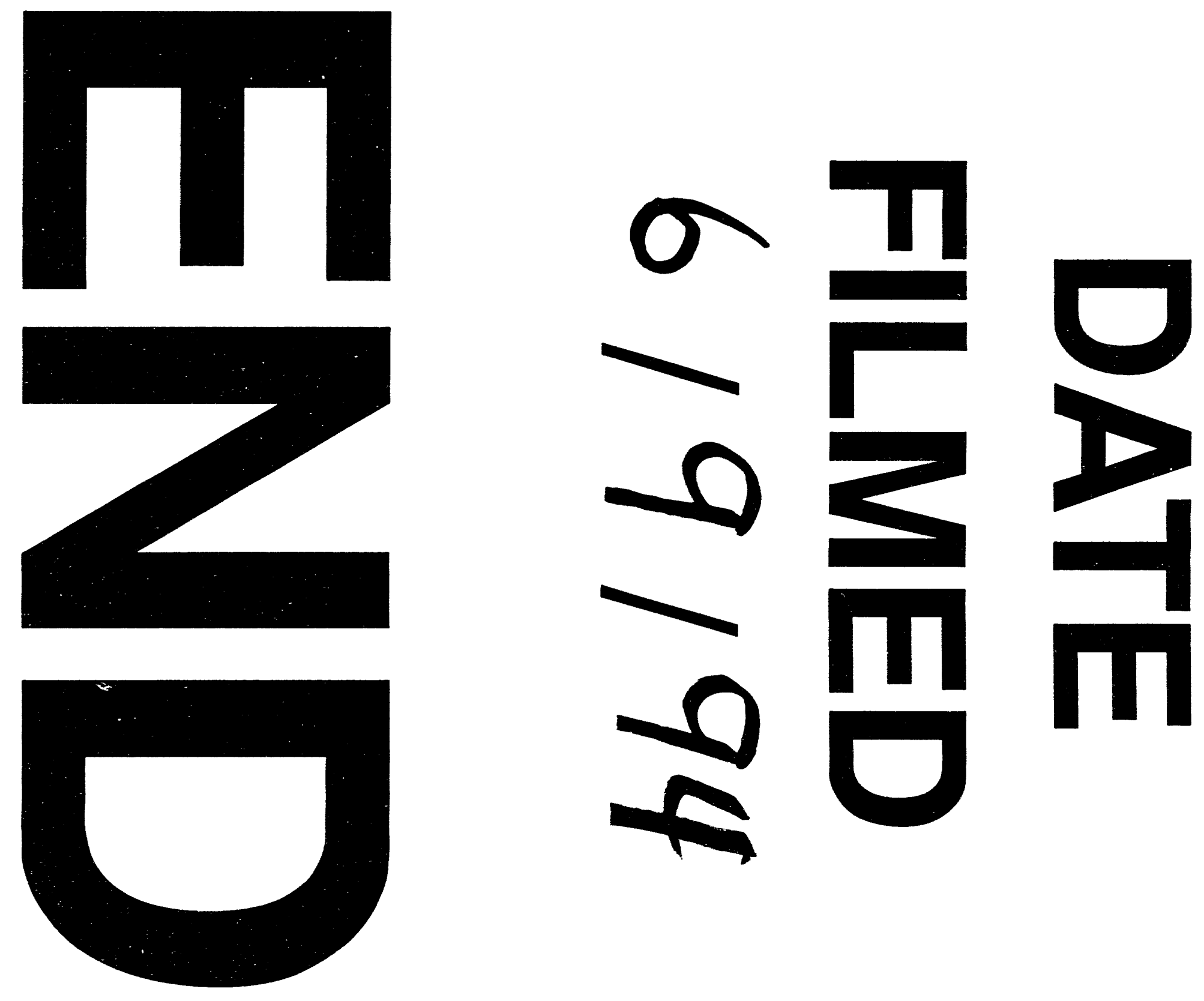
